\title{
Talking Heads
}

Interviewing Suspects from a Cultural Perspective

Karlijn Beune 


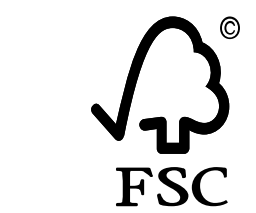

Mixed Sources

Product group from well-managed

forests, controlled sources and

recycled wood or fibre

Cert no. CU-COC-811465

www.fsc.org

๑ 1996 Forest Stewardship Council

Thesis, University of Twente, 2009

(c) Karlijn Beune

ISBN: 978-90-265-2902-0

Cover by Bob Jansen

Bookdesign and printed by Gildeprint Drukkerijen, Enschede, the Netherlands 


\title{
TALKING HEADS
}

\section{INTERVIEWING SUSPECTS FROM A CULTURAL PERSPECTIVE}

\section{PROEFSCHRIFT}

\author{
ter verkrijging van \\ de graad doctor aan de Universiteit Twente, \\ op gezag van de rector magnificus, \\ prof. dr. H. Brinksma, \\ volgens besluit van het College voor Promoties \\ in het openbaar te verdedigen \\ op donderdag 1 oktober 2009 om 15.00 uur
}

door

Karlijn Beune

geboren op 26 maart 1981

te Enschede 
Dit proefschrift is goedgekeurd door de promotoren prof. dr. K.I. van Oudenhoven - Van der Zee en prof. dr. H.W.A.M. Coonen en de assistent-promotor dr. E. Giebels. 


\title{
Samenstelling promotiecommissie
}

\author{
Promotoren: $\quad$ Prof. dr. K.I. van Oudenhoven - Van der Zee \\ Prof. dr. H.W.A.M. Coonen \\ Assistent-promotor: \\ Dr. E. Giebels \\ Leden: \\ Prof. dr. R. Bull \\ Prof. dr. M. Junger \\ Prof. dr. E. R. Seydel \\ Referenten \\ Dr. W.L. Adair \\ Dr. P.J. Taylor
}





\section{Contents}

$\begin{array}{lll}\text { Chapter } 1 \quad \text { General Introduction } & 9\end{array}$

Chapter 2 Are you talking to me?

Influencing behaviour and culture in police interviews

Chapter 3 Chatting with suspects

Strategic sequences and the importance of order and cultural fit

Chapter 4 Look who's talking!

Interaction patterns and their cultural dependency

Chapter 5 General Discussion

References

Summary in Dutch (Samenvatting) 

General Introduction 


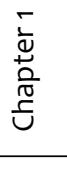

10 
"We do not torture." - (President G.W. Bush to reporters during a visit to Panama in November 2005)

“Mr. Obama's opening gambits as president were bold declarations of new directions, from announcing the closing of the detention centre at Guantánamo Bay, Cuba, to sweeping restrictions on interrogation techniques." - (New York Times, May 16, 2009)

Although research on the interrogation of suspects has steadily increased over the past decade (e.g., Bull \& Milne, 2004; Gudjonsson, 2003; Inbau, Reid, \& Buckley, 1986; Inbau, Reid, Buckley, \& Jayne, 2001; Milne \& Bull, 1999, Moston \& Engelberg, 1993; Moston \& Fisher, 2007; Moston \& Stephenson, 1993), attention to interrogation techniques has become overwhelming since the discovery of the controversial techniques used by U.S. officers in the 'War on Terror' (e.g., McIntire Peters, 2005). Fortunately, these are not typical examples of how suspects are interrogated, but the existence of such unethical behaviour may undermine public confidence and leave the police with a serious skills deficit in its ability to obtain evidence through questioning (Williamson, 1994, p. 107). Williamson, a former English senior police officer, was one of the first to urge police officers and researchers to move away from questioning suspects primarily to obtain a confession (Williamson, 1993) and toward obtaining accurate, credible and reliable information conducive to finding the truth (Baldwin, 1993; Milne \& Bull, 1999). This approach to the interrogation of suspects is now more commonly referred to as "investigative interviewing” (Bull \& Soukara, in press; Soukara, Bull, Vrij, Turner, \& Cherryman, 2009) and has been adopted in most western European countries (e.g., the UK, Norway, and The Netherlands). A crucial aspect of the investigative interviewing approach is an open-minded interviewer who acts fairly and asks questions to establish the truth (Bull \& Cherryman, 1996; Bull \& Soukara, in press; Milne \& Bull, 1999). Notwithstanding the importance of such 'humanitarian' interview techniques (Holmberg \& Christianson, 2002), the question is what to do when a suspect remains silent or is unwilling to talk (Moston \& Engelberg, 1993). Interestingly, this topic is relatively understudied in the literature. As noted by Bull and Soukara (in press), "published studies of what really happens in police interviews with suspects are exceedingly rare" and "even rarer are publications concerning the actual relationships between the tactics/skills used by police officers and the behaviours of suspects" (see also Soukara et al., 2009).

The present dissertation aims to fill these voids by identifying behaviours that appeal to and persuade suspects to talk (i.e., influencing behaviour), focusing on the effects of such behaviours and their dependency on cultural context. This is important since an increasing number of suspects deviate from the mainstream's cultural background (Jennissen \& Blom, 2007), and the impact of influencing behaviour has been found to be culturally specific (Fu \& Yukl, 2000; Giebels \& Taylor, 2009). Put differently, we propose that effective influencing 
is intertwined with suspects' cultural backgrounds, and therefore, the true impact of such behaviour needs to be examined from a cultural perspective. This proposition is examined in three empirical studies.

The remainder of this introductory chapter first discusses relevant social psychological research on influencing behaviour. Then, a brief overview of evidence on important cultural dimensions on which cultures vary and their importance to police interviews will be provided. Together, these approaches provide the theoretical argument underlying this dissertation. I will conclude this chapter with a brief overview of the three empirical chapters.

\section{The Power of Influencing}

Influencing behaviours are a basic force in social interactions of all kinds and natures (Cialdini \& Goldstein, 2004; Nail, MacDonald, \& Levy, 2000). The potential power of influencing behaviour has been studied extensively in many domains of psychological research, including consumer behaviour, organisational psychology, communication theory and crisis negotiations (for overviews, see, e.g., Cialdini, 2001; Giebels \& Taylor, 2009; Higgins, Judge, \& Ferris, 2003; Kellerman \& Cole, 1994). Although a detailed and integrative review of these various literatures is beyond the scope of the present dissertation, I will give a short overview of the different research lines. This will be followed by a more extensive discussion of the works that are particularly relevant for our research question and the context of investigative interviewing. I will start with the pioneering work of Robert Cialdini as his work on social influence can be considered the cornerstone of modern influencing research. Next, I will focus on interpersonal influencing behaviour. Together, these fields describe a range of different influencing behaviours that were recently captured in one framework, the Table of Ten (Giebels, 2002; Giebels \& Taylor, in press). The Table of Ten integrates "why" (i.e., the psychological mechanism) and "how" (i.e., through which specific behaviour) people are influenced in dyadic settings. This comprehensive theoretical framework for the examination of interpersonal influencing behaviour constitutes the foundation of the present dissertation.

Although numerous descriptions of influential attempts exist, a first categorisation can be made on the basis of the fundamental psychological mechanisms that direct our behaviour (for a detailed discussion, see Cialdini, 2001). These include commitment/ consistency, reciprocity, authority, scarcity, liking, and social proof, and respond to principles such as "We should repay what we receive from others" (reciprocity) or "We should obey those who are in power" (authority). Another powerful principle is the human tendency to strive for consistency between present and past behaviour and/or attitudes (see also Festinger, 1957). Particularly, once people have committed themselves to a certain act, they will have a natural tendency to behave in a way that is consistent with the act of commitment (e.g., Cialdini, Cacioppo, Bassett, \& Miller, 1978; Cialdini \& Goldstein, 2004; Cialdini \& Trost, 1998; Cialdini, Wosinska, Barrett, Butner, \& Gornik-Durose, 1999). 
Together, these psychological mechanisms have proved powerful in directing human behaviour. Although this notion is particularly embraced within the domain of "mass communication" (i.e., in advertisements or by sales people; cf. Cialdini, 2001), it is also well applicable to interpersonal situations, for instance at the dyadic level (e.g., Giebels \& Taylor, 2009). In these situations, as will be highlighted in the present dissertation, the emphasis lays on the reciprocal use of influencing behaviours. Put differently, I will direct attention to understanding how people behave in order to influence each other (Higgins et al., 2003) and what the consequences of these behaviours are.

A second categorisation follows this previous work and focuses on capturing how people influence others and the effects of these different types of behaviour. Work in organisational settings, for example, has examined how various influence tactics are related to work outcomes. For instance, a meta-analysis by Higgins et al. (2003) revealed that the use of rational arguments (messages referring to data and information to build a logical argument) and inspirational appeals (a request that arouses enthusiasm by appealing to values, ideals, and aspirations) has positive effects on employees' performance assessments and extrinsic motivation. Rational persuasion also proved effective for managers who wanted to influence their subordinates, peers, or superiors (Yukl \& Tracey, 1992). Other important work has been done by scholars in the field of communication research. They identified, for example, that demonstrating some authority was an effective way of influencing a subject's cooperation in terms of compliance-gaining (Kellerman \& Cole, 1994; see also Giebels \& Taylor, in press).

Notwithstanding the importance of these works, not all influencing behaviours are relevant for police-civilian interactions. Typical features of these interactions are that parties not only tend to have (partly) opposing interests, but that high stakes are usually combined with low trust. As such, influencing behaviours such as legitimising or rational arguments appear to be well applicable, while others, such as inspirational appeals, may seem less appropriate in a police context. Recently, an important contribution to policing research has been made by integrating the research lines discussed above into one framework: the Table of Ten (Giebels, 2002; Giebels \& Taylor, in press). The Table of Ten was developed for the domain of interpersonal police-civilian interactions in particular. Until now, this framework has been applied to and tested in a crisis negotiation context (e.g., Giebels \& Noelanders, 2004; Giebels \& Taylor, 2009). Clearly, parallels with police interviews exist; police officers and suspects may also believe that their interests conflict, while both parties are dependent on each other to achieve their goals or to come to some accommodation (Brodt \& Tuchinsky, 2000). Therefore, this dissertation will depart from the Table of Ten for the examination of police officers' behaviour (see Table 1). 
Table 1

The Table of Ten influence tactics

\begin{tabular}{|c|c|c|}
\hline Strategy & Underlying principle & Description of behaviour \\
\hline Being kind & Sympathy & All friendly, helpful behaviour \\
\hline Being equal & Similarity & $\begin{array}{l}\text { Statements aimed at something the parties have in } \\
\text { common }\end{array}$ \\
\hline Being credible & Authority & $\begin{array}{l}\text { Behaviour showing expertise or proving you are } \\
\text { reliable }\end{array}$ \\
\hline Emotional appeal & Self-image & Playing upon the emotions of the other \\
\hline Intimidation & Deterrence / fear & $\begin{array}{l}\text { Threatening with punishment or accusing the other } \\
\text { personally }\end{array}$ \\
\hline Imposing a restriction & Scarcity & $\begin{array}{l}\text { Delaying behaviour or making something available in } \\
\text { a limited way }\end{array}$ \\
\hline Direct pressure & Power of repetition & $\begin{array}{l}\text { Exerting pressure on the other in a neutral manner } \\
\text { by being firm }\end{array}$ \\
\hline Legitimising & Legitimacy & $\begin{array}{l}\text { Referring to what has been agreed upon in society } \\
\text { or with others }\end{array}$ \\
\hline Exchanging & Reciprocity & Give-and-take behaviour \\
\hline Rational persuasion & Cognitive consistency & Using persuasive arguments and logic \\
\hline
\end{tabular}

The Table of Ten distinguishes between relationship-oriented and content-oriented influencing behaviours. Relationship-oriented influencing behaviours focus on the sender and his or her relationship with the other person rather than the content of a message. An example of such behaviour is being equal. Being equal refers to behaviour that includes statements aimed at something that both parties have in common. Another example is being kind, which refers to behaviour that is friendly and helpful (Giebels \& Taylor, in press). Content-oriented influencing behaviours are about how to effectively frame the content of a message. For example, imposing a restriction includes messages that communicate the postponement of a certain act or introducing time limits, while exchanging implies that one asks a favour in return for a concession that is being made (see also Giebels, 2002).

Based on the research evidence presented above, it could be expected that influencing behaviour may also prove powerful in police interviews. However, despite this promising prospect, until now the topic has received scant attention in the literature. Moreover, little is known about the boundary conditions of interpersonal influencing behaviour' (Higgins et al., 2003), such as its dependency on the cultural context (cf. Fu \& Yukl, 2000; Hilty \& Carnevale, 1993). These issues will be addressed in the present dissertation.

\footnotetext{
1 Please note that our conceptualisation of influencing behaviour is distinct from the behaviours advocated by the controversial Reid Technique (including, for example, minimising the moral seriousness of a crime or lying to a suspect about possible consequences of admitting the crime) and in line with the principles of investigative interviewing (see, e.g., Bull \& Milne, 2004; Bull \& Soukara, in press; Milne \& Bull, 1999, Soukara et al., 2009).
} 


\section{A Cultural Context}

Across many subfields in psychology, research has advanced our understanding of the influence of culture and cultural differences on how people feel, think, and behave (Brewer \& Chen, 2007, p. 133). Culture can be defined as a society's characteristic profile with respect to values, norms, behaviours, and institutions (Lytle, Brett, Barsness, Tinsley, \& Janssens, 1995; see also Triandis \& Suh, 2002). As such, it provides a way to frame and interpret the world around us. Various cultural dimensions have been distinguished, some measuring culture as an attribute at the cultural level (e.g., individualism/collectivism), others as a psychological variable (e.g., independent/interdependent self-construal; Brewer \& Chen, 2007) or in terms of differences in communication style (e.g., low-/high-context communication; Hall, 1976). With respect to the former, one of the most widely used frameworks for characterising and examining cultural differences is the distinction between individualism and collectivism (Brewer \& Chen, 2007; Cialdini et al., 1999; Fiske, 2002; Hofstede, 2001; Kagitcibasi, 1997; Kashima et al., 1995; Oyserman, Coon, \& Kemmelmeier, 2002; Smith \& Bond, 1994; Triandis, 1995; Triandis \& Suh, 2002). As noted by Cialdini et al. (1999), individualism/collectivism can be considered "the core dimension of cultural variability (see also Hofstede, 2001; Kim, 1994; Smith \& Bond, 1994).

In individualistic cultures, self-definition is based on individual autonomy and separation from others, while in collectivistic cultures, the self-concept is primarily defined in terms of social relationships and interdependence with others (Brewer \& Chen, 2007). Consequently, an important characteristic of collectivistic cultures is their notable concern with relationships (Triandis \& Suh, 2002), which is judged primarily with respect to the value of these relationships to the group (Cialdini et al., 1999). In individualistic nations, on the other hand, people tend to establish and maintain relationships on a calculation of personal costs or benefits (Emans, Laskewitz, \& Van de Vliert, 1994; Triandis, 1995). Generally, Western societies, such as the United States or the Netherlands, can be regarded as more individualistic, while non-Western societies, such as China or the Arabic countries, are considered more collectivistic in nature (Hofstede, 2001).

A related approach that addresses cultural differences is represented by intrapersonal representations of the self (i.e., the extent to which one views oneself as connected to others). That is, cultural differences are measured through the concept of independent versus interdependent self-construal (Brewer \& Chen, 2007; Cross \& Madson, 1997; lyengar \& Brockner, 2001; Markus \& Kitayama, 1991; Shweder \& Bourne, 1984; Triandis, 1989). People may either define themselves on the basis of their unique abilities or attributes, seeing themselves as independent from others, or as more interdependent, based on group membership and harmonious relationships (Cross \& Madson, 1997; Markus \& Kitayama, 1991). Constructing the self in terms of independence is often attributed to people in Western, individualistic cultures (Hofstede, 2001; Triandis, 1994), while interdependence is primarily 
found in non-Western, more collectivistic cultures (Kashima et al., 1995), including Asian, African, Latin American and southern European cultures (Markus \& Kitayama, 1991, p. 225). An important characteristic of in/interdependent self-construal is that it can be measured as a psychological variable (Brewer \& Chen, 2007; i.e., at the individual level of analysis).

Finally, an important way of approaching cultural differences is via styles of interpersonal communication. In this regard, peoplemay vary, for example, in communicational (in)directness (Hall, 1976; Holtgraves, 1997). As communication lies at the heart of social interaction (Holtgraves, 1997), culture is likely to influence the way people communicate (cf. Adair, 2003). In his theoretical framework, Hall (1976) argues that people differ fundamentally on what he referred to as low-context and high-context communication. Low-context communication involves the use of explicit and direct messages in which meanings are principally contained in the transmitted messages (e.g., "Can you open a window ?"), while in high-context cultures, people rely on the context of a message to convey meaning (e.g., "It's warm in here" as a request to open a window; Holtgraves, 1997). These manifestations are the result of context-specific preferences for communication outcomes (Victor, 1992). Because low-context cultures usually strongly value facts and factual information, communication is presented in a direct way, focusing on the content of a message (Brinker Dozier, Husted, \& McMahon, 1998). High-context cultures, on the other hand, generally have strong notions of face saving (Ting-Toomey, 1988; Tse, Lee, Vertinsky, \& Wehrung, 1988) and maintaining harmonious relationships (Kim, Pan, \& Park, 1998; Brinker Dozier et al., 1998). Ting-Toomey and Oetzel (2001, p. 31) explained these differences in terms of "I-identity" and relational harmony. That is, when "I-identity" is a highly appreciated cultural value, an ideal way of dealing with conflicting interests is to discuss these in a direct way, focusing on facts (i.e., low-context communication). When emphasising relational harmony, on the other hand, an important notion is to save or maintain face (see also Ting-Toomey, 1988; Ting-Toomey \& Kurogi, 1998). As a consequence, communication is usually indirect and roundabout, stressing issues of relational harmony (i.e., high-context communication; Adair, Okumura, \& Brett, 2001; Hall, 1976; Kim et al., 1998). Generally, low-context communication is predominant in Western, individualistic cultures, while high-context communication is characteristic for nonWestern, collectivistic cultures (Adair, 2003; Adair \& Brett, 2005; Gudykunst \& Ting-Toomey, 1988; Hofstede, 2001; Triandis \& Suh, 2002). Because the focus in the present thesis is on the communicational dynamics of police interviews, we use Hall's (1976) theory on low-/highcontext communication to examine cultural differences.

As elements of culture shape the way in which the environment is perceived (Triandis \& Suh, 2002), cultures differ in the sampling of information and the weight that is assigned to these sampled elements (Triandis, 1989). Consequently, it is likely that people from different cultures perceive influential attempts in different ways (Adair \& Brett, 2004). Therefore, it is not surprising that the effectiveness of influencing behaviour has been found to be culture- 
specific (Fu \& Yukl, 2000; Giebels \& Taylor, 2009). For instance, research indicates that, in general, people are persuaded most by those acts to which they have committed themselves in a public, effortful, irrevocable and freely chosen way (Iyengar \& Brockner, 2001) because they tend to behave and think consistently with these acts (Aronson, 1992; Cialdini, 1993, 2001). Interestingly, Cialdini and colleagues (1999) demonstrated that this consistency principle had more impact on American (individualistic) than on Polish (collectivistic) students (see also Choi \& Nisbett, 2000). In contrast, the Polish students appeared to assign more decisional weight to evidence of what their peers had done in the past than did American students (Cialdini et al., 1999). This finding can be explained by collectivists' emphasis on their relatedness with others (Hofstede, 2001; Markus \& Kitayama, 1991; Triandis, 1995). As a result, they are likely to resolve (internal) conflict by relationship-oriented conflict behaviour (cf. Ohbuchi, Fukushima, \& Tedeschi, 1999) or by inferring how to behave from similar others (i.e., principle of social proof; Cialdini et al., 1999). Thus, when settling disputes, collectivists prefer relationship-oriented conflict resolution, whereas individualists adopt a more contentoriented approach and are willing to fight their way through the conflict until justice is achieved (Leung, 1997; Triandis \& Suh, 2002).

Despite the significant attention to cultural influences on various forms of human responding in recent years (Cialdini et al., 1999), research on the moderating role of culture in police interviews is virtually absent (cf. Gudjonsson, 2003, p. 376). Moreover, police interviews increasingly involve suspects from different cultural backgrounds (Viki, Culmer, Eller, \& Abrams, 2006). For instance, in the Netherlands, thirty-two percent of suspects originate from a non-Western society, including Morocco (8\%), Turkey (5\%), Surinam (7 \%), and the Dutch Antilles (4\%; Jennissen \& Blom, 2007). Given the fact that the effectiveness of influencing behaviour has been found to vary considerably across cultures (e.g., Fu \& Yukl, 2000; Giebels \& Taylor, 2009), this seems a missed opportunity.

\section{Focus of this Dissertation}

The present dissertation aims to extend previous research on police interviews (e.g., Bull \& Milne, 2004; Bull \& Soukara, in press; Dando, Wilcock, \& Milne, 2009; Dando, Wilcock, Milne, \& Henry, in press; Milne \& Bull, 1999) by integrating theory on interpersonal influencing behaviour and culture into the police interview context. The core assumption developed in the present dissertation is that the impact of influential messages is dependent on the suspect's cultural framework. Therefore, we examined police officers' influencing behaviours, with a particular focus on being kind, rational arguments, and intimidation and their impact on several interview outcomes as a function of suspects' cultural background. Since we aim to provide a sound and valid test of our assumption, we conducted multi-method research in a variety of settings, ranging from an authentic police interview to a controlled experiment. First, we asked student participants to steal money, after which they were interviewed by a 
real police officer (Chapter 2). Both police officers' and suspects' actual behaviour (through the use of transcripts and videotapes) and self-report measures (by means of a post-interview questionnaire) were analysed in order to identify which influencing behaviours work well in police interviews. Next, we manipulated two central influencing behaviours -rational arguments and being kind-in controlled experiments (Chapter 3 ). In doing so, we could rule out the possibility of other behaviours and/or situational factors obscuring our results. Rational arguments and being kind were contrasted against intimidation in a first study, while their joint impact was examined in a second study. Finally, we analysed videotapes of authentic police interviews in order to examine the impact of rational arguments, being kind and intimidation in a naturalistic setting (Chapter 4). Together, this dissertation will consist of three empirical chapters (Chapters 2, 3 and 4, discussed in more detail below) providing the basis of our theoretical framework on interpersonal influencing behaviour in police interviews and its dependency on cultural context.

Although research has examined interview styles via observation (Leo, 1996; Moston \& Engelberg, 1993) or by questioning police officers about their behaviour inside the interrogation room (Kassin et al., 2007), none of this earlier work departed from a theoretical framework underlying such behaviours. Moreover, until now, studies have failed to examine the relationship between these behaviours and the behaviour of suspects, for example, in terms of cooperation, information provision, and/ or admissions (Bull \& Soukara, in press). Neither have they studied the dependency of such behaviours on situational factors (Gudjonsson, 2003), such as the cultural background of suspects. In response to these issues, we will identify several influencing behaviours based on (social) psychological theory (Chapter 2). We test how these influencing behaviours relate to suspects' cooperation in terms of admissions, information provision and perceived quality of the relationship. Furthermore, the question of whether the cultural background of suspects moderates these relationships will be examined. In doing so, we base our examination on a recently proposed framework on interpersonal influencing in police-civilian interactions (Giebels, 2002; Giebels \& Taylor, in press) and integrate existing literature on cultural communication (first described by Hall, 1976) into the context of police interviews. Chapter 2 provides the theoretical foundation for the following empirical chapters.

In Chapter 3, two behaviours that are central to police interviews are further examined: being kind and rational arguments. These behaviours are likely to co-exist in police interviews (Bull \& Soukara, in press), but their joint impact has, as far as we know, never been examined. Moreover, there is growing research evidence that social interactions are most effective when (two) behaviours are combined rather than used separately (Carnevale \& Pruitt, 1992; Hilty \& Carnevale, 1993; Olekalns \& Smith, 2000, 2003; Olekalns \& Weingart, 2008; Pruitt, 1981; Rafaeli \& Sutton, 1991; Rubin \& Brown, 1975; Van de Vliert, Nauta, Giebels, \& Janssen, 1999). Therefore, we examine the impact of being kind and rational arguments 
when combined into strategic sequences. The central assumption underlying this chapter is that the effectiveness of such sequences will be dependent on cultural fit. That is, we expect sequences to be most influential when they match the cultural framework of the suspect. A first empirical study examines whether the effectiveness of being kind and rational arguments can be increased by contrasting them against more firm behaviours (i.e., intimidation; cf., Hilty \& Carnevale, 1993; Rafaeli \& Sutton, 1991). A second study adds the investigation of the joint impact of being kind and rational arguments (i.e., when combined into one sequence) and tests whether these effects are dependent on order (Van de Vliert et al., 1999; Yukl, Falbe, \& Youn, 1993).

A criticism of the first two empirical chapters may be that they involve a student population and are therefore difficult to translate into real-world settings (Mann, Vrij, Fisher, \& Robinson, 2008). It therefore seemed important to replicate these findings in a naturalistic setting (Vrij, 2004; Vrij et al., 2009). Furthermore, we expand our focus to examine the single effects of intimidation, next to rational arguments and being kind, on the informationgathering process. More precisely, we directed our attention at two types of intimidation: intimidation of the individual (i.e., directed at the suspect personally) and intimidation of the context (i.e., directed at the suspect's friends and/or family). In response to these issues, we examined the interaction between police officers and suspects in authentic police interviews (Chapter 4). As (truthful) information gathering could be considered the primary purpose of investigative interviewing (Bull \& Milne, 2004; Milne \& Bull, 1999), we analysed how police officers' behaviours were directly related to different types of information provision by suspects. These were case-related personal information (e.g., motivation of behaviour), caserelated contextual information (e.g., information about the criminal event), and refusing to give information (e.g., invoking the right to remain silent). I conclude this dissertation with a summary of our conclusions, and implications for theory and practice will be discussed. 


\section{Figure 1}

Overview of the empirical chapters

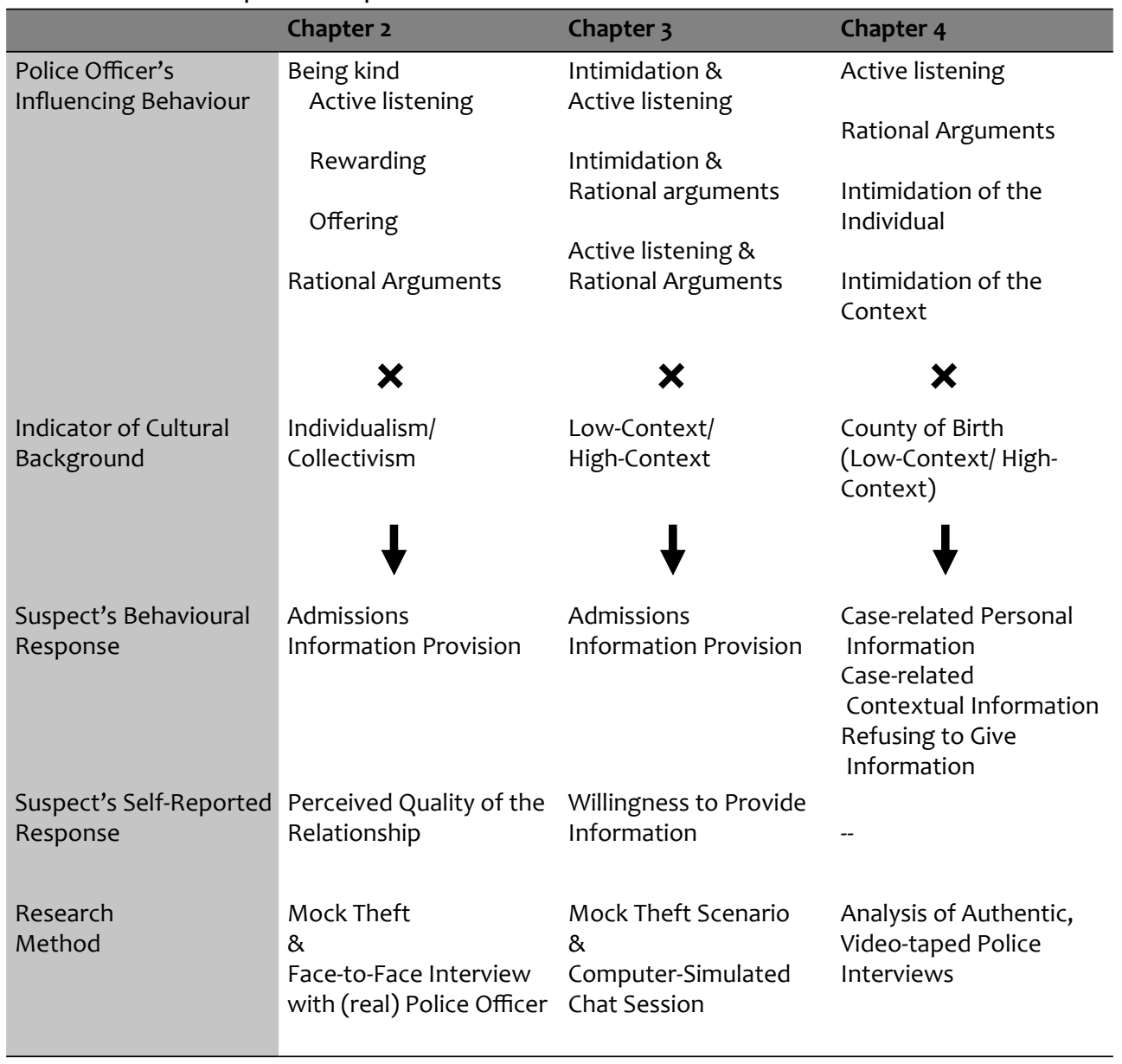




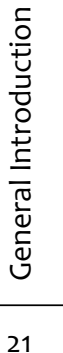





\section{Are you talking to me? Influencing behaviour and culture in police interviews ${ }^{1}$}

1 This chapter is a modified version of an article that is in press as Beune, K., Giebels, E., \& Sanders, K. Are you talking to me? Influencing behaviour and culture in police interviews. Psychology, Crime \& Law. 


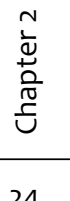

24 
During the 1990s, Williamson (1994) was one of the first to notice that traditional coercive interrogations had left the police with a lack of proficiency and had undermined public confidence (Gudjonsson, 2003; Williamson, 1994; see also Baldwin, 1993; Moston \& Engelberg, 1993). Since then, the field of suspect interrogation (as of then more commonly referred to as "investigate interviewing"), moved away from interviewing crime suspects primarily to obtain a confession. Instead, the emphasis was placed on employing accurate listening skills and the gathering of complete and reliable information in order to obtain evidence, and ultimately to find the truth (Baldwin, 1993; Bull \& Milne, 2004). Until now, relatively little attention has been paid to how police officers deal with suspects who are reluctant to talk or how they deal with situations in which resistance to tell the truth is inferred. Irrespective of whether a suspect is guilty or not, he or she may be showing resistance for various reasons: There could be much at stake for the suspect, a suspect might not want to make incriminating statements, or a suspect might not trust the police (cf. Shepherd, 1993). This means that police officers urgently need the cooperation of a suspect to find the truth, but may well experience some kind of resistance from a suspect in the investigative process. In these situations, the effectiveness of a police officer's behaviour is not only dependent upon information-gathering strategies, yet also on the officer's knowledge about how to present messages in a way that appeal to and persuade the suspect to tell the truth. We therefore propose that influencing behaviour - which is defined as the deliberate actions of an agent (e.g., police officer) directed towards a recipient (e.g., suspect) with the intention of altering the recipient's attitudes and/or behaviours (cf. Gass \& Seiter, 1999) - may play a significant role in investigative interviewing.

In the current study we will examine the role of influencing behaviour in police interviews by analyzing videotapes of fifty-two simulated police interviews that were conducted in a controlled field setting (i.e., experienced police officers interviewed mock theft suspects). As such, we aim at furthering the field of investigative interviewing (e.g., Bull \& Milne, 2004; Bull \& Soukara, in press; Fisher \& Geiselman, 1992; Milne \& Bull, 1999, Soukara et al., 2009) in three ways. First, our study provides insight into the extent to which influencing behaviour is exhibited in police interviews in general, and pinpoints the specific types of influencing behaviours that are being used. Second, we direct our research at uncovering associations between two specific influencing behaviours (being kind and rational arguments) and three different types of interview effectiveness, all which could be considered conducive to the ultimate goal of finding the truth. In line with the emphasis on the gathering of complete and reliable information (Milne \& Bull, 1999), the overall willingness of a suspect to provide information may be regarded as an important effectiveness measure. In this way, the suspect may provide the officer with incriminating information (Leo, 1996) or other caserelated information that (dis)confirms and/or legitimates a police narrative (Gudjonsson, 2003; see also McConville, Sanders, \& Leng, 1991). Furthermore, previous research suggests 
that a good quality relationship with the officer is also an indicator of interview effectiveness, particularly if continued interaction with a suspect is expected (Viki, Culmer, Eller, \& Abrams, 2006). Finally, as the success of many police interviews is still depending on the admission of a guilty suspect (cf. Blair, 2007), this could also be considered an important outcome measure (Holmberg \& Christianson, 2002). Third, as police interviews increasingly involve suspects from different cultural backgrounds, and as the effectiveness of influencing behaviour tends to be culturally specific (e.g., Fu \& Yukl, 2000), we will examine the effectiveness of influencing behaviour used by police officers on individuals from different cultural backgrounds. More specifically, based on Hall's (1976) theory we will distinguish between interviews with suspects from low-context cultures, in which communication is direct and contentoriented and interviews with suspects from high-context cultures, in which communication is more indirect and context-oriented. In the following, we will introduce a framework of interpersonal influencing behaviour, relate this to current interviewing practices and argue why it is important to take the cultural background from suspects into account.

\section{Influencing Behaviour}

Substantial research efforts have been directed towards a categorization of influencing behaviour. For example, important work has been done by Cialdini (for a recent discussion, see Cialdini, 2001; Cialdini \& Goldstein, 2004), who identifies a number of influencing behaviours based on six psychological mechanisms. Other areas of work stem from communication theory (e.g., Kellerman \& Cole, 1994) and organizational psychology (e.g., Higgings, Judge, \& Ferris, 2003), where researchers have considered influencing behaviour at the dyadic level and examined up to 20 different influencing behaviours. A recently proposed framework - the Table of Ten (Giebels \& Taylor, in press; see Table 2a) - integrates previous research findings but concentrates specifically on interpersonal behaviour in interdependent situations such as police interviews.

The Table of Ten distinguishes between relationship-oriented and content-orientated influencing behaviours. Relationship-oriented influencing behaviours have in common that they have more to do with the sender and his or her relationship with the other person than with the substantive content of the message. For example, being kind refers to behaviour that is friendly and helpful, while being equal refers to behaviour that includes statements aimed at something that both parties have in common (Giebels \& Taylor, in press). Contentoriented influencing behaviours are geared toward framing the content of the message. For example, emotional appeals are behaviours playing upon the emotions of the other, while rational arguments are behaviours making use of persuasive arguments and logic. Although all behaviours of the Table of Ten may occur in police interviews, two behaviours in particular, i.e. being kind and rational arguments can be linked to previous research on police interviewing (e.g., Bull \& Cherryman, 1996; Hartwig, Granhag, Strömwall, \& Kronkvist, 2006), 
as well as to the basics of investigative interviewing taught in many Western countries, such as Britain (for an overview see Milne \& Bull, 1999) and the Netherlands (Nierop, 2005, p. 888; Van Amelsfoort, Rispens, \& Grolman, 2005).

\section{Investigative Interviewing}

The purpose of investigative interviewing is to obtain evidence through correct and reliable information from suspects (Milne \& Bull, 1999). Investigative interviewing, thus, seems to serve a clear substantive purpose. To achieve this, investigative interviews should usually centre on the employment of active listening skills (cf. Bull \& Cherryman, 1996). This includes using open-ended questions to get the broad picture, summarizing the other's story to check whether the situation has been understood correctly, and using closed questions to attain specific information (cf. Nierop, 2005; Van Amelsfoort, Rispens, \& Grolman, 2005). Interestingly, from an influencing perspective, the employment of active listening skills can be regarded as relational influencing behaviour, i.e. being kind. That is, by showing interest in the other person and paying attention to him or her personally, the police officer may appear friendly and helpful and the suspect may feel understood and comfortable (cf. Holmberg \& Christianson, 2002). Other ways of being kind that have been previously identified in investigate interviews are the rewarding of cooperative behaviour and the offering of a drink or cigarette (Nierop, 2005). Such behaviour may prove fruitful as people tend to reciprocate kind behaviour from others (see also Leary, 1957). As a consequence, being kind may be particularly effective in stimulating suspects to talk (cf. Bull \& Cherryman, 1996), and enhancing the quality of the relationship between the interviewer and suspect (Viki, Culmer, Eller, \& Abrams, 2006).

Next to information gathering through active listening skills, recent research suggests that police interviews should centre on the strategic use of evidence (Hartwig, 2006; Hartwig, Granhag, Strömwall, \& Kronkvist, 2006; Hartwig, Granhag, Strömwall, \& Vrij, 2005). That is, more and more often, police officers are trained not to disclose all the evidence to the suspect beforehand, but to use this information strategically at different times throughout the interview. One reason for this is that the freely recalled statements of guilty suspects are more likely to contradict pieces of evidence or known facts than the freely recalled statements of innocent suspects (see also Hartwig, 2007). Furthermore, a police officer who has uncovered such an inconsistency can confront the suspect with it and ask for a plausible explanation. This confrontation with inconsistencies is one of the main premises of Dutch interviewing methods (Nierop, 2005). In this way, a police officer tries to convince a suspect to tell the truth by referring to logical arguments. In influencing terms, this behaviour can be labelled rational arguments. The effectiveness of this behaviour is ascribed to the cognitive pressure that inconsistencies evoke, and the general tendency of people to reduce such cognitive inconsistencies. As such, rational arguments - through the principle 
of cognitive dissonance reduction (Festinger, 1957) - may be particularly able to further suspects' willingness to tell the truth about a given criminal event (including admissions from guilty suspects).

In the preceding section we have argued how two influencing behaviours of police officers in particular, may relate to interview effectiveness. Moreover, we expect that their impact on interview outcomes is dependent upon the cultural background of the suspect (cf. Fu \& Yukl, 2000).

\section{Cultural Background: Low-context and High-context Communication}

Nowadays, police interviews increasingly involve suspects from different cultural backgrounds. Culture can be defined as a society's characteristic profile with respect to values, norms, behaviours, and institutions (Lytle, Brett, Barsness, Tinsley, \& Janssens, 1995). Because culture influences the way in which people communicate, and our study focuses on communication in investigative interviews, we use Hall's (1976) theory of low-/high-context communication to build our hypotheses.

According to Hall, low-context communication involves the use of explicit and direct messages in which meanings are principally contained in the transmitted messages. In highcontext cultures, people rely on the context of a message to convey meaning, including, for example, the roles, status, and past history of the parties (Brinker Dozier, Husted, \& McMahon, 1998). As a consequence, communication is usually indirect and roundabout, stressing issues of relational harmony and face (Adair, Okumura \& Brett, 2001; Hall, 1976; Kim, Pan, \& Park, 1998). Generally, low-context communication is predominant in Western, individualistic cultures while high-context communication is found to be predominant in non-Western collectivistic cultures (Adair, 2003; Adair \& Brett, 2005; Giebels \& Taylor, 2009; Gudykunst \& Ting-Toomey, 1988; Hofstede, 2001; Triandis \& Suh, 2002). Ting-Toomey and Oetzel (2001, p. 31) explain this strong link, by arguing that for cultures that emphasize "I-identity" and selfinitiative, the ideal way of dealing with issues is to be direct and content-oriented about the issues at stake. In contrast, in cultures that emphasize values of relational harmony, it is more common to talk around the point and not deal directly with the issues at stake (see also Kim, Pan, \& Park, 1998).

Following this line of reasoning, we expect the effect of being kind and rational arguments to differ for suspects from low-context cultures (such as the Netherlands) compared to suspects from high-context cultures (such as Turkey or Armenia; cf. Onkvisit \& Shaw, 1993, p. 261). That is, it is often assumed that people from high-context cultures tend to think of interdependency as a relationship-oriented process, whereas people from low-context cultures think of it as a content-focused process (cf. Adair \& Brett, 2004). This notion is consistent with research in a number of areas. For example, research by Gelfand et 
al. (2001) revealed a universal dimension of conflict construal, namely, compromise versus win, which reflects the emphasis people place on the nature of blame in a dispute (cf. Pinkley, 1990). Specifically, Japanese, high-context negotiators framed their disputes in terms of "compromise" more than American, low-context negotiators did. This because ascribing blame to both parties allows the maintenance of the social unit, which is in line with the relational focus of individuals from high-context cultures. Furthermore, a recent study by Lalwani, Shavitt and Johnson (2006) suggests that in order to maintain good relationships with others, Japanese engage more in socially desirable responding than Americans do. This focus on maintaining a good working relationship may make relational strategies, such as being kind, more effective when communicating with suspects from high-context cultures than suspects from low-context cultures. Based on the research and theory discussed above, we expect that in police interviews with high-context suspects being kind is more strongly related to interview effectiveness, particularly in terms of the suspects' willingness to provide a statement and to the suspects' perception of the quality of the relationship, than it is in police interviews with low-context suspects (hypothesis 1 ).

Furthermore, cultural differences may also influence the effectiveness of rational arguments. An important assumption in low-context cultures is the quality maxim: one should state only that which is believed to be true on the basis of sufficient evidence (Grice, 1975; see also Gudykunst \& Matsumoto, 1996). This maxim implies that low-context rather than high-context communication typically centres on logic and rationality (cf. Adair \& Brett, 2004). This implication is consistent with literature in a number of areas. For example, Cialdini and colleagues (1999) found that commitment/consistency arguments were more effective in influencing people from low-context cultures than from high-context cultures when it came to responding to a request to participate in a market survey. Similarly, Choi and Nisbett (2000) found that low-context Americans have a lower tolerance for cognitive inconsistencies than high-context East Asians. That is, low-context Americans were more likely to change their behaviour when confronted with cognitive inconsistencies than highcontext East-Asians. Furthermore, a scenario study by Fu and Yukl (2000) showed that American managers perceive the use of arguments as more effective in influencing people and resolving differences than high-context Chinese managers. This collection of research suggests that influence exercised through the use of content-oriented, rational strategies is likely to be more effective in police interviews with low-context than with high-context suspects (cf. Adair \& Brett, 2004; Giebels \& Taylor, 2009). In sum, in police interviews with low-context suspects, we expect rational arguments to be more strongly related to interview effectiveness, particularly in terms of suspects' $\mid$ admissions, than it is in police interviews with high-context suspects (hypothesis 2). 


\section{Method}

\section{Overview}

Experienced police officers $(n=52)$ were asked to interview mock theft-suspects in a field study setting. These mock theft suspects were students who had all stolen money in a controlled setting prior to the interview (cf. Vrij, 1992). Suspects were placed in either the low-context or high-context condition based on their cultural background (Dutch vs. non-Western). Police officers were randomly assigned to suspects, and informed that the suspects could be either innocent or guilty. All police officers were instructed to find the truth.

To be able to establish influencing behaviours of the police officers and to establish the subject's actual information provision (dependent variable 1), all police interviews were video-taped, and content-coded. Afterwards, the suspects filled out a questionnaire. This questionnaire contained items to measure the perceived quality of the relationship (dependent variable 2), and items to check the presumed low-/high-context categorization. A third dependent variable we established was whether or not suspects admitted the theft (admissions). All participants were assured that their individual responses would remain confidential and that videotapes and the questionnaires were for research purposes only and would not be disclosed to anyone other than the researchers.

\section{Suspects}

Fifty-two students (all male; mean age $=18.2$ years, $S D=1.6$ ) from middle vocational training programs voluntarily participated in our project. Since we were interested in the effects of suspects' cultural background, gender was kept consistent. That is, only male students were invited to participate (as in reality most suspects are male; e.g., Leo, 1996, p. 273). Students were - with the school boards permission - recruited during regular class hours. A total of 25 participants had the Dutch nationality, with both parents having been born in the Netherlands (low-context culture, referred to in the following as LCC). For 27 students included in our analyses, one or both parents were born in a range of non-western countries, including Turkey, Morocco, Indonesia, Armenia, Azerbaijan and Iraq. Of this subgroup, 20 students also had a non-Dutch nationality (high-context culture, referred to in the following as HCC; cf. Onkvisit \& Shaw, 1993, p. 261).

\section{Procedure}

A participant was welcomed by a research assistant who explained to him that he was first going to participate in a food habit test conducted by a biologist. Next, the following information was disclosed:

"Imagine that you have heard from a friend that the biologist keeps a large amount of money in a closet in his room. This money is meant for reimbursing travel expenses for 
research participants. This is a good opportunity for you to get some extra money! Your assignment is to steal 200 Euros from the box in the closet".

The research assistant also stressed that the participant could not be held legally responsible for the mock theft. Next, the participant was brought to a waiting room. After a few minutes, he was picked up by the biologist and escorted to the test room (this walk took about three minutes). Upon arrival the biologist said:

"I am so sorry, but I have left the questionnaires at the copying machine in the central hall. Please have a seat while I will get them. If you would like to read something, there are some magazines over there in the closet".

The biologist then left the room for approximately five minutes. Upon return, the participant filled out the food habit test and was brought back to the waiting room. All participants stole the money, and therefore could be considered guilty. After several minutes, the research assistant arrived and told the participant the following:

"Imagine that it is the next day and that your phone rings. It is the police. They inform you that during your presence the day before the biologist was robbed". He was further informed that he would be interviewed by a police officer in approximately ten minutes. The participant was told that -since he was guilty-it would not be to his advantage to admit the mock theft at the outset of the interview. He was further instructed to convince the police officer of his innocence but that it would also be important that his behaviour appeared credible. In other words, if he felt that he had to admit the theft due to the police officer's behaviour, he was encouraged to do so. To increase the participant's motivation, he was informed that his final reward depended on the credibility of his performance (reward varying between 15 and 30 Euros).

\section{Police Officers}

The group of participants serving as police interviewers consisted of 52 experienced police officers ( 32 males, 20 females, mean age $=40.5$ years, $S D=6.8$ ). All police officers were taught at the Dutch Police Academy, which included training in the standard interviewing method (for detailed information see Nierop, 2005; Van Amelsfoort, Rispens, \& Grolman, 2005). On average, they had 10.1 years of experience with conducting police interviews $(S D=7.5)$.

All officers had the Dutch nationality. For 9 officers -all of whom had lived in the Netherlands for over 30 years- one or both parents were born in a non-Western country, including Turkey, Greece, Italy and Surinam. ANOVA analyses of the cultural background of the officer on all influencing behaviours and interview outcomes showed no effect, all $F(1,50)<2.21$, ns. Therefore, we assume that the cultural background of the police officers was not influencing our results, likely due to the standard interviewing method that the officers all had been taught. This standard interviewing method contains both relational and substantive components (see also our introduction section), and usually concerns three phases: preparation, interview, and conclusion. In the underlying study we will focus on the actual police interview. 
Procedure

After being welcomed, the police officers were informed that they were going to be interviewing a suspect of a money theft, who could be either guilty or innocent. Although all officers knew they were participating in a research project, we did not explicitly tell them that the theft was staged. Their task was to uncover the truth. The officers had 15 minutes to prepare themselves for the interview on the basis of a standard police report containing a few tactical clues. These included, for example, a fingerprint of the suspect on the closet that contained the moneybox, and a witness who spotted the suspect near the money. These clues alone were not sufficient for prosecution. The officers were informed that they would have 45 minutes to conduct the interview and that they would be stopped after that.

\section{Independent Variables}

Influencing Behaviours

Two student-assistants were trained to content-code transcripts using the speaking turn as the unit of analysis; i.e. to every speaking turn one code was assigned to describe how the behaviour expressed in the particular speaking turn could be labelled best. For each interview, and for every code, the relative frequency in relation to the total of coded behaviours of the police officers was determined.

Coders worked independently at coding a police interview transcript in terms of the Table of Ten and then met to establish a consensus for all codes assigned. The coding scheme included three conceptually different categories of being kind: active listening, rewarding, and offering (cf. Nierop, 2005). The total coding scheme, therefore, consisted of 12 categories plus a "not applicable". For the purpose of this study we will focus our analyses on active listening, rewarding, offering, and rational arguments.

After 30 hours of training on practice material, the agreement between coders was, on average, $82 \%$, and varied between $65 \%$ and $93 \%$. We considered this to be sufficient for the coding of the 52 transcripts. Two student-assistants coded each transcript (overall Cohen's kappa was .79). When the coders disagreed about a certain code, they established the correct code with help of a trained facilitator. In sum, $76.7 \%$ of the behaviour of the police officers could be typified as influencing behaviour. Active listening was used most often (40.1\%), followed by rational arguments ( $7.3 \%)$, rewarding ( $0.5 \%)$, and offering ( $0.4 \%)$. Other behaviours that occurred frequently were direct pressure (15.7\%) and being credible (7.2\%; see Table $2 b$ ).

\section{Cultural Background}

Suspects were placed in either the low-context or high-context condition based on both their cultural background, and previous research supporting this categorization (Adair, 2003; Adair \& Brett, 2005; Brett, 2001; Fu \& Yukl, 2000; Hall, 1976; Hall \& Hall, 1990; Hofstede, 2001). Furthermore, in the post-interview questionnaire, we included three items that have 
been identified in previous research (cf. Kim, Pan, \& Park, 1998) to represent the low-/highcontext difference well: "I try to keep harmony in my group", "I am loyal to my group, even in hard times", and "If the people close to me are happy, then I am" ( $1=$ totally not agree, $6=$ totally agree). With these items a culture scale was constructed $(\alpha=.66)$. An ANOVA analysis revealed that $\mathrm{HCC}$ suspects indeed scored significantly higher on the culture scale than LCC suspects $\left(M_{\text {hcc }}=5.02, M_{\text {lcc }}=4.56 ; F(1,50)=4.68, p<.05\right)$, which supports our cultural categorization.

\section{Table 2}

The Table of Ten influence behaviours

\begin{tabular}{lll} 
Table 2a & & Table 2b \\
Strategy & Description of behaviour & Percentage \\
\hline $\begin{array}{l}\text { Being kind } \\
\text { Active listening }\end{array}$ & All friendly, helpful behaviour & 41.0 \\
Rewarding & & 40.1 \\
Offering & & 0.5 \\
Being equal & Statements aimed at something the parties have in common & 0.4 \\
Being credible & Behaviour showing expertise or proving you are reliable & 0.4 \\
Emotional appeal & Playing upon the emotions of the other & 7.2 \\
Intimidation & Warning of consequences or accusing the other personally & 1.1 \\
Imposing a restriction & Delay behaviour or making something available in a limited way & 0.1 \\
Direct pressure & Exerting pressure on the other in a neutral manner by being firm & 15.7 \\
Legitimizing & Referring to what has been agreed upon in society or with others & 0.7 \\
Exchanging & Give-and-take behaviour & 0.4 \\
Rational persuasion & Use of persuasive arguments and logic & 7.3 \\
\hline
\end{tabular}

\section{Dependent Variables}

Actual Information Provision

After two independent coders randomly coded $25 \%$ of the police interviews for actual information provision, the agreement between coders was 100\%. From this point forward, one coder proceeded to code all of the material, resulting in one code assigned to each interview ( 1 = a little, 2 = moderately, 3 = completely; $M=2.19$, SD = .77).

\section{Quality of the Relationship}

In the post-interview questionnaire, suspects rated the quality of the perceived relationship with the police officer and indicated the extent to which they agreed with the following statements ( 1 = totally not agree, 6 = totally agree): "During the police interview the quality of the relationship was good", "... the atmosphere was good", “... we understood each other well”, “... we trusted each other”, “... we respected each other”, and “... believed each other". The mean value of the six items was used to create a 'quality of the relationship'-scale $(\alpha=.79)$, which is used in further analyses $(M=4.29 ; S D=.76)$. 


\section{Admissions}

Suspect admissions were coded as a dichotomous variable (admission $=1$, denial $=0$ ). That is, when suspects admitted committing the crime this was coded as "admission". Since all suspects were guilty, we could be certain that admissions were truthful. Altogether, 7 admissions were made (13.5\%; 4 LCC and 3 HCC suspects).

\section{Results}

We conducted a series of ANOVA analyses to check whether the cultural background of the suspects directly influenced the interviewers' effectiveness. We only found a marginally significant effect on the quality of the relationship: HCC suspects tend to perceive the quality of the relationship with the police officer as being somewhat better than LCC suspects did $\left(M_{\text {hcc }}=4.48, M_{\text {lcc }}=4.09 ; F(1,50)=3.72, p<.06\right.$; see Table 3). No significant results were found for either actual information provision or admissions (see Table 2 and 4 ).

Correlation analysis showed that the three types of being kind (active listening, rewarding, and offering) are unrelated $\left(r_{A L-R}=.01, r_{A L-O}=-.06, r_{R-O}=.18\right.$, all $\left.n s\right)$. This supports the idea that it indeed concerns three conceptually different categories. Furthermore, no association was found between the effectiveness indicators: actual information provision and the perceived quality of the relationship ( $r=.14, n s)$; actual information provision and admissions $(r=.05, n s)$; and quality of the relationship and admissions $(r=-.02, n s)$.

\section{Hypotheses Tests}

34 To test our hypotheses we conducted a series of hierarchical regression analyses. Analyses were run separately for each of the four influencing behaviours -active listening, rewarding, offering, and rational arguments- and successively on all three dependent variables. Each regression analysis consisted of three steps. In the first step, the specific characteristics of the police officer - gender and experience with conducting a police interview - were entered to control for relationships with the predictor and outcome variables. Since our primary interest was the two-way interaction of (the four distinct) influencing behaviours and cultural background of the suspects on our dependent variables, the second step was a control procedure for the main effects of these predictor variables. In the third step, the crossproduct term of the two predictor variables was entered to test the hypothesized two-way interaction effects. To facilitate interpretation and minimize problems of multicollinearity, we standardized the influencing behaviours and the cultural background before calculating the cross-product term and regression statistics (cf. Aiken \& West, 1991). To further analyze the interaction effects found, the regression equations were rearranged into simple regressions of the outcome variables on influence behaviours, under the condition of high-context culture (mean +1 s.d.) and low-context culture (mean -1 s.d.). 

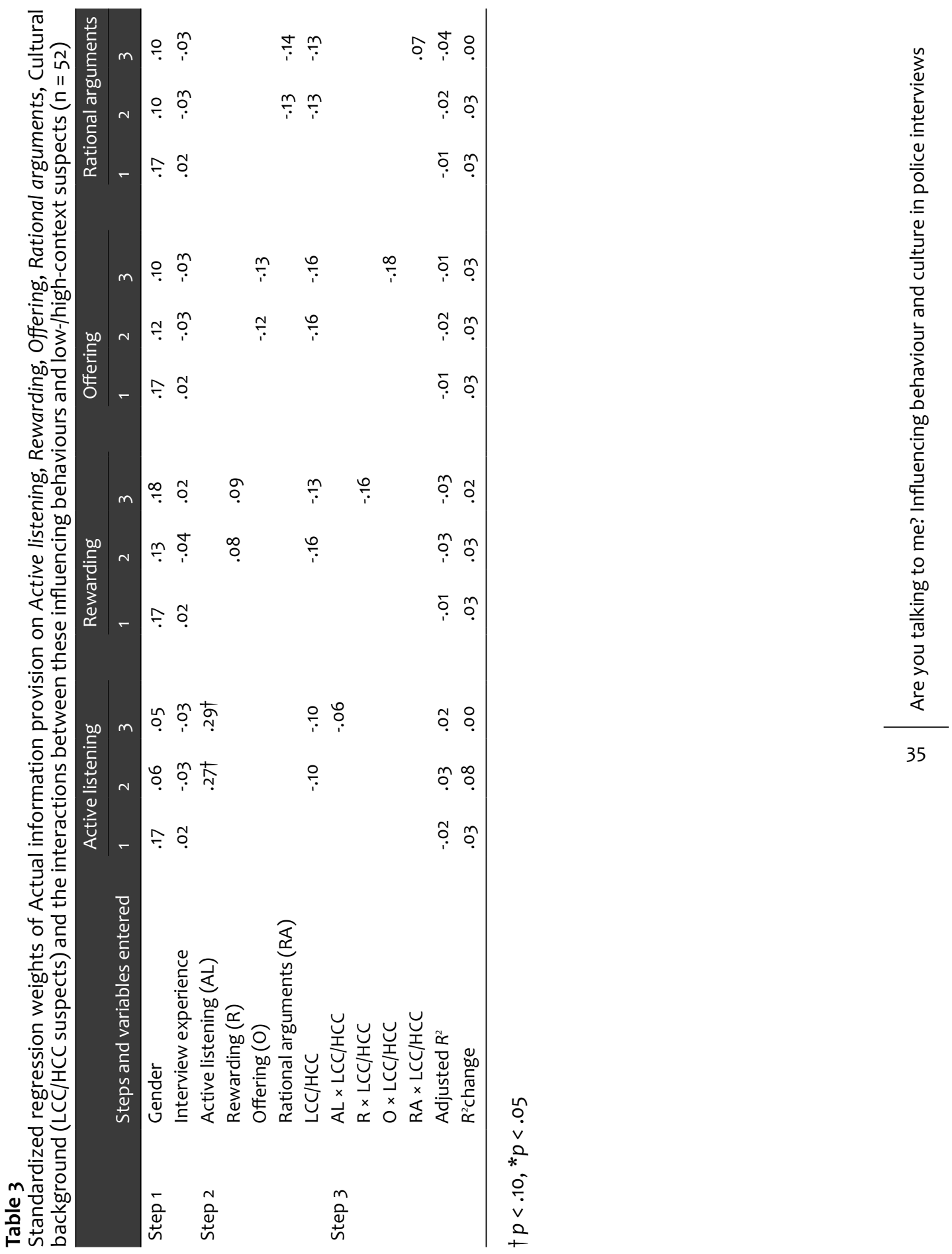


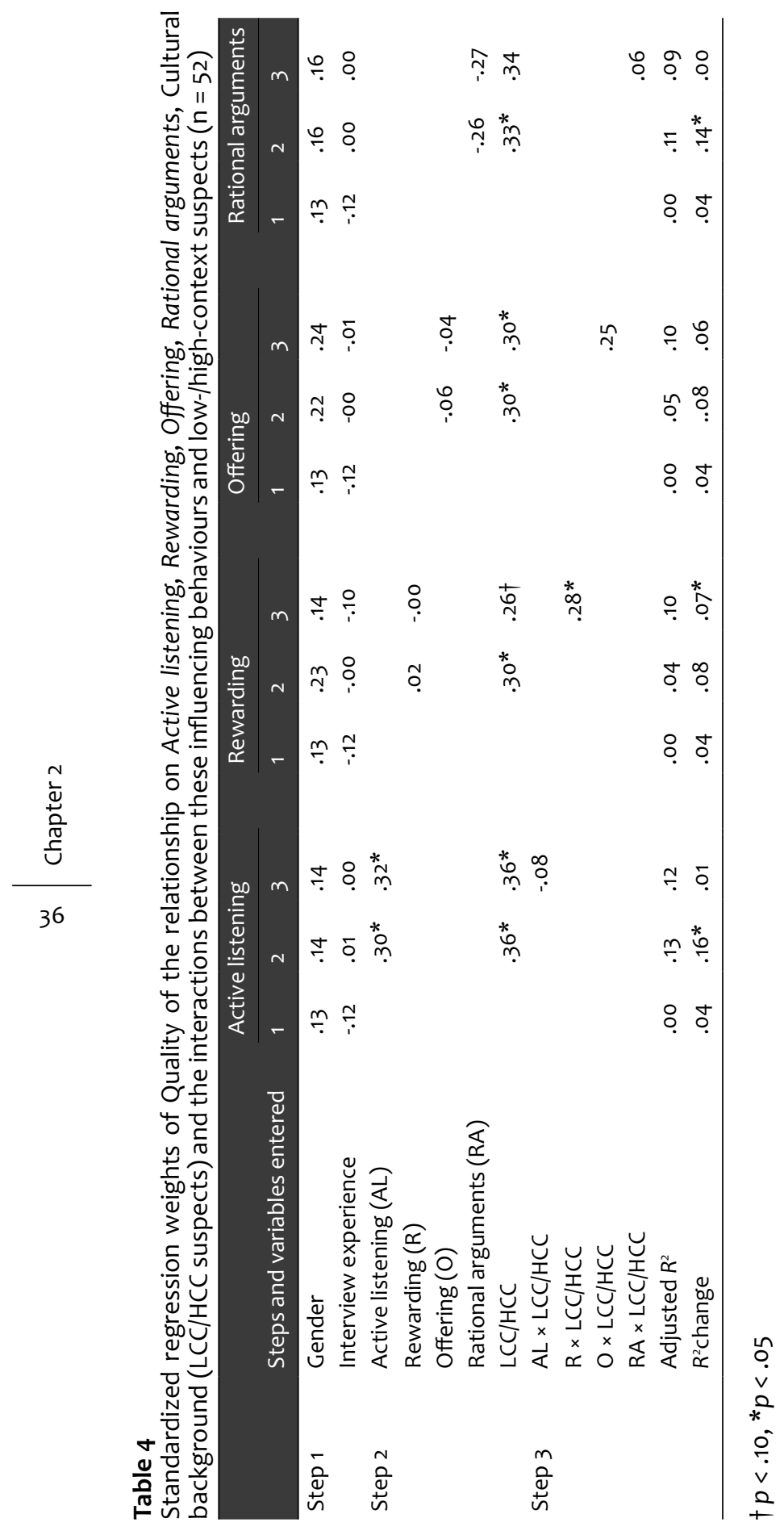




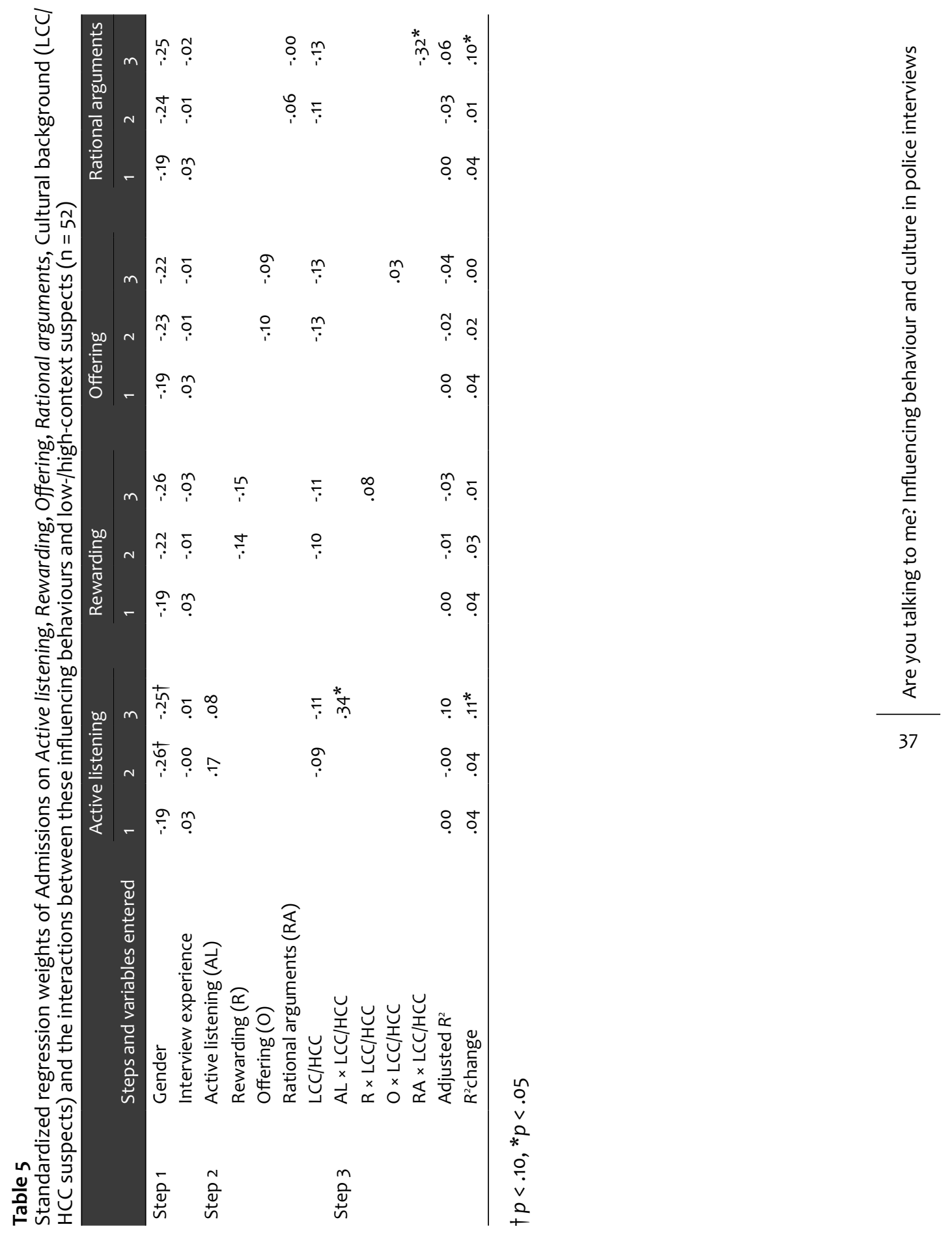




\section{Hypothesis 1}

Hypothesis 1 predicted that in police interviews with high-context suspects, being kind is more strongly related to interview effectiveness -particularly in terms of the suspects' willingness to provide a statement and to the suspects' perception of the quality of the relationshipthan it is in police interviews with low-context suspects. Results in Table 3 show that only active listening behaviour of the police officer is positively related to actual information provision $(\beta=.29, p<.06$ ). This effect occurred regardless of the cultural background of the suspects. For the quality of the relationship we found a similar effect: active listening is positively related to the quality of the relationship $(\beta=.30, p<.03$; see Table 4$)$. Again, no interaction with the cultural background of the suspects was found. However, for the quality of the relationship, the predicted interaction effect did occur for the rewarding behaviour of the officer $(\beta=.28, p<.05$; see Table 4$)$. As expected, the interpretation of this effect revealed that the rewarding behaviour of the police officer was positively related to the quality of the relationship, in particular in police interviews with high-context suspects (see Figure 2). Also for the quality of the relationship, a marginally significant interaction effect was found for the offering behaviour of the police officer and the suspect's cultural background $(\beta=.23, p<$ .10; see Table 4). As can be seen in Figure 3, this pattern matches our findings for rewarding behaviour and shows that the offering behaviour of the police officer was positively related to the quality of the relationship, in particular in police interviews with high-context suspects. Finally, for admissions, we found a significant interaction effect between active listening and the cultural background of the suspects ( $\beta=.34, p<.02$; see Table 5 ). When examining the direction of this interaction-effect, the data showed that an increase of active listening was context suspects (see Figure 4). Taken together, these findings largely confirm hypothesis 1. 


\section{Figure 2}

Two-way interaction between Rewarding and Cultural background on Quality of the relationship

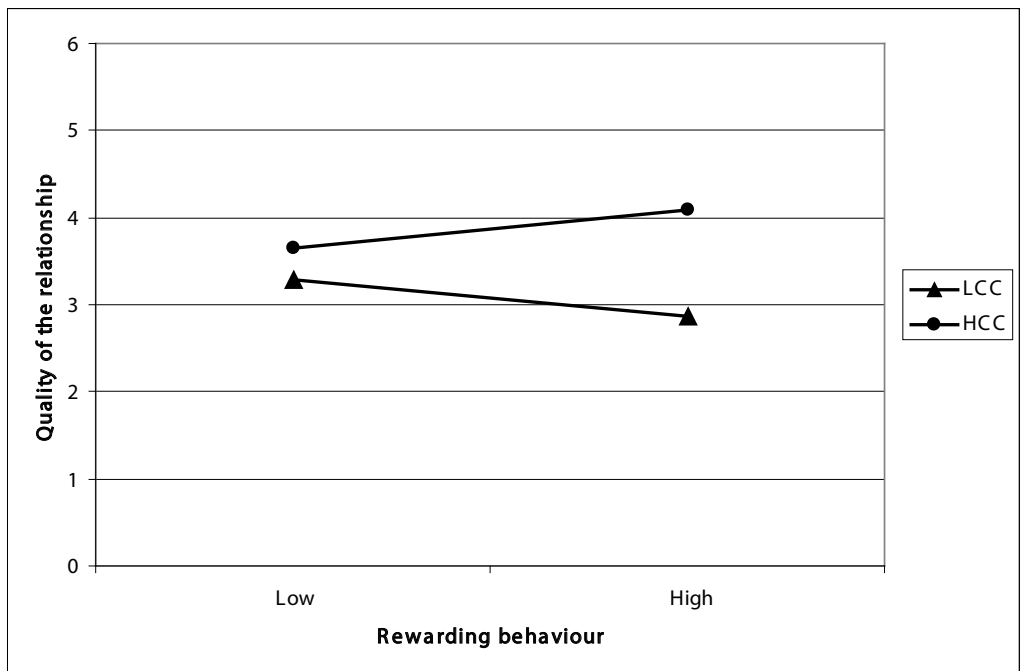

Figure 3

Two-way interaction between Offering and Cultural background on Quality of the relationship

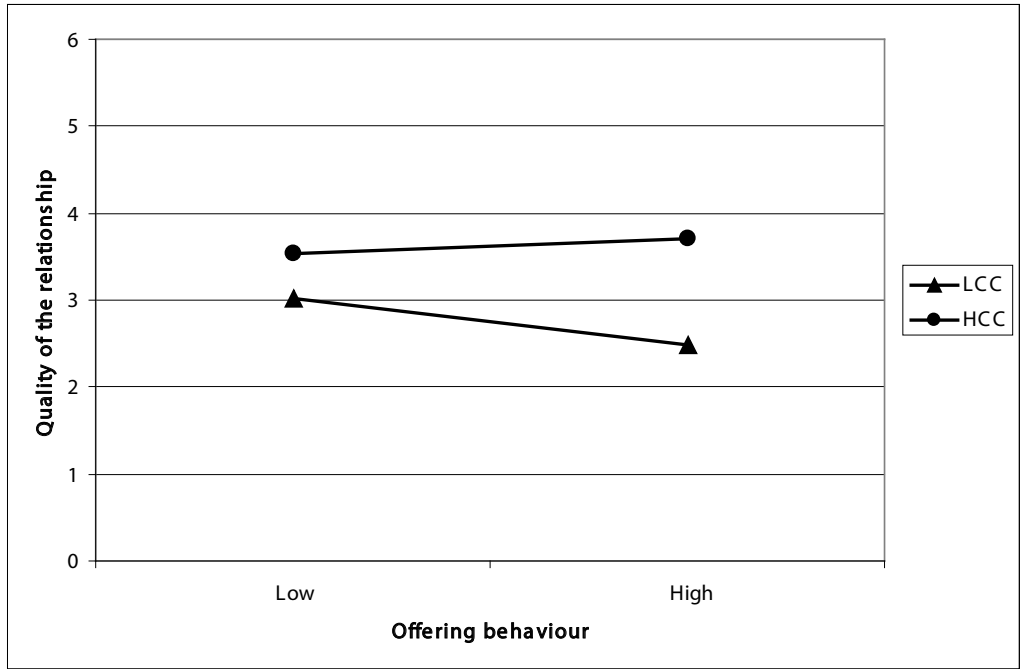




\section{Figure 4}

Two-way interaction between Active listening and Cultural background on Admissions

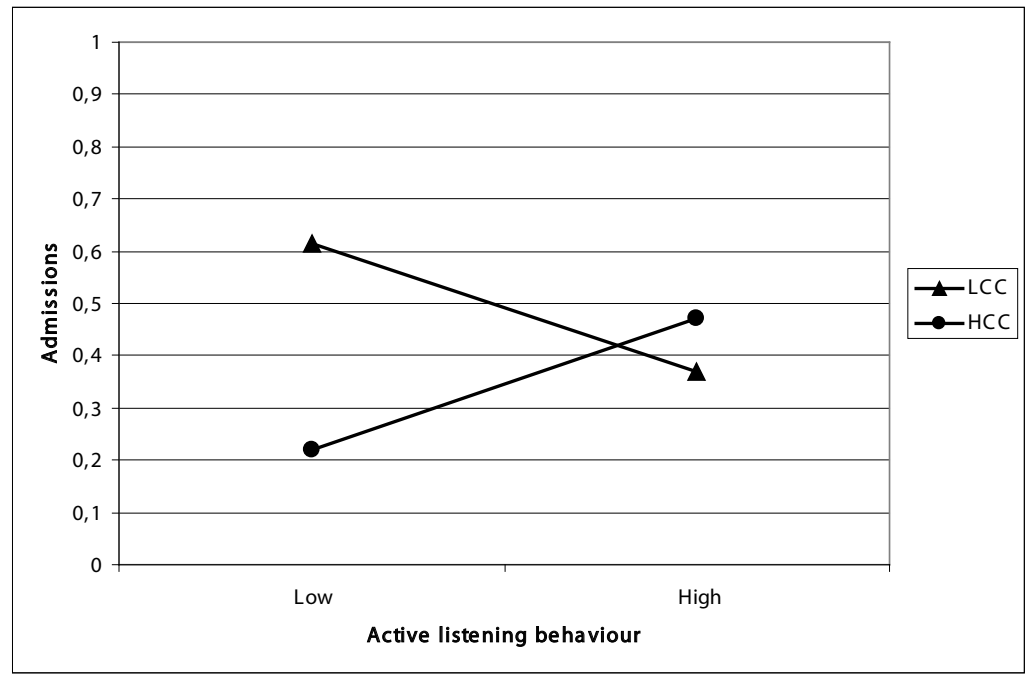

\section{Hypothesis 2}

Hypothesis 2 predicted that in police interviews with low-context suspects, rational arguments are more strongly related to interview effectiveness -particularly in terms of suspect admissions- than it is in police interviews with high-context suspects. As expected, we found a significant interaction effect between rational arguments and cultural background on admissions ( $\beta=-.32, p<.03$; see Table 5 ). With respect to the interpretation of this interaction effect, our data showed that rational arguments were indeed positively related to admissions, particularly for low-context suspects (see Figure 5). Moreover, and in line with our reasoning, it appeared to be negatively related to admissions in police interviews with high-context suspects. Taken together, hypothesis 2 is thus supported. Our results did not reveal any main effects or interaction effects of rational arguments and cultural background on either actual information provision or quality of the relationship. 


\section{Figure 5}

Two-way interaction between Rational arguments and Cultural background on Admissions

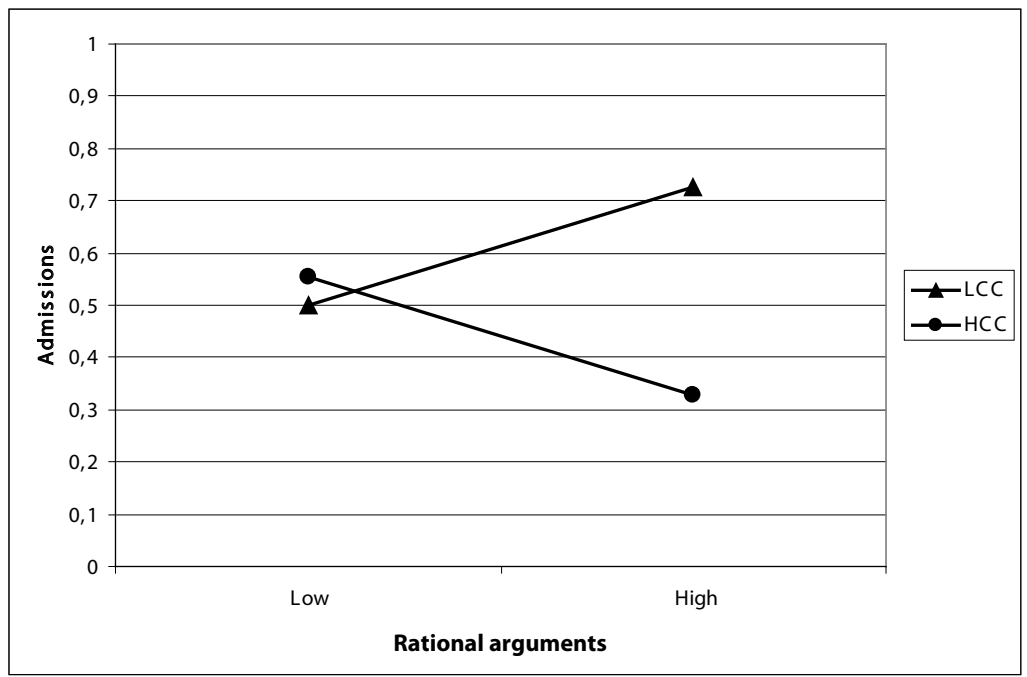

\section{Discussion}

The aim of this research was to introduce the concept of influencing behaviours to the context of police interviews and to explore the effects of different types of influencing behaviours on suspects from low-context and high-context cultures. In general, our findings suggest that influencing behaviour plays an important role in police interviews: well over seventy percent of the officers' behaviour could be typified as influencing behaviours. Furthermore, the two specific types of influencing behaviour that were the focus of this research (being kind and rational arguments) appear to be frequently used and to work out differently for low-context and high-context suspects.

The results for the three different types of being kind (i.e. active listening, rewarding and offering) predominantly support our predictions. That is, rewarding -and to a lesser extend offering- seems to foster the perceived quality of the relationship, particularly for high-context suspects. This is in line with the idea that a defining character of people from high-context cultures is their pronounced concern with (maintaining) relationships in interdependent situations (cf. Ohbuchi, Fukushima, \& Tedeschi, 1999). Furthermore, the admission-rate of high-context suspects in particular, increases with the police officers' use of active listening behaviour. Thus, particularly relational influence strategies in terms of being kind seem to be effective for high-context suspects. Please note, however, that the admission rate of low-context suspects seems to be negatively related to the active listening 
behaviour of the police officers. This might suggest that although active listening in general may promote a suspect's willingness to provide information (cf. Bull \& Cherryman, 1996; cf. Lamb et al., 1996), and the perceived quality of the relationship with a police officer (as our findings indeed show), it may not be effective in eliciting an admission from low-context suspects. A possible explanation could be that if a police officer uses a lot of active listening behaviour there is not enough room for building up cognitive pressure.

In line with this reasoning, we find confirmation for our expectation that rational arguments are more effective in terms of admissions for low-context suspects. That is, frequent use of this content-oriented influencing behaviour by the police officers is related to an increase in suspects' admissions. This is in line with previous research showing that people from low-context cultures are more likely to change their behaviour when confronted with logic and inconsistencies than people from high-context cultures (Choi \& Nisbett, 2000). Interestingly, our findings also suggest that rational arguments may be ineffective when interviewing high-context suspects. That is, for high-context suspects, rational arguments were negatively associated with suspects' admissions. Apparently, using behaviours that do not fit with the cultural background of suspects will work out negatively. Departing from the assumption that individuals from high-context cultures place a strong emphasis on values such as maintaining harmony and preserving face (Triandis \& Suh, 2002), the use of more factual rational arguments may be viewed as inappropriate and disruptive. Consequently it may reduce the suspect's level of cooperation. Moreover, it is easy to understand that with the increase of content-oriented influencing behaviour, such as rational arguments, the attention paid to the interpersonal relationship may be perceived to be declining. This may be particularly true in the first phases of a contact, where parties are building a relationship (Adair \& Brett, 2005).

A contribution of the present research is the demonstration that, under specific, interdependent conditions, suspects from low-context and high-context cultures respond differently to different types of influencing behaviour (cf. Adair \& Brett, 2004; Giebels \& Taylor, 2009). As noted by Baldwin (1993), the fundamental purpose of investigative interviewing is a 'search for truth', which, in daily practice, can be seen as a mechanism towards the 'construction of proof' (see also Milne \& Bull, 1999). Thus, in essence, police interviews can be considered to serve a substantive purpose. Hence, much research on police interviews has focused on improving substantive effectiveness (Bull \& Cherryman, 1996; Fisher \& Geiselman, 1992; Hartwig, 2006; Hartwig et al., 2006). In addition to dealing with substantive effectiveness, the present study demonstrates that different types of influencing behaviours may also have consequences for relational effectiveness. This may be regarded particularly important if continued interaction with a suspect is expected (cf. Viki et al, 2006). Moreover, as stated by Adair and Brett (2004), individuals from high-context cultures may engage in influencing behaviour in the service of a more relational goal, whereas influencing behaviour 
in low-context cultures seems to be more content-oriented. This means that, in addition to the possibility of affecting both substantive and relational outcomes, the use of different influencing behaviours allows police officers to specifically and more effectively influence suspects from low-context and high-context cultures.

Finally, several issues warrant attention in evaluating our findings. First, it is important to note that our findings are based on a relatively small sample size. Nevertheless, all interviews were content-coded, which is a procedure conducive to an elaborate dataset. Furthermore, our data are based on simulated police interviews. This might raise the question to what extent our findings can be generalised to authentic police interviews (Mann, Vrij, Fisher, \& Robinson, 2008). For instance, it could be argued that suspects in a real-life situation experience higher stakes than the mock theft suspects in our experiment because the potential consequences are more severe (e.g., prosecution; cf. Vrij et al., 2009). However, we have several indications that our suspects took their task rather seriously. For example, many suspects showed signs of nervousness during both the stealing of the money as well as during the interviews, such as sweating and making nervous gestures. Actually, three students that were initially involved in the study could not proceed to the interview because they were either too scared to take the money, not able to pursue at the moment, or refused to steal the money because of religious convictions. Furthermore, most suspects indicated that they were highly motivated to earn the highest amount of money possible (which is quite an amount of money for students). Yet, follow-up research on influencing behaviour in authentic police interviews is needed to strengthen the ecological validity of our findings.

Another issue that merits attention is one of the effectiveness indicators we included in this study, namely suspects' admissions. An advantage of our study is that we can actually establish a ground truth since all suspects were guilty of the crime. However, using such a measure in practice may be problematic (Baldwin, 1993) because in reality no such objective external criterion exists and the suspect may well be innocent (Milne \& Bull, 1999). Even more so, focussing on gaining an admission may result in too much pressure being exerted and even false confessions (cf. Vrij, 2004). Interestingly, the admission rate in the current study was rather low. One explanation for this finding (at least for low-context suspects) may be that persuasive arguments may require time in order to be effective. Especially when people become aware that they are the target of an influential attempt, their natural reaction is to attend more carefully and thoughtfully to every aspect of the situation (Langer, 1989; Petty \& (acioppo, 1986). As such, suspects may weigh the strengths of an argument: when these are appreciated and accepted suspects may be willing to change their behaviour. However, if the weaknesses of an argument are exposed, they will be evaluated and countered (Knowles \& Linn, 2004). Thus, if a suspect perceives the evidence as weak, he will probably remain resistant (Milne \& Bull, 1999), even in the face of a lot of rational arguments on the part of the police officer. It would therefore be recommendable to further investigate types and strength of arguments in future research. 
Another limitation of the present study may be that we did not take the cultural background of the police officers into account. It could be the case that high-context police officers prefer different strategies than low-context police officers (cf. Giebels \& Taylor, 2009), which are perhaps better suited for the interviewing of high-context suspects. However, in the current study we did not find any differences in police officers' behaviours nor a relationship between their cultural background and interview outcomes. This is probably due to the fact all participants were taught standard interviewing method and lived in the Netherlands for many years. Therefore, it would be interesting to investigate how police interviews by high-context officers are conducted, and whether this may improve high-context suspects' cooperation.

Finally, in this study, we focused on the influencing behaviours of police officers. Although it provides us with some initial insights into the relevance of an influencing behaviour framework for police interviews, the dynamics of the situation are not taken into account. This may be important, as several studies in interdependent contexts suggest that the interrelationships among behaviours have a significant impact on their meaning and context (Giebels \& Taylor, 2009; Taylor \& Donald, 2004, 2007). An understanding of these interrelationships may also provide additional knowledge concerning the (informationgathering) process of investigative interviewing, and would incorporate the behaviour of the suspect. It would, therefore, be beneficial to conduct interaction analyses in future research.

\section{Practical Implications and Conclusions}

Although an extensive body of literature on police interviews exists (e.g., Baldwin, 1993; Bull \& Milne, 2004; Gudjonsson, 2003; Milne \& Bull, 1999; Moston \& Stephenson, 1993; Vrij, 1994, 2001), the present study is -as far as we know - the first to examine police officers' behaviour from a theoretical (influencing) perspective. In doing so, we were able to demonstrate how specific types of influencing behaviour relate to several interview outcomes (Bull \& Soukara, in press), dependent on the cultural background of suspects. This is important since knowledge about different types of influencing behaviour and their effects allows police officers to switch between strategies in order to adapt to the unique requirements of the situation. This study shows that one important contextual variable is the cultural background of suspects. 


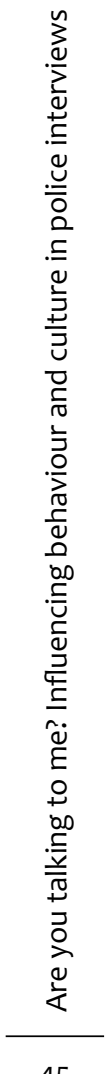





\section{Chatting with suspects: Strategic sequences and the importance of order and cultural fit}

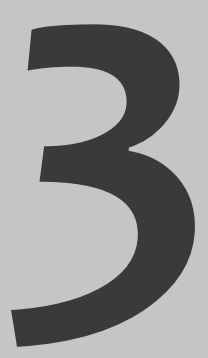

$1 \quad$ This chapter is a modified version of the manuscript Beune, K., Giebels, E., Adair, W. L., Fennis, B.M., \& Van der Zee, K.I. (submitted). Chatting with suspects: Strategic sequences and the importance of order and cultural fit. 
$m$
$\frac{m}{d}$
$\stackrel{0}{0}$
$\frac{\sigma}{U}$
48 
A great deal of empirical and theoretical attention has been focused on police officers' skills for the interviewing of suspects (Bull \& Milne, 2004; Gudjonsson, 2003; Kassin et al., 2007; Milne \& Bull, 1999). One important feature these scholars clearly agree upon is that police officers combine several skills in one interview (see also Vrij, Mann, \& Fisher, 2006). Despite this recognition, research until now has focused on the use and effectiveness of single interview skills (Beune, Giebels, \& Sanders, in press; Bull \& Soukara, in press), rather than some sort of combination. This seems a missed opportunity since there is growing evidence that social interactions are most effective when (two) behaviours are combined rather than using one behaviour exclusively (Carnevale \& Pruitt, 1992; Hilty \& Carnevale, 1993; Olekalns \& Smith, 2000, 2003; Olekalns \& Weingart, 2008; Pruitt, 1981; Rafaeli \& Sutton, 1991; Rubin \& Brown, 1975). For instance, the combined communication of two distinct emotions (happiness and anger) by negotiators has been found to increase integrative, cooperative behaviour of their opponent (Pietroni, Van Kleef, De Dreu, \& Pagliaro, 2008). Similarly, Lindskold and Bennett (1973) showed that negotiators in a prisoner's dilemma game evaluated their negotiation partner more favourably when this partner used a mixture of threats and promises rather than a promise alone. In addition, work on organisational conflict resolution has demonstrated that the combination of problem solving and forcing behaviour is particularly powerful in enhancing substantive and relational organisational outcomes (Van de Vliert, Nauta, Giebels, \& Janssen, 1999).

Although the interactive or synergetic effects of jointly presented multiple interview techniques may also have important implications for the police context, until now this topic has received scant attention in the literature. The present article tries to fill this void by predicting how different combinations of behaviours may impact the interview's effectiveness, depending on the context in which these strategic sequences are presented. More specifically, this research asks whether suspects from high-context cultures will be more responsive to sequences containing an affective component, whereas suspects from low-context cultures will be more responsive to sequences containing a rational component. As such, we will test the role of cultural fit, a moderator that may qualify the impact of strategic sequences on police interview outcomes. In doing so, we elaborate on existing theory on the good-cop/bad-cop technique (Brodt \& Tuchinsky, 2000; Rafaeli \& Sutton, 1991), and research on (intercultural communication in) investigative interviewing (Beune et al., in press; Bull \& Milne, 2004; Bull \& Soukara, in press; Holmberg \& Christianson, 2002; Milne \& Bull, 1999; Shepherd, 1991).

We begin this article with a brief overview of the various literatures on strategic sequences in interdependent settings, noting that these sequences may differ in terms of effectiveness. Then, we move on to discuss a specific context against which these sequences are generally evaluated: i.e., the context of intercultural communication. The core argument developed in this research is that strategic sequences are most effective when they 'fit' with 
a suspect's cultural background. Two studies are reported and discussed in which specific predictions are tested. In these studies, we investigate how two frequently used behaviours in police interviews -being kind in terms of active listening (further referred to as kind behaviour; cf. Bull \& Cherryman, 1996; Lamb et al., 1996) and rational arguments (cf. Beune et al., in press; Walton, 2003)- impact the (actual and self-reported) information provision of suspects when combined into a strategic sequence. In previous research, kind behaviour has been found to stimulate suspects' cooperation (Beune et al., in press; Holmberg \& Christianson, 2002), while rational arguments -messages that refer to logic and proof(Giebels \& Taylor, 2009) are an important prerequisite in order to address the evidence (Baldwin, 1993). More specifically, in Study 3.1, we examine the effects of kind behaviour and rational arguments when combined in a contrast sequence with firm behaviour (i.e., contrast sequences). We also test whether these effects are moderated by 'cultural fit'. In Study 3.2, we increase our knowledge on these two central elements of investigative interviewing by examining how the order of kind behaviour and rational arguments together in a sequence impacts the information provision of suspects and - again - whether this depends on cultural fit. Together, these experiments reveal that when both kind behaviour and rational arguments occur in a contrast sequence with firm behaviour, they elicit more information from suspects when they fit with suspects' cultural backgrounds, while information provision in response to sequences consisting of kind behaviour and rational arguments is a function of both the order in which they are presented and cultural fit.

\section{Strategic Sequences}

50 Similar to other interdependent situations (cf. Adair \& Brett, 2005), police interviews are mixed-motive in nature: on the one hand, police officers need to address certain points to build their case (Baldwin, 1993; Brodt \& Tuchinsky, 2000), while on the other hand, suspects' cooperation is required to enable (future) interaction (Bull \& Milne, 2004; Milne \& Bull, 1999; Shepherd, 1993; Viki, Culmer, Eller, \& Abrams, 2006). Moreover, police officers might want to strategically adjust their behaviour over time based on the information content obtained from suspects (cf. Milne \& Bull, 1999; Olekalns \& Weingart, 2008). This requires a great deal of flexibility on the part of the police officer (Bull \& Soukara, in press) and illustrates that a combination of skills seems to be required for the effective interviewing of suspects (Vrij et al., 2006). Although research in related areas has already discovered the powerful potential of combined behaviours in social interaction (Carnevale \& Pruitt, 1992; Hilty \& Carnevale, 1993; Olekalns \& Smith, 2000, 2003; Olekalns \& Weingart, 2008; Pruitt, 1981; Rafaeli \& Sutton, 1991; Rubin \& Brown, 1975), the literature on strategic sequences in police interviews is virtually nonexistent. 
A strategic sequence is defined as a display of a combination of behaviours, which are aggregated into a unique manifestation of components of influencing behaviour (cf. conglomerated conflict behaviour; Van de Vliert, 1997). One particular sequence that is widely associated with police interviews is the good-cop/bad-cop technique (Kamisar, 1980; Rafaeli \& Sutton, 1991). Traditionally, this sequence involves two different roles: one particularly firm (bad-cop) and the other kind and warm (good-cop; Brodt \& Tuchinsky, 2000). These roles are found to be effective when enacted by either two different persons or a single one (Rafaeli \& Sutton, 1991; see also Pietroni et al., 2008). Ironically, and despite this strong conceptual association, which is even captured in the technique's name, the effectiveness of this combination has barely been tested in police interview settings. An exception is the observation of Rafaeli and Sutton (1991), who found that bill collectors and Israeli police investigators identified the combination of the two behaviours (firm followed by friendly) as highly effective in bringing about compliance from targets. They explained this apparent success in terms of perceptual contrast; i.e., perceptions of behaviours are relative, and by providing a meaningful context, one behaviour serves as the contextual reference point against which the other behaviour is evaluated (Bazerman, 1990; Eiser, 1990; Pietroni et al., 2008, p. 1452). Thus, when two behaviours are combined, their characteristics may be accentuated (e.g., friendly behaviour may appear friendlier when juxtaposed to firm behaviour than when presented alone; Hilty \& Carnevale, 1993; Rafaeli \& Sutton, 1991). This assumption was empirically tested and confirmed in research on negotiation in work teams (Brodt \& Tuchinsky, 2000).

Although the literature on contrast sequences (e.g., Brodt \& Tuchinsky, 2000; Rafaeli \& Sutton, 1991) initially focused on the affect dimension (i.e., contrasting firm behaviour with kind behaviour; cf. Pietroni et al., 2008), research by Hilty and Carnevale (1993) found that when initial firm behaviour was followed by concession-making behaviour, subjects were more likely to reciprocate concessions that were made. Consequently, distance to agreement was reduced. Because concession making behaviour aims at settlement through discussion of the issues at hand (Van de Vliert, 1997), it can be considered a more contentfocused strategy. According to this line of reasoning, Hilty and Carnevale's research suggests that any combination that produces a shift from firm to cooperative behaviour may foster an interaction's success. Similar effects might occur for firm behaviour (further referred to as 'intimidation'; Giebels \& Taylor, in press) followed by rational arguments because rational arguments generally give suspects the opportunity to give an explanation for the issues raised, signalling a willingness to listen and to take the other party seriously. Thus, where previous studies have pointed to the beneficial effects of juxtaposing kind behaviour against intimidation, we propose that similar benefits may exist for rational arguments that are contrasted with intimidation. As such, this could be referred to as a more 'substantive' rather than 'affective' contrast. Taken together, and based on the notion of perceptual contrast, we 
propose that both of the above identified affective and substantive contrasts may influence suspects' information provision. Moreover, we expect that the effectiveness of each of these two strategic contrasts is sensitive to the (cultural) context in which they are presented (cf. Hilty \& Carnevale, 1993). Put differently, we predict their impact to be dependent upon the fit with the cultural background of the interviewed suspects.

\section{Cultural Fit}

Police interviews now increasingly take place in a cross-cultural context as more and more suspects have cultural backgrounds different from the culture in which they reside (e.g., Beune et al., in press; Viki, Culmer, Eller, \& Abrams, 2006). Culture can be defined as a society's characteristic profile with respect to values, norms, behaviours, and institutions (Lytle, Brett, Barsness, Tinsley, \& Janssens, 1995), as well as communication preferences (Hall, 1976; Holtgraves, 1997; Triandis \& Suh, 2002). As communication lies at the heart of social interaction (Holtgraves, 1997), examining police interviews from a cultural perspective is appropriate because culture affects the way people communicate (cf. Adair, 2003). In his theoretical framework, Hall (1976) argued that people differ fundamentally in what he labelled low-context and high-context communication. Low-context communication involves the use of explicit and direct messages in which meanings are principally contained in the transmitted messages. By contrast, in high-context cultures, people rely on the context of a message to convey meaning (see also Holtgraves, 1997). These manifestations are the result of contextspecific preferences for communication outcomes: facts, saving face and harmonious interpersonal relationships (Victor, 1992). Because low-context cultures usually strongly value facts and factual information, communication is presented in a direct way, focusing on the content of a message (Brinker Dozier, Husted, \& McMahon, 1998). High-context cultures, on the other hand, generally have strong notions of face saving (Ting-Toomey, 1988; Tse, Lee, Vertinsky, \& Wehrung, 1988) and maintaining harmonious relationships (Brinker Dozier et al., 1998; Kim, Pan, \& Park, 1998). As a consequence, communication in high-context cultures is usually indirect and roundabout, stressing issues of relational harmony and face saving (Adair, Okumura \& Brett, 2001; Hall, 1976; Kim et al., 1998). Generally, low-context communication is predominant in Western, individualistic cultures, while high-context communication is found to be predominant in non-Western, collectivistic cultures (Adair, 2003; Adair \& Brett, 2005; Gudykunst \& Ting-Toomey, 1988; Hofstede, 2001; Triandis \& Suh, 2002).

Examining strategic sequences in the context of culture may offer an avenue for further sophistication of investigative interviewing since evidence is growing that the effectiveness of verbal behaviour is cultural specific (Fu \& Yukl, 2000). Indeed, a number of scholars have argued and found that the effectiveness of strategic (sequential) behaviour varies across cultures in situations in which two parties are mutually dependent (Adair \& Brett, 2005; Giebels \& Taylor, 2009). For instance, people from low-context cultures not only 
prefer direct and content-oriented communication, but strategies that are responsive to these preferences also seem to be more effective in influencing their behaviour. Evidence supporting this idea comes from Giebels and Taylor (2009), who found that when crisis negotiators interacted with low-context perpetrators, rational arguments were more central and effective compared to negotiations with high-context perpetrators. Further evidence comes from a study by Beune et al. (in press), who showed that only for mock theft suspects originating from low-context cultures, the number of admissions was positively related to the rational arguments used by the police officer. The reason for the success of rational arguments may be that logic and deductive thinking are generally highly valued in low-context cultures (Gelfand \& Dyer, 2000), and behaviours that make use of this way of thinking are rewarded (Giebels \& Taylor, 2009). For high-context cultures, on the other hand, relationship-oriented behaviour has been found to be particularly effective (Beune et al., in press). This may be explained by the notion that in high-context cultures, people tend to think of interdependency as a relationship-oriented process (Adair \& Brett, 2004). That is, as they place a strong emphasis on social harmony (Hall, 1976) and avoiding direct confrontation (Holtgraves, 1997), relationship-oriented behaviour may be effective because of its appeal to these values (see also Brinker Dozier et al., 1998; Victor, 1992). The core argument underlying the current study is that we predict the effectiveness of strategic sequences to be dependent on the cultural context. Based on the research evidence presented above, we predict that sequences are most effective when they 'fit' the cultural framework of the suspect; i.e., strategic sequences with an affective or relational component are predicted to fit best with high-context individuals, while strategic sequences with a substantive or rational component will fit best with individuals from low-context cultures. When combined with a firm, intimidating tactic, more specifically, affective contrast is expected to be more effective than substantive contrast for participants from high-context cultures, while for individuals from low-context cultures, substantive contrast is predicted to be more effective than affective contrast (Hypothesis 1).

\section{Study 3.1}

\section{Method}

\section{Participants and Design}

Participants in this study were 52 students ( 27 from low-context cultures and 25 from highcontext cultures; $79 \%$ male; average age $=17.9$ years) in lower vocational training. They were invited to participate for the possibility to win an iPod. Participants were assigned to experimental conditions on a random basis. The experiment was conducted at different school locations under similar circumstances by one female experimenter. Both written responses and webcam images were recorded for further analyses. 
The design was a $2 \times 2$ factorial design with strategic sequence (affective contrast vs. substantive contrast) and participants' cultural background (low-context vs. high-context) as between-subjects factors. Dependent variables were willingness to provide information, actual information provision and admissions.

\section{Procedure}

To test our hypotheses, we developed the following research paradigm. Participants were told that they were about to participate in an innovative police project called "the police interview of the future". The objective of this project was "to develop ways of virtual interviewing"; i.e., ways of interviewing suspects via a computer-supported chat session. Participants were asked to enter a live chat session with a police officer. In fact, this chat was simulated, and all participants were responding to a pre-programmed computer program. All responses were recorded, and participants filled out a questionnaire afterwards.

Upon arrival at the classroom, participants were positioned (three at a time) in different corners of the classroom in such a way that no participant could see any other. They were told not to communicate with each other during the session. The experimenter was physically present throughout all experiments; however, she remained distant so as not to compromise any of the participants' privacy. Each set of participants received the following standardised oral instructions from the experimenter:

"You are about to participate in a recently developed study about "virtual police interviewing". Perhaps you have heard something about this in the media? Virtual interviewing means that the police would like to find out about possibilities to interview suspects via a computer-supported chat session. You could probably imagine that this would be beneficial for both the police and the suspect as it might save a lot of time. In order to test this, we would like to ask chat experts - young people like you - to participate in a live chat session with a police officer from the Dutch Police Academy. This police officer will ask you some questions about a theft. That is, you have to answer his or her questions as if you have committed a theft. In order for you to better imagine this situation, you are about to see a video in which this theft is committed. It is very important that you carefully watch this video and imagine you are actually in that particular situation stealing the money. Afterwards, a live network connection with the Police Academy will be established. An experienced police officer will interview you about the theft you committed. It is his or her job to uncover the truth, but it is up to you what you will answer. No right or wrong answers exist: it is important that you act as you would in a real-life situation."

The video depicting the theft was modelled after a paradigm used in previous research (Beune et al., in press) and filmed from a first-person perspective. In this paradigm, participants rob a biologist who asks them to fill out a food habit test. To motivate the participants in the current study, they were told that they could win an iPod depending on how 
"successful" (i.e., credible) they were. Success was said to be determined by an independent committee on the basis of their written responses and webcam recordings. However, in fact, all participants who completed the experiment were entered into a raffle for two iPods.

The experimenter instructed the participants that the laptop in front of them would provide them with further detailed step-by-step instructions via video-messages. Furthermore, they were informed that their behaviour would be recorded on webcam, both to assess their credibility and "for the police officer to be able to see their face during the chat session". It was stressed that all recordings would be strictly confidential and used for research purposes only. From this point forward, the experiment was run individually.

Each chat session began with the same introduction questions, involving - in chronological order - the right to remain silent (i.e., "caution"), consent on the webcam recordings, and some demographic variables (e.g., name, age, place of birth), followed by a strategic sequence each of which contained four questions to which the suspect had to respond. These questions were presented written in the chat screen, while participants could see an image of "the police officer". The chat session was designed to be interactive and was programmed to "crash" after the participant had fully responded to our manipulation. In this way, we could assess the direct effects of the strategic sequences. After the crash, the participants had to ask the experimenter how to proceed. In order for the "crash" to appear credible, the experimenter expressed her mild surprise about the "bad internet connections at the specific location" and asked the participant to fill out the questionnaire "since first impressions are also very significant, thus filling out the questionnaire would still be useful". This was done to ensure that all participants filled out the questionnaire, even though they thought their interview was being interrupted. Upon completion, participants were debriefed and dismissed.

\section{Independent Variables}

Strategic Sequences: Affective vs. Substantive Contrast

Before the strategic sequences were constructed, our conceptualisation of the behaviours was pretested in a pilot study among a student population $(n=58)$. For each type of behaviour (intimidation, kind behaviour, and rational arguments), two sets of communicational statements were developed ${ }^{2}$. Intimidation was represented by: "<Name of participant> I can be very clear about this. We have a number of clues indicating you're involved in this matter. You seem to be guilty to me! What do you have to say about that?" followed by "Are you lying to me right now? Because if you do, and we'll find out about that, it won't be to your advantage, you know. What do you have to say to that?" Kind behaviour was defined in terms

$2 \quad$ All statements are based on typical examples of each behavioural category observed in authentic and simulated police interviews (Beune et al., in press). Due to translation, the number of words per question differs slightly; in Dutch, all questions contain exactly thirty words. 
of active listening (cf. Beune et al., in press) and represented by: "I can imagine that you are quite shocked. Therefore it is important for me to hear your side of the story. Please tell me what happened according to you?" followed by "So if I understood correctly, you came for a food habit test, and during that test the test leader left the room for several minutes? Could you please elaborate on this?" Finally, Rational arguments were represented by: "We have a witness reporting seeing you in front of the closet that contained the money box. How would you explain this?" followed by "What if we took your fingerprints and compared those to a fingerprint we found on the money box. How do you think this would work out for you?" By means of a questionnaire presenting the three types of statements in a random order, we asked participants to rate the extent to which they considered each statement intimidating, kind, and rational. A t-test revealed that all ratings on the conceptualised constructs (i.e., our operationalisations of intimidation, kind behaviour and rational arguments and whether participants indeed scored these behaviours as such) were significantly higher than ratings on the other behaviours (e.g., the extent to which participants, for instance, rated "intimidation" as kind behaviour), all $t(57)>4.05, p<.001$. We then constructed the following strategic sequences: affective contrast (intimidation - kind behaviour) and substantive contrast (intimidation - rational arguments). The computer program assigned all participants randomly to either the affective contrast or the substantive contrast condition.

\section{Cultural Background}

Previous research has identified low-/high-context communication to be a powerful indicator of cultural background (Adair, 2003; Adair \& Brett, 2005; Brett, 2001; Fu \& Yukl, 2000; Hall, 1976; Hall \& Hall, 1990; Hofstede, 2001). Therefore, participants were classified as either lowcontext or high-context based on their country of birth (see also Beune et al., in press; Giebels \& Taylor, 2009). To check whether the division we made was valid, we included a 16 -item scale in the post-chat questionnaire that was recently found to be a valid measure of general differences in low/high context communication (Adair, Buchan, \& Chen, 2008). The scale includes items tapping into issues such as guessing meaning (e.g., "I am able to recognise others' subtle and indirect messages"), humbleness in communication (e.g., "I am modest when I communicate with others"), and truth bending (e.g., "I often bend the truth, if it protects the social harmony"; 1 = strongly disagree, 7 = strongly agree; Cronbach's $\alpha=.75 ; M$ $=4.48, S D=0.80)$.

\section{Dependent Variables}

In order to assess the interview's effectiveness, we identified the following outcome measures: willingness to provide information, actual information provision, and admission of the alleged theft. 
Willingness to Provide Information

Willingness to provide information was assessed in the post-chat questionnaire with three items: "Due to the police officer ... I told everything I knew", "... I gave a lot of information", “... I gave truthful information", ( 1 = strongly disagree, $6=$ strongly agree $)^{3}$. The mean of these items was used to construct a "willingness to provide information" scale (Cronbach's $a=.83 ; M=4.13 ; S D=1.62$ ).

\section{Actual Information Provision}

Using the transcripts of the 52 chat sessions, a trained coder (unaware of the hypotheses) coded the suspects' responses to the contrast sequences in terms of the amount of information provided by suspects ( 1 = little, 2 = moderate, $3=$ full ; cf. Beune et al., in press). Before coding the 52 chat sessions, two coders were trained on unrelated material. After 30 hours of training on practice material, Cohen's Kappa was .71, which we considered sufficient for coding the 52 police interviews. From this point forward, one coder proceeded to code all of the material for actual information provision $(M=1.43, S D=.53)$.

\section{Admissions}

Suspect admissions were coded as a dichotomous variable (admission $=1$, denial $=0$ ). That is, when suspects admitted committing the crime, this was coded as "admission". Since all suspects were guilty, we could be certain that admissions were truthful. Altogether, 22 admissions were made (42.3\%; 14 Low-Context and 8 High-Context participants).

\section{Results}

\section{Manipulation Checks}

\section{Validity of Research Paradigm}

In order to assess the validity of our research paradigm, we asked participants to rate the credibility of their interaction partner. This perceived credibility of the police officer was assessed in the post-chat questionnaire by eight items derived from previous research (Corrigan \& Schmidt, 1983; see also Ohanian, 1990), which we slightly modified to apply to a police interview context (i.e., we replaced "counsellor" with "police officer"). These items measured two distinct constructs: expertise and trustworthiness. Participants could indicate to what extent they agreed with the following statements ( 1 = not very, 7 = very) on expertise: "To what extent did you think the police officer was ... experienced?", “... expert?”, “... prepared?”, “... skilful”. The mean values of the items were used to create an expertise scale

3 We assumed that self-reported information provision is more likely to reflect suspects' willingness to provide information than an accurate assessment of the actual amount of provided information. Hence, we labeled this variable "willingness to provide information". 
(Cronbach's $\alpha=.86 ; M=5.08 ; S D=1.31$ ). A similar procedure was followed for trustworthiness, which was measured by the following items: "To what extent did you think the police officer was ... honest?”, “... reliable?”, “... sincere?”, and “... trustworthy?” (Cronbach's $a=.80 ; M$ = 4.99; $S D=1.28$ ). These high scores indicate that participants perceived 'the police officer' as quite credible. Furthermore, all participants involved in this study reported believing that they were chatting 'live' with a police officer. Taken together, these results support the validity of our research paradigm.

\section{Cultural Background}

All participants who were classified as "low-context" originated from the Netherlands $(n=27)$. The participants who were classified as "high-context" ( $n=25)$ originated from a variety of non-Western countries that can be typified as high-context (cf. Onkvisit \& Shaw, 1993). These were Afghanistan (1), Armenia (3), Cambodia (1), Congo (1), Indonesia (1), Iran (1), Iraq (1), Morocco (4), Syria (1), Turkey (10), and Yugoslavia (1). An independent samples t-test revealed that participants who were typified as high-context indeed scored (marginally) significantly higher on the "high-/low-context culture" scale than participants who were typified as low$\operatorname{context}\left(M_{\text {hcc }}=4.66, \mathrm{SD}_{\text {hcc }}=0.75 ; M_{\text {lcc }}=4.30, \mathrm{SD}_{\text {lcc }}=0.81 ; \mathrm{t}(50)=-1.61, p<.05\right.$, one-sided $)$. Hence, our classification of low-context vs. high-context cultures seems adequate.

\section{Hypothesis Tests}

We predicted that affective contrast would be particularly effective for high-context participants compared to substantive contrast, while for low-context suspects, the opposite was expected to be true (Hypothesis 1). A univariate analysis of variance with strategic sequence and cultural background as between-subjects factors revealed the predicted interaction effect on willingness to provide information, $F(1,48)=5.45, p<.05, \eta^{2}=.10$, and admissions, $F(1,48)=4.75, p<.05, \eta^{2}=.09$ (see Figures 6 and 7). That is, an affective contrast resulted in greater willingness to provide information and admissions for high-context participants than did a substantive contrast (willingness to provide information: $M_{\text {affective }}=4.59$, $S D=1.26 ; M_{\text {substantive }}=3.83, S D=1.93 ;$ admissions: $M_{\text {affective }}=0.42, S D=0.49 ; M_{\text {substantive }}=0.25, S D$ $=0.45$ ). For low-context suspects, on the other hand, a substantive contrast yielded more willingness to provide information and admissions than did an affective contrast (willingness to provide information: $M_{\text {substantive }}=4.67, S D=1.43 ; M_{\text {affective }}=3.38, S D=1.63$; admissions: $M_{\text {substantive }}$ $\left.=0.71, S D=0.47 ; M_{\text {affective }}=0.31, S D=0.48\right)$. These findings support Hypothesis 1 . Simple effect analysis showed that these differences were significant for low-context individuals, $F(1,48)=$ $4.49, p<.05$ (willingness to provide information) and $F(1,48)=4.96, p<.05$ (admissions), but not for high-context individuals, $F(1,48)=1.45$, ns (willingness to provide information) and $F(1,48)$ $=0.78$, ns (admissions). Although the expected interaction effect was not demonstrated for actual information provision, $F(1,48)=0.32$, ns, our results did reveal a significant main 
effect of contrast sequence, $F(1,48)=5.12, p<.05, \eta^{2}=.10$. That is, participants provided more information when they were confronted with the affective $(M=1.59, S D=0.49)$, rather than the substantive $(M=1.27, S D=0.53)$, contrast.

\section{Figure 6}

Mean assessment of Willingness to provide information given Substantive and Affective contrast sequences for Low-Context and High-Context participants

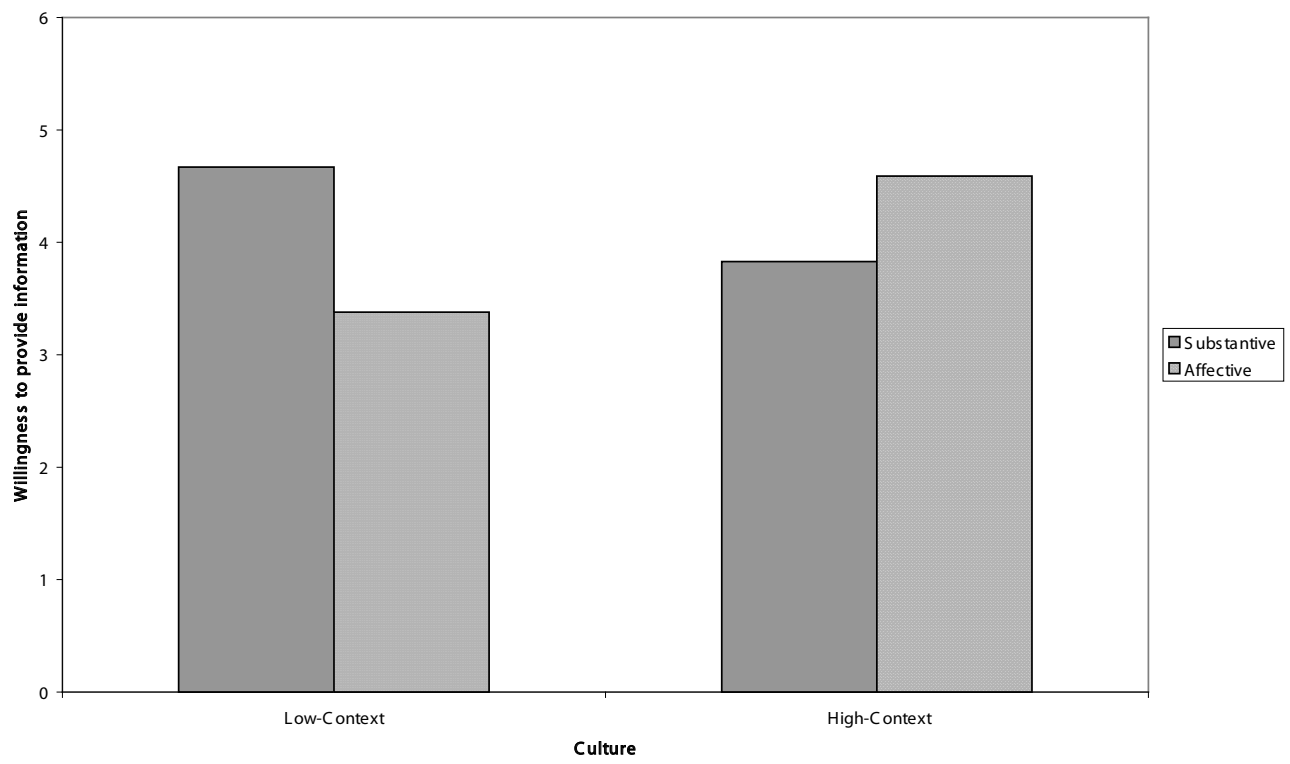




\section{Figure 7}

Mean assessment of Admissions given Substantive and Affective contrast sequences for LowContext and High-Context participants

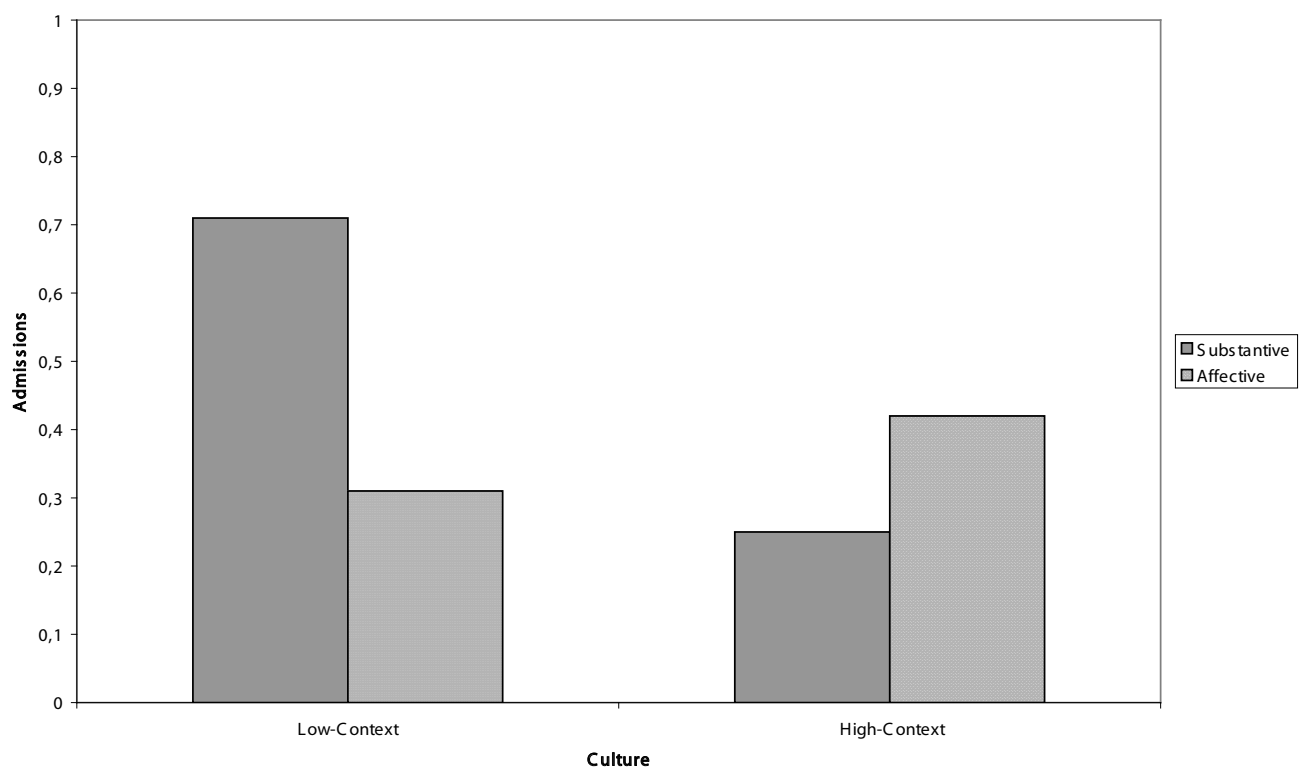

\section{Discussion}

60 Consistent with our hypothesis, Experiment 1 showed that participants from low-context cultures responded more positively to a substantive strategic sequence that 'fits' with their cultural background than to an affective strategic sequence. More specifically, compared to an affective contrast, they responded to a substantive contrast with more admissions and greater willingness to provide information. These findings support our proposition that the accentuation of rational arguments (by contrasting them against intimidation) positively impacts low-context suspects. Although the pattern for high-context participants was congruent with our reasoning, it was not significant. One explanation for this finding may be that relationship building, particularly for people from high-context cultures, takes some time (cf. Adair, Weingart, \& Brett, 2007). For instance, research involving Japanese, high-context, negotiators showed that people do not tend to trust others before a strong relationship is formed. In addition, it has been found that good quality contact is often a prerequisite for cooperation (Viki et al., 2006). In this study, the simple two-sentence affective strategy may not have been strong enough to distinguish it from the rational strategy to high-context participants. This notion implies that for individuals from high-context cultures, it is important to engage in relationship building before talking about the issues at hand. 
Perhaps more importantly, research suggests that conflict can be settled through the use of a single relationship-oriented or content-oriented strategy, as well as a combination of several (Van de Vliert, Euwema, \& Huismans, 1995; Van de Vliert et al., 1999). Considering the prominent role of kind behaviour and rational arguments in police interviews, this begs the question of what their joint impact on suspects' cooperation would be. We know, for instance, from the literature on managers' influence tactics, that a mixture of kind behaviour and rational arguments is more effective than any single tactic or combination of tactics (Falbe \& Yukl, 1992; see also Higgins, Judge, \& Ferris, 2003). To address these issues, we conducted a second experiment in which we examined the combined effect of kind behaviour and rational arguments.

\section{Study 3.2}

\section{Introduction}

To provide a first test of our hypothesis that strategic sequences work best when they fit the cultural backgrounds of suspects, in Experiment 1 we relied on sequences in which two frequently used behaviours in police interviews were preceded by intimidation. The use of such sequences has proved successful in past research (e.g., Brodt \& Tuchinsky, 2000; Hilty \& Carnevale, 1993; Van de Vliert et al., 1999). A limitation of this approach is that we are not able to assess the joint impact of kind behaviour and rational arguments. Clearly, this is a knowledge gap (cf. Vrij et al., 2006) since these behaviours are important elements of most police interviews and are often used in conjunction (Beune et al., in press).

To address this issue, we conducted a second experiment in which participants were confronted with a strategic sequence containing a mix of kind behaviour and rational arguments. As there is growing evidence that the order in which behaviours occur has a significant impact on their meaning and effects (Adair, 2003; Adair \& Brett, 2005; Giebels \& Noelanders, 2004; Giebels \& Taylor, 2009; Taylor \& Donald, 2003, 2004; Vrij et al., 2008), we examined the strategic sequences' impact as a function of order. For instance, Hartwig et al. $(2005 ; 2006)$ found that the strategic disclosure of evidence (i.e., through rational arguments; cf. Walton, 2003) is particularly effective when it follows a suspect's own account (e.g., obtained through active listening; Bull \& Cherryman, 1996), rather than precedes it. Kind behaviour, on the other hand, is likely to work best when it precedes other behaviour (cf. Viki et al., 2006). That is, kind behaviour may be interpreted as showing interest in a suspect personally (Beune et al., in press). Such behaviour has been found to make suspects feel understood and comfortable, resulting in higher levels of cooperation (Holmberg \& Christianson, 2002) and good quality relationships (Beune et al., in press). 
Taken together and based on the research evidence above, we propose a mix of kind behaviour and rational arguments as an effective means of influencing suspects' information provision. However, we expect this mixture to be more effective when kind behaviour precedes rather than follows rational arguments because it is better for the development of the interpersonal relationship (cf. Viki et al., 2006). Furthermore, since a good quality relationship before 'doing business' is of particular importance in high-context cultures (e.g., Brinker Dozier et al., 1998; Hall, 1976), this effect is predicted to be stronger for high-context suspects compared to lowcontext suspects (Hypothesis 2).

\section{Method}

\section{Participants, Design, and Procedure}

Participants in this study were 53 students (27 low-context and 26 high-context; 67.9\% male; average age $=17.7$ years) in lower vocational training, who participated for the possibility to win one of two iPods. The design was a $2 \times 2$ factorial, with order (kind behaviour followed by rational arguments vs. rational arguments followed by kind behaviour) and participants' cultural background (low-context vs. high-context) as between-subjects factors. Dependent variables were willingness to provide information, actual information provision, and suspects' admissions to the alleged theft. Procedures were similar to Experiment 1.

\section{Independent Variables}

\section{Strategic Sequences}

62 Based on the pre-test mentioned in Experiment 1, two sequences were constructed: kind behaviour followed by rational arguments and rational arguments followed by kind behaviour. The communicational statements representing kind behaviour and rational arguments were similar to Experiment 1.

\section{Cultural Background}

Again, participants were classified as either low-context or high-context. All participants who were classified as 'low-context' ( $n=27)$ were born in the Netherlands, except one who originated from Canada. Participants who were classified as 'high-context' $(n=26)$ originated from a range of non-Western countries, including Afghanistan (1), Brazil (2), Dutch Antilles (3), Iraq (2), Morocco (3), Sierra Leone (1), Syria (5), Sri Lanka (1), and Turkey (8). The same low-/high-context scale was used as in Experiment 1 ( 1 = strongly disagree, 7 = strongly agree; Cronbach's $\alpha=.72 ; M=4.82, S D=0.76)$. 


\section{Dependent Variables}

Dependent variables were similar to Experiment 1, including willingness to provide information (Cronbach's $\alpha=.85 ; M=4.19 ; S D=1.59)$, actual information provision $(M=1.68, S D=0.67$ ), and admissions (29 admissions were made; i.e., 54.7\% consisting of 13 low-context and 16 high-context).

\section{Results}

\section{Manipulation Checks}

Validity of Research Paradigm

Similar to Experiment 1, the perceived credibility of the police officer was assessed in the post-chat questionnaire by eight items derived from previous research (Corrigan \& Schmidt, 1983; see also Ohanian, 1990). Participants could indicate to what extent they agreed with four statements measuring expertise ( 1 = not very, 7 = very), e.g., "To what extent did you think the police officer was experienced?" (Cronbach's $\alpha=.73 ; M=5.37 ; S D=1.03$ ); and four items measuring trustworthiness, e.g., "To what extent did you think the police officer was trustworthy?" (Cronbach's $a=.85 ; M=5.60 ; S D=1.24$ ). Again, high scores on credibility were found, and all participants reported believing that they were chatting 'live' with a police officer. Taken together, these results support the validity of our research paradigm.

\section{Cultural Background}

Our data provided support for our cultural categorisation, as an independent samples t-test revealed that participants who were classified as high-context indeed scored significantly higher on the "high-/low-context culture" scale than participants who were classified as low$\operatorname{context}\left(M_{\text {hcc }}=5.06, \mathrm{SD}_{\text {hcc }}=0.64 ; M_{\text {lcc }}=4.58, \mathrm{SD}_{\text {Icc }}=0.79 ; \mathrm{t}(51)=-2.40, p=.05\right)$.

\section{Hypothesis Tests}

We predicted that kind behaviour followed by rational arguments would be more effective than rational arguments followed by kind behaviour and that this would be the case particularly for suspects originating from high-context cultures. First, our results showed, in line with our predictions, main effects across all three dependent variables: willingness to provide information $\left(M_{K R}=4.56, S D=1.64 ; M_{R K}=3.81, S D=1.49\right), F(1,49)=3.13, p<.08, \eta^{2}=.06$; actual information provision $\left(M_{K R}=1.93, S D=0.62 ; M_{R K}=1.42, S D=0.64\right), F(1,49)=9.36, p<.01$, $\eta^{2}=.16$, and admissions $\left(M_{K R}=0.67, S D=0.48 ; M_{R K}=0.42, S D=0.50\right), F(1,49)=3.53, p<.06, \eta^{2}=$ .07. Two of these main effects were qualified by an interaction effect. In line with Hypothesis 2, we found that, for high-context suspects, kind behaviour followed by rational arguments yielded more admissions than rational arguments followed by kind behaviour (high-context: $M_{K R}=0.84, S D=0.38, M_{R K}=0.38, S D=0.51$; low-context: $M_{K R}=0.50, S D=0.52, M_{R K}=0.46, S D$ 
$=0.51$ ), $F(1,49)=2.52, p<.05$ (one-sided), $\eta^{2}=.05$ (see Figure 8 ). Simple main effect analysis confirmed that this difference was significant for high-context, $F(1,49)=5.90, p<.01$, but not low-context suspects, $F(1,49)=0.04$, ns. Furthermore, a significant interaction effect on actual information provision was found (low-context: $M_{K R}=2.14, S D=0.66, M_{R K}=1.15, S D=$ 0.38; high-context: $\left.M_{K R}=1.69, S D=0.48, M_{R K}=1.69, S D=0.75\right), F(1,49)=9.36, p<.01, \eta^{2}=.16$ (see Figure 9). Interestingly, however, the difference was significant for low-context, $F(1,49)$ $=19.07, p<.001$, but not high-context suspects, $F(1,49)=0.00$, ns. No other differences were significant.

\section{Figure 8}

Mean effect on Admissions of the Kind behaviour - Rational argument sequence for LowContext and High-Context participants

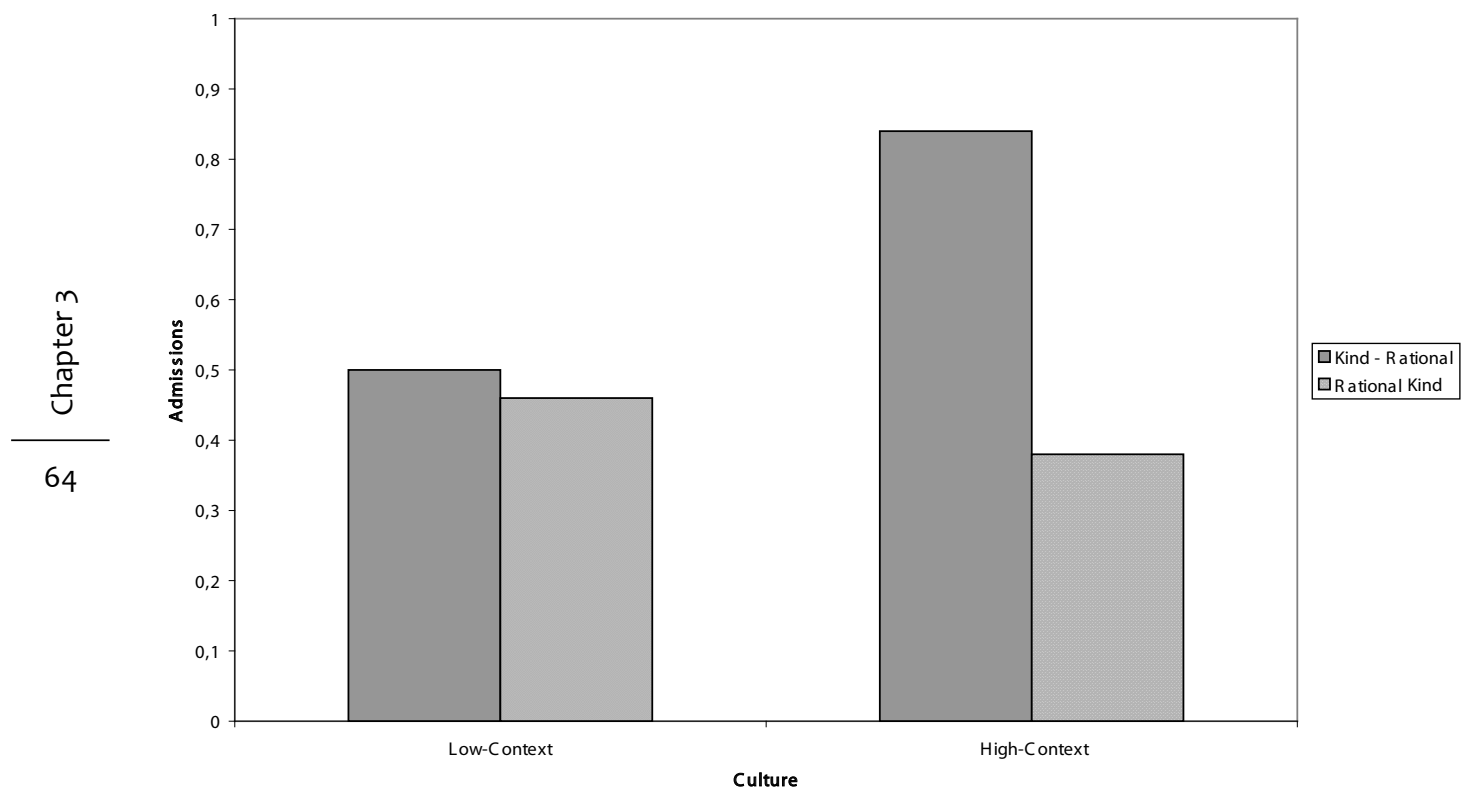




\section{Figure 9}

Mean effect on Actual information provision of the Kind behaviour - Rational argument sequence for Low-Context and High-Context participants

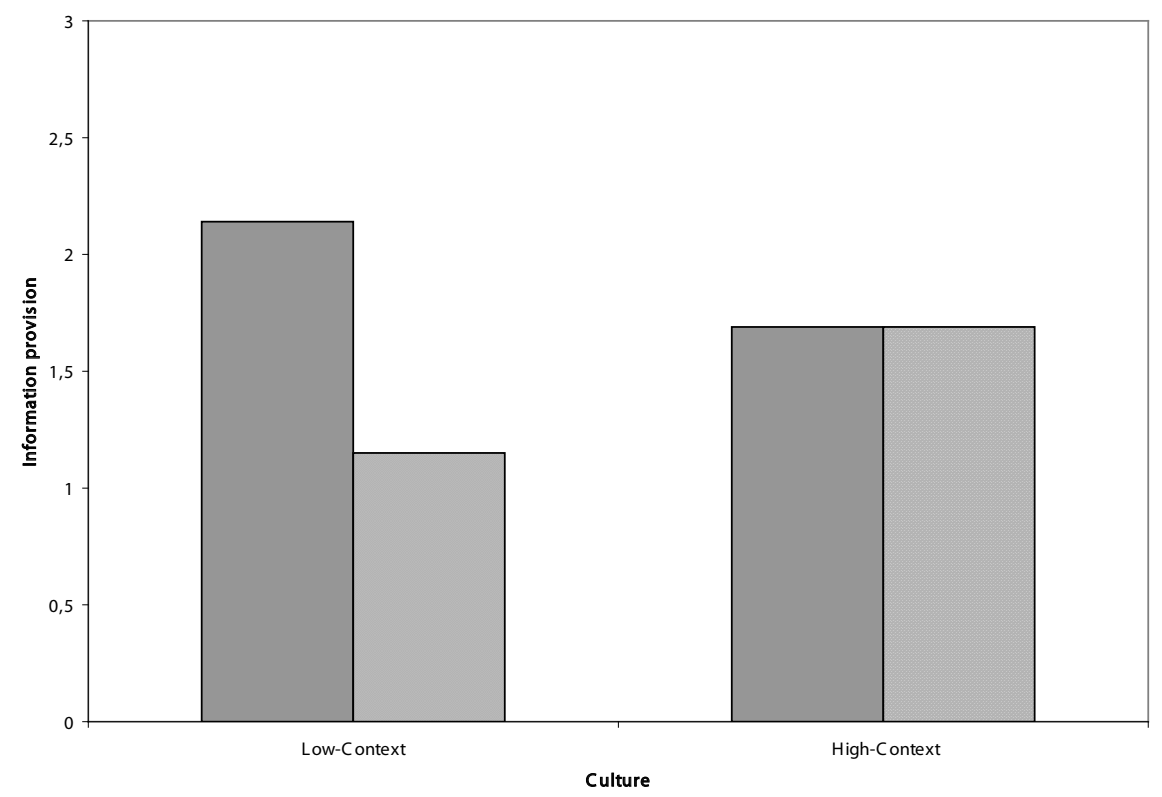

\section{General Discussion}

\section{General Discussion}

Lack of information constitutes a major barrier to the solution of many crimes (cf. Williamson, 1994). Therefore, the primary purpose of investigative interviews is to gather complete and reliable information (Bull \& Milne, 2004; Milne \& Bull, 1999) in order to obtain evidence (Baldwin, 1993). To gather information, however, police investigators must rely heavily on the cooperation of suspects (Moston \& Engelberg, 1993). Consequently, it is crucial to identify interview skills that appeal to suspects in order to establish and maintain cooperation (Bull \& Soukara, in press). Previous research on social interactions has identified strategic sequences as an effective means of influencing a person's cooperation (e.g., Brodt \& Tuchinsky, 2000; Olekalns \& Smith, 2000, 2003; Olekalns \& Weingart, 2008; Pietroni et al., 2008). However, how influential these behaviours are is dependent on the context in which they are presented (Hilty \& Carnevale, 1993). As the context for police investigators increasingly involves suspects of a different cultural background than their own, this may have important consequences. Drawing on research indicating that the impact of strategic behaviour is culturally specific (Beune et al., in press; e.g., Fu \& Yukl, 2000; Giebels \& Taylor, 2009), we proposed that strategic sequences are most effective when they 'fit' the cultural background of the suspect. 
Consistent with our reasoning, the present study shows that suspects respond differently to strategic sequences as a function of cultural fit. Specifically, we demonstrated that low-context suspects admitted the theft more often and were more willing to provide information when confronted with substantive rather than affective contrast sequences, while for high-context suspects, this pattern was reversed. This is in line with research indicating that people from low-/high-context cultures are influenced by different principles; i.e., rationality (low-context) and affect (high-context; Adair \& Brett, 2004). Furthermore, these findings extend existing work on perceptual contrast effects (Brodt \& Tuchinsky, 2000; Hilty \& Carnevale, 1993; Pietroni et al., 2008; Rafaeli \& Sutton, 1991) by demonstrating that contrast effects are transferable to more substantive behaviour as well. Applying this notion to police interviews, strategic contrast sequences may provide police investigators with an effective means of increasing the impact of kind behaviour and rational arguments. However, our findings suggest that the true impact of such a sequence is dependent on the fit with a suspect's cultural framework.

Furthermore, we argued and demonstrated that a mixture of kind behaviour and rational arguments is most effective when kind behaviour precedes (rather than follows) rational arguments. Again, these results are dependent on cultural fit; as hypothesised, we found this specific combination to increase the admissions of particularly high-context compared to low-context suspects. This finding is congruent with research that indicates that relationship-building in an important notion when interacting with people from high-context cultures (e.g., Ohbuchi, Fukushima, \& Tedeschi, 1999; Triandis \& Suh, 2002). Interestingly, a different pattern of results emerged for the actual information provision of suspects. Although similar order effects were found, the difference appeared to be significant for lowcontext but not high-context suspects. A logical explanation for this unanticipated finding may be found in the nature of this behavioural outcome. More specifically, actual information provision was measured as the amount of information provided by suspects. In other words, our finding implies that low-context participants gave more information than high-context participants when kind behaviour preceded rational arguments. This means that they were first encouraged to provide free recall (through kind behaviour, which is operationalised as active listening behaviour) before some evidence was disclosed (through rational arguments). Research evidence shows that the late disclosure of evidence will increase possible inconsistencies between a statement and the evidence (Hartwig, et al., 2006; Hartwig, et al., 2005) because when suspects are first stimulated to talk their statement is more likely to contradict the evidence (Bull \& Soukara, in press). As people from low-context cultures are particularly sensitive to the principle of (in)consistency (cf. Cialdini, Wosinska, Barrett, Butner, \& Gornik-Durose, 1999), they may be more inclined to explain apparent contradictions than are people from high-context cultures. Based on the above logic, one would predict low-context suspects to tell more than high-context suspects when confronted with inconsistencies, or 
likewise, with behaviour referring to this principle (e.g., rational arguments). Indeed, our results seem to provide some support for this notion. However, if true, this explanation seems to be restricted to the actual information provision of suspects. Why could that be? An explanation may lie in different levels of awareness underlying actual and self-reported behaviour. As noted by Perloff (1993, p. 274), in interactions, people often act mindlessly by employing culturally specific scripts (Langer, 1978; Roloff, 1980), while being more mindful and self-conscious when their attention is directed at possible persuasive attempts. When applied to our suspects, actual information provision may be the result of a mindless act (i.e., they were not thinking about how much they were saying), while self-reported information provision is not (i.e., we directed their attention at how much they told by asking about it in the questionnaire, which may have influenced their responses). The latter might explain why we found a significant difference for actual information provision but not self-reported information provision when rational arguments followed on kind behaviour.

Our findings have several implications for theory and practice. First, the results add to a growing body of literature on strategic sequences, pointing at the importance of cultural fit in police interviews and in interactions in general. Previous research has predominantly focused on the effectiveness of single interview skills rather than a combination of these, mostly regardless of the cultural context in which interviews frequently take place. That is, several studies have documented that kind behaviour (e.g., Bull \& Cherryman, 1996; Dando, Wilcock, \& Milne, 2009; Dando, Wilcock, Milne, \& Henry, in press; Holmberg \& Christianson, 2002; Shepherd, 1991, 1996) and the strategic confrontation with evidence (Bull \& Soukara, in press; Hartwig, 2006; Hartwig et al., 2005, 2006) through rational argument (Beune et al., in press; Walton, 2003) are important elements of police interviews. The present study contributes to the existing literature by examining the combination of these frequently used behaviours in addition to and in contrast to firm behaviour (i.e., intimidation), demonstrating that their effectiveness depends on order and cultural fit. More practically, the notion of strategic sequences and cultural fit may help to improve the (training of the) interview skills of police officers.

Like all studies, there are reasons for exercising some caution in generalising our results. A first critical note is that one might argue that our paradigm is hard to translate into police interview practice; i.e., a simulated chat session is obviously quite different from being interviewed by a police officer in reality. For instance, it begs the question of whether suspects were aware of chatting with a computer rather than a living person, as this might have influenced our results. Although this is a legitimate question, we provide two reasons that make - at least to our opinion - this possibility seem unlikely. First, all participants perceived the credibility of the 'police officer' as relatively high (above 5 on a 7-point Likert scale). One would not expect such high credibility rates if suspects were aware of the fact that they were chatting with a computer program. Moreover, when the experimenter asked 
them how they experienced the 'virtual interview', participants' responses included "I think it is good for suspects to be interviewed via the internet because it is less stressful" and "Virtual interviewing is not good because it is easy to lie to the police officer". Interestingly, however, none of the participants involved noticed that it was not a real interaction. Taken together, we believe that our data and observations provide reasonable support for the validity of our paradigm. Notwithstanding this face validity, however, the credibility of our conclusions will clearly benefit from replicating these findings in authentic police interviews.

Another issue is that a relatively high percentage of our suspects admitted the theft despite the short period of interaction. Although previous mock-theft research reported lower levels of admissions (Beune et al., in press), admissions rates of around fifty percent are not uncommon in practice (e.g., Pearse \& Gudjonsson, 1996). For instance, statistics in the Netherlands demonstrate that on average, around seventy percent of police interviews results in full admissions, ranging from forty (personal assault) to seventy (theft) or eighty (fraud) percent (Jacobs, 2004). From this perspective, it seems that our participants followed our instructions to 'act as they would do in real life' fairly well. However, it begs the question of whether these findings are transferable to such short interaction sequences. One possibility may be that suspects decide whether they admit a crime at the outset of an interview (Baldwin, 1993). However, if this were the case, one would expect the admissions to be consistent over the different strategic sequence conditions, which is contradicted by our results. This observation has the important implication that the influencing behaviour of police officers can make a difference (King \& Snook, in press). In support of this notion, King and Snook found that interviews resulting in partial or full admissions (rather than denials) involved higher proportions of influencing behaviour.

An alternative explanation for the relatively quick admissions by our participants may be found in the way the messages were presented. That is, in a chat session messages are presented in written form, while in an authentic setting, the same messages are presented orally. As in live interactions, language does not proceed unidirectionally from speaker to receiver (Perloff, 1993); the latter may be distracted by several contextual factors, such as speech speed (Giles \& Street, 1985) or speech style (Giles \& Smith, 1979). Arguably, written messages cause less distraction, which might increase their impact. Applying this notion to the current study, it could be the case that presenting the evidence in written form (rather than orally) may have caused the suspects to perceive the evidence as relatively strong. As this has been found to be a powerful indicator of suspects' tendency to admit an alleged crime (Baldwin, 1993; Moston \& Engelberg, 1993), it may explain the relatively high admission rate in the current study. As our 'virtual interview' appears to have this beneficial side effect, it is an interesting avenue for future research to consider more systematically whether 'virtual interviewing' (including web-cam recordings) is worth putting into practice. Another potential benefit is, for instance, that suspects can put their own statement -in their own words- onto 
paper, minimising possible errors (e.g., when police officers translate the suspect's verbal statement into a written account). An additional advantage is that everything that is said will be recorded (i.e., there is no way to switch off the chat session at a crucial moment; an often-heard criticism of videotaped interviews; Moston \& Stephenson, 1993). Questions that remain to be answered include the feasibility of chatting with suspects and the impact on suspects in terms of cooperation and truth telling.

Finally, it is a fact that participants in our study were confronted with only a short strategic sequence, rather than experiencing a complete police interview. Although this might suggest that our results are particularly representative of the start of police interviews, our results are consistent with research that examined strategic behaviour in full interactions (Brodt \& Tuchinsky, 2000). In addition, research suggests that different strategic sequences may be appropriate at different times (cf. Adair \& Brett, 2005; Olekalns \& Smith, 2000; Olekalns, Smith, \& Walsh, 1996). Future work might consider what their joint effect on interview outcomes will be and if these sequences can be aggregated into phases of strategic activity (Olekalns \& Weingart, 2008). Most importantly, however, this study suggests that strategic sequences and cultural fit as predictors of interview effectiveness ought to receive greater attention than has been the case to date. 



\section{Look who's talking! Interaction patterns and their cultural dependency'}

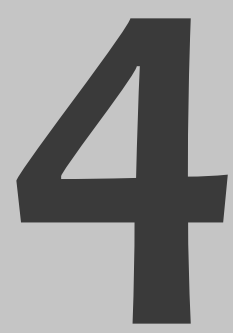

This chapter is a modified version of the manuscript

Beune, K., Giebels, E., \& Taylor, P.J. (submitted). Look who's talking! Interaction patterns in police interviews and their cultural dependency. 


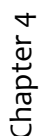

U

72 
How should police officers deal with a situation in which a suspect is reluctant to talk or resists providing relevant answers? Research suggests that many police officers are unsure about what to do when a suspect shows signs of resistance (Moston \& Engelberg, 1993) and that they often interpret resistance as an indication of guilt (Milne \& Bull, 1999, p. 71). Yet, suspects may show resistance for a number of reasons, even when they are not guilty. For example, they may not trust the police to recognise their innocence, or they may be concerned about incriminating themselves in the enquiry (see also Shepherd, 1993). In recognition of such possibilities, studies in the field of investigative interviewing are moving away from seeking to understand how to obtain a confession and moving toward seeking to understand how to gather information from the person interviewed and the circumstances and actions surrounding the crime (Bull \& Milne, 2004). As noted by Walton (2003), information obtained in investigative interviewing may serve a variety of purposes, such as serving justice (Dillon, 1990), establishing a motive (McConville \& Baldwin, 1982), or crystallising the overall pattern of a case (Irving, 1980). In essence, any information provided by a suspect-whether true or false-may confirm or disconfirm information from other sources (McConville, Sanders, \& Leng, 1991). Therefore, the provision of any case-related information by a suspect may be considered helpful in legitimising a police narrative and, ultimately, in finding the truth (Baldwin, 1993).

In general, investigative interviewing may be considered a formal way of questioning a suspect or anyone else who is reluctant to freely provide information (s)he possesses (Buckwalter, 1983, p. 4). In order to overcome this resistance and to acquire information, it is of the utmost importance that these conversations are carefully managed (Shepherd \& Kite, 1988). Effective information gathering may thus depend on the officer's knowledge about how to present messages in a way that appeals to and persuades the suspect to talk. This suggests that interpersonal influencing, defined as the deliberate action(s) of an agent (e.g., police officer) toward a recipient (e.g., suspect) with the intention of altering the recipient's attitudes and/or behaviours (cf. Gass \& Seiter, 1999), may be an important aspect of police interviews.

However, to date, few studies have examined police interviews from an influencing perspective, and little is known about the effectiveness of specific influencing behaviours (King \& Snook, in press). An exception is a recent study by Beune, Giebels, and Sanders (in press) that demonstrated that police officers frequently use influencing behaviour in response to uncooperative suspects of a mock theft. Specifically, they found that two influencing behaviours, rational arguments and being kind, are important building blocks of effective police interviews. Moreover, they showed that these tactics work out differently for suspects from Western, low-context cultures and suspects from non-Western, high-context cultures. In this study, we build on this previous research in three ways. 
First, the Beune et al. (in press) study examined simulated police interviews in which students were instructed to steal a fixed amount of money and were then interviewed by police officers. The issue is to what extent these findings are transferable to real-life settings. One might argue that the stakes for both suspects and police officers are much higher in authentic police interviews (Vrij et al., 2009). This might lead to a very different interaction process compared to that found in the simulations (Roger \& Schumacher, 1983). For example, police officers in authentic interviews may be more prone to put pressure on suspects, and at the same time, suspects may be more likely to resist this pressure rather than cooperate. Indeed, research suggests that when dealing with non-cooperative suspects, police officers sometimes use more confrontational strategies, such as accusations (Moston \& Engelberg, 1993) and warnings (see also Kassin et al., 2007; Leo, 1996). While these intimidation (Giebels \& Taylor, 2009) behaviours are generally considered inappropriate, police officers do use these behaviours (Kassin et al., 2007), even in a simulated context (Beune et al., in press). In the current study, therefore, we will examine influencing behaviours in authentic police interviews, expanding our focus to examine the effects of intimidation, in addition to rational arguments and being kind, on the information-gathering process (see also Beune, Giebels, Adair, Fennis \& Van der Zee, submitted).

Second, in the Beune et al. (in press) study, the behaviour of police officers was aggregated over the entire interaction and related to interview outcomes, including the suspects' overall willingness to provide information, the perceived quality of the relationship, and whether or not the suspects admitted their guilt. However, interviewing a suspect in an investigative context involves a complex conversation that unfolds over time. That is, the police officer and suspect engage in a dynamic interaction and will respond to each other's behaviours over the course of the interaction (Brett, Northcraft, \& Pinkley, 1999; Donohue, 1981; Greeno \& Simon, 1988; Kelley, 1997; Newell \& Simon, 1972; Weick, 1979). When the primary purpose of investigative interviewing is information gathering, the "outcome" of the interview occurs repeatedly across the interaction (i.e., information is gathered or not gathered) rather than as one end-state. This suggests that it is important to understand the actual cue-response makeup of the interaction (Taylor et al., 2008). We therefore focus our examination on the officers' and suspects' behaviours at the micro-level of cueresponse patterns, focusing in particular on the impact of police cues on suspects' provision of information. A focus on the interrelationships among behaviours allows our analysis to consider how the influencing behaviours of police officers (directly) impact whether suspects respond in a desirable or undesirable way (cf. Giebels \& Taylor, 2009).

More specifically, we will direct our enquiries toward behaviours that directly impact either the provision of information by the suspect or reluctance to do so throughout the interview. In doing so, we will thus take into account sequential effects (Leo \& Ofshe, 1998). Such a focus on the information-gathering process, as opposed to focusing on interview 
outcomes (cf. Bull \& Soukara, in press; Milne \& Bull, 1999), is important for two reasons. First, assessing overall interview effectiveness in real life seems to be problematic (Baldwin, 1993). Although one may sometimes presume guilt (or innocence) beyond a reasonable doubt, one can never be certain that the truth is actually found (Kassin, Goldstein, \& Savitsky, 2003). For instance, an innocent suspect may be truthfully denying the crime. Moreover, focusing on a confession may result in too much pressure being exerted and, consequently, even in false confessions (Kassin, 1997). As such, a confession (or the lack thereof) may say little about interview effectiveness. Likewise, overall information provision may be considered a rather crude measure of interview effectiveness. For instance, it does not take into account different types of information or how suspects respond to a specific message or series of messages during the interview. Indeed, there is growing evidence to suggest that the order in which behaviours occur -the interrelationships among behaviours- has a significant impact on their meaning and effects (Adair, 2003; Adair \& Brett, 2005; Giebels \& Noelanders, 2004; Taylor, 2002; Taylor \& Donald, 2003, 2004; Vrij et al., 2008).

Third, previous work showed that the effectiveness of different influencing behaviours varies across cultures (e.g., Adair \& Brett, 2005; Fu \& Yukl, 2000; Giebels \& Taylor, 2009). Since authentic police interviews often involve suspects from different cultural backgrounds, we include differences in cultural communication in building up our hypotheses and analyses. In line with previous research (Beune et al., in press; Beune et al., submitted), we base our hypotheses on Hall's (1976) theory on low-/high-context communication cultures. According to this theory, people in low-context cultures are highly individualised and view themselves as being independent from others. As a result, communication tends to be more explicit and direct; the content of a message is important, meaning that most (if not all) information is conveyed in explicit codes (Hall, 1976). In contrast, high-context cultures are characterised by strong social bonds, and individual feelings and opinions are suppressed to serve the community (Hall, 1976). Consequently, communication tends to be indirect, evasive and relationship-oriented (cf. Kim, Pan, \& Park, 1998). These differences in communication styles may have consequences for the effectiveness of different types of influencing behaviours expressed in police interviews. Therefore, we will compare police interviews with suspects from the Netherlands, which can be regarded as a low-context culture, and from Morocco, a relatively high-context culture (e.g., Giebels \& Taylor, 2009). Since police contact with minority groups in the Netherlands is most frequently with Moroccan suspects (Jennissen \& Blom, 2007), we focus our comparison on this group. In the following sections, we discuss how the cultural background of suspects may impact the investigative process and relate this to the effectiveness of rational arguments, being kind, and intimidation. 


\section{Information-gathering Influencing Behaviours}

Research suggests that the influencing behaviour of police officers is largely based on two strategies: rational arguments and being kind (cf. Beune et al., in press; Bull \& Cherryman, 1996; Hartwig, Granhag, Strömwall, \& Vrij, 2005; Moston \& Engelberg, 1993). Rational arguments refers to messages based on logic and rationality, while being kind refers to all friendly and helpful behaviour, usually expressed through active listening behaviour (Beune et al., submitted, in press; see also Giebels \& Taylor, 2009). Generally, reasoned argumentation is considered a core element of successful police interviews (Walton, 2003) because police interviews are conducted in the specific context of proof (Baldwin, 1993). In these contexts, securing evidence is an important consideration (Williamson, 1993). An important way to address this evidence is by referring to logic and rationality. For example, suspects may be challenged to give explanations for seemingly illogical actions or statements (e.g., “you said you went shopping, but aren't the shops closed at 11 p.m.?”). Suspects may also be confronted strategically with evidence (Hartwig, Granhag, Strömwall, \& Kronkvist, 2006), such as physical evidence (Park, Levine, McCornack, Morrison, \& Ferrara, 2002) or witness testimonies (Hartwig et al., 2006). The assumption underlying this behaviour is that a lack of consistency is considered to make a statement less plausible and, hence, less truthful (cf. Granhag \& Strömwall, 1999). In addition, if a suspect cannot provide a logical explanation for inconsistent statements, this may evoke a feeling of cognitive pressure. To reduce this internal pressure, a suspect is expected to be more willing to tell the truth (cf. cognitive dissonance reduction; Festinger, 1957; see also Beune et al., in press). As such, the use of rational arguments as an important building block of investigative interviewing is acknowledged in most Western interviewing methods, including the Dutch Standard Interviewing Method (Nierop, 2005; Van Amelsfoort, Rispens, \& Grolman, 2005).

The use of rational arguments may be considered particularly consistent with lowcontext communication. That is, it is not only direct and explicit, but it is also in line with an important assumption in low-context cultures known as the quality maxim. The quality maxim suggests that one should state only that which is believed to be true on the basis of sufficient evidence (Grice, 1975; see also Gudykunst \& Matsumoto, 1996). This maxim implies that lowcontext rather than high-context communication typically centres on logic and proof (cf. Adair \& Brett, 2004). In support of this notion, research has shown that influencing people on the basis of (in)consistency is particularly effective in low-context cultures (Cialdini et al., 1999). That is, people from low-context cultures are more likely to change their behaviour when confronted with inconsistencies than are people from high-context cultures (see also Choi \& Nisbett, 2000). Taken together, the research evidence presented above suggests that rational arguments are likely to be more compatible with and effective for low-context than high-context suspects. 
Being kind, another frequently expressed behaviour in investigative settings, is arguably important for the gathering of correct and reliable information (Bull \& Milne, 2004; Milne \& Bull, 1999). The effectiveness of this behaviour can be ascribed to the empathy and respect it portrays to the suspect (cf. Holmberg \& Christianson, 2002), which encourages mutual cooperation (Shepherd, 1991). In the Beune et al. (in press) study, it was expected that being kind would be particularly effective in influencing high-context suspects as being kind seems to serve a more relationship-oriented purpose (see also Beune et al., submitted). They further argued that being kind appeals to high-context cultural values because it is more indirect and context-oriented in nature (cf. Brinker Dozier et al., 1998).

Interestingly, however, suspects from low-context and high-context cultures did not seem to differ with respect to their actual information provision in response to being kind and rational arguments. One explanation for these unanticipated findings is that the interrelationships between behaviours may obscure direct effects of being kind and rational arguments on suspects' information provision. That is, suspects may decide to (strategically) adjust the information they provide in the face of different types of behaviours (more or less compatible with their cultural background), and examining aggregated outcomes may not capture these dynamics (cf. Olekalns \& Weingart, 2008). To test these possibilities, we retest the hypotheses of the research evidence discussed above using a methodology more sensitive to interaction dynamics. Specifically, we expect that low-context rather than highcontext suspects will respond more positively (i.e., provide information) to the rational arguments strategy (Hypothesis 1), while high-context suspects will respond more positively (i.e., provide information) to the relationship-oriented strategy of being kind (Hypothesis 2).

\section{Intimidating the Suspect?}

The dominant view in investigative interviewing research is that accusatory behaviour, such as intimidation, is inappropriate (Walton, 2003) because it is generally perceived as hostile (Cheney, Harford, \& Solomon, 1972), aggressive (Sinaceur \& Neale, 2005), and may evoke feelings of being disrespected and dominated among suspects (Holmberg \& Christianson, 2002). Nevertheless, accusatory behaviours are still used by police officers (Kassin et al., 2007; King \& Snook, in press; Leo, 1996). For example, a police officer might warn a suspect that a particular course of action might result in certain consequences (Kassin et al., 2007; Leo, 1996; Walton, 2003) or accuse the suspect personally (Moston \& Engelberg, 1993). These behaviours could be summarised as one particular influencing behaviour: Intimidation (Beune et al., submitted; Giebels \& Taylor, 2009). Given the continuous presence of intimidating behaviour, it seems surprising that research has paid little attention to how the use of intimidation by police officers may influence the information-gathering process. This may prove to be important because intimidating behaviour may serve a legitimate and useful function as well (Walton, 2003). 
Some initial evidence for positive effects of intimidation comes from research on the communication of threats. For instance, it was found that a threat may serve a signal function when the threat's intention is separated from threat fulfilment (Shomer, Davis, \& Kelley, 1966). As such, it may reduce uncooperative behaviour and facilitate coordination (see also Cheney et al., 1972). Previous research has also demonstrated that when parties engage in relationship building, the expression of threats increases the willingness to make concessions (Sinaceur \& Neale, 2005). Additional research suggests that intimidation may be effective when it is combined with other, more cooperative, behaviours (e.g., Brodt \& Tuchinsky, 2000; Van de Vliert et al., 1999). For instance, a study on the effects of strategic sequences in police interviews showed that intimidation could stimulate suspects' information provision when it was combined with rational arguments or kind behaviour (Beune et al., submitted). Taken together, there is research evidence suggesting that the use of intimidation does not necessarily have to be unconstructive.

However, the effectiveness of intimidation might also be dependent on culture (see also Beune et al., submitted). A defining feature of people in high-context cultures is that they try to avoid direct confrontation in order to preserve face (cf. Ting-Toomey \& Kurogi, 1998; see also Tse, Lee, Vertinsky, \& Wehrung, 1988). The notion that confrontation needs to be avoided is supported in a number of studies. For example, research has shown that high-context Japanese negotiators preferred to frame their conflict more in terms of harmony (compromise) than in terms of confrontation (win; Gelfand et al., 2001) and engaged in socially desirable behaviour for presumably the same reason (Lalwani, Shavitt, \& Johnson, 2006). Since intimidation is highly confrontational and direct in nature (Kassin et al., 2007), we expect that this strategy may be less appropriate when interviewing suspects from high-context cultures. This suggests that high-context suspects, compared to lowcontext suspects, will respond less positively (i.e., provide less information) to intimidation (Hypothesis 3).

\section{Method}

\section{Participants}

Data were videotaped authentic police interviews from a central district in the Netherlands. Cases were randomly selected from a series of interviews with either Dutch or Moroccan suspects. The resulting data consisted of 27 police interviews: 12 interviews with Dutch suspects (11 male and 1 female), and 15 interviews with Moroccan (all male) suspects. The average length of the interviews was 95 minutes ( $S D=57.2)$. The videotapes contained all of the conversation recorded during the interviews, minus possible leads in time (e.g., due to preparation or report typing). All interviews were about suspected involvement in crimes 
classed in the Netherlands as misdemeanour offences, which include simple assault, theft with assault, threats with violence, and domestic violence.

Twelve suspects $\left(M_{\text {age }}=38 ; S D=11.3\right.$ ) originated from the Netherlands and so were regarded as coming from a low-context society (cf. Brett, 2001; Giebels \& Taylor, 2009; Hall, 1976; Hall \& Hall, 1990; Hofstede, 2001; Triandis, 1994). The remaining fifteen suspects $\left(M_{\text {age }}\right.$ $=25 ; \mathrm{SD}=6.9$ ) originated from Morocco and so were regarded as coming from a (relatively) high-context society (Adair, 2003; Adair \& Brett, 2005; Brett, 2001; Fu \& Yukl, 2000; Giebels \& Taylor, 2009; Hall, 1976; Hall \& Hall, 1990).

All of the interviews with suspects were conducted by male Dutch police officers $\left(M_{\text {age }}=38 ; \mathrm{SD}=7.2\right)$. All had previously received training in standard interviewing techniques at the Dutch Police Academy and all were Dutch nationals (i.e., from a low-context society). Furthermore, they all reported having five or more years of "substantial experience" with interviewing suspects.

\section{Coding Schemes and Reliability}

Using digital video-recordings of the 27 police interviews, two trained coders (unaware of the hypotheses) coded all of the speaking turns of both the police officer and suspect. A speaking turn is the single utterance of one party without interruption of the other party. The speaking turns of the police officers were coded using an established coding framework known as the "Table of Ten," which we modified by dividing intimidation into two categories (intimidating the individual and Intimidating the context), and by adding a twelfth "Other" category. The Table of Ten was derived in previous research (Giebels, 2002, Giebels \& Taylor, in press) and captures the use of ten major influencing behaviours that occur in police-civilian interactions. These influencing behaviours can be either relationship-oriented (i.e., Being kind, Being equal, and Being credible) or content-oriented (i.e., Emotional appeal, Intimidation, Imposing a restriction, Direct pressure, Legitimising, Exchanging, and Rational arguments). The relationship-oriented behaviours emphasise the sender and his or her relationship with the other person. For example, being credible is used to express expertise or prove reliability (e.g., "I have heard this story many times before during my twenty year experience with police interviewing"). In contrast, the content-oriented behaviours are geared toward framing the substantive content of the message. For example, emotional appeals are behaviours playing upon the emotions of the other (e.g., "So how would you feel about your parents finding out?"). For the purposes of this research, we focus on influencing behaviours in particular. These are rational arguments, which are messages that appeal to logic and/or facts; being kind, which refers to active listening behaviours expressed to show empathy and friendliness towards the suspect; intimidating the individual, which includes messages that intimidate or accuse the suspect personally and imply a warning of particular consequences for the 
suspect; and intimidating the context, which includes messages that intimidate or accuse friends and/or family of the suspect and imply a warning of particular consequences for the family and/or friends (see Table 6 for an overview).

Because we are interested in determining how suspects respond in terms of information provision, the suspects' speaking turns were coded using a different set of codes. As information-gathering aims at serving justice (Dillon, 1990), the specific aspects of a case need to be addressed. For instance, one could gather information to establish a motive (McConville \& Baldwin, 1982) or to crystallise the overall pattern of events in a case (Irving, 1980). When motive is of interest, personal information could be considered of particular importance. When the events leading to the crime are important, contextual information is needed, such as information about possible involvement of others or information concerning the criminal event. Finally, as information provision is generally seen as an act of cooperation (cf. Adair \& Brett, 2004), it could be argued that a lack of information provision is suggestive of non-cooperation. This implies that when determining a police officer's efficiency, it is important to examine both information provision and the reluctance to do so. Based on the theory above, suspects' behaviour was coded as one of the following categories: Caserelated personal information, which is coded when the suspect gives personal information to motivate his actions and/or to explain his feelings, thoughts or background; Case-related contextual information, which is coded when the suspect gives information about the criminal event, involvement of family and/or friends, or other - non-personal - information; Refusing to give information, which is coded when the suspect remains silent or refuses to give an answer; and Other, which is coded when the suspect's speech act does not easily fit into one of the other three codes (see Table 6 for an overview).

Before coding the 27 interviews, the two coders were trained to use the Table of Ten on unrelated material using the same procedure as described in Beune et al. (in press). This material consisted of parts of videotaped police interviews and included interactions with individuals from low-context and high-context cultures to ensure that the coders had exposure to both types of dialogue. As with the main coding, they were trained to give each speaking turn one code that best described the behaviour within the utterance. After 60 hours of training on practice material, Cohen's Kappa was .71, which we considered sufficient for coding the 27 police interviews. The coders then coded 12 of the 27 police interviews examined in the paper. The 12 were chosen at random from the complete data set and included interactions with both low-context and high-context suspects. The reliability of coding, measured using Cohen's Kappa, ranged from .69 to .79 $(M=.74)$, suggesting a good level of coding reliability. After coding the 12 interviews, the coders discussed and resolved areas of disagreement, and one coder proceeded to code the remainder of the material. 
Table 6

Descriptions and examples of coded behaviours

Rational arguments

Use of arguments based on logic and/or facts

\section{Being kind}

All active listening behaviours to show

empathy and friendliness

\section{Intimidating the individual}

Behaviours that intimidate, warn or accuse the suspect personally

Intimidating the context

Behaviours that intimidate, warn or accuse the suspect's family and/or friends

"You said you haven't been in that book store, so how do you explain that we have a witness who saw you there?"

"So if I understood it correctly, you spent most of your youth in foster homes? That must have been really hard for you."

“I think you're lying right now!"

Case-related personal information

Information about the suspect's motivation, "I took the money because I have a lot of debts."

feelings, thoughts or background

Чु Case-related contextual information

Information about the criminal event and/or "I took the money while the attendant was smoking the involvement of others a cigarette."

Refusing to provide information

Being silent or refusing to answer

"No comment."

"Your brother should stay out of trouble, or next time we'll bring him in for an interview too."

\section{Analysing Cue-response Sequences}

To examine the interrelationships among the influencing behaviours of the police officer and the information suspects provided, we constructed event sequences (Bakeman \& Gottman, 1997). Specifically, for each interview, the series of assigned codes were used to create a single sequence in which one code appeared on one line of the data file. This sequence of codes represented the occurrence of police officers' influencing behaviours and suspects' responses across the complete interview. Because the coding was performed at the level of speaking turns, the codes alternated between representing the utterances of the police officer and the utterances of the suspect.

The interrelationships among these codes were examined using proximity coefficients (Taylor, 2006). The proximity coefficient provides a measure of the immediacy with which particular responses follow particular cues on average over an interaction sequence. The coefficient is based on the notion that behaviours close together in a sequence have more in common than behaviours that occur far apart. A current behaviour is the result of many previous behaviours within an interaction, but the extent of this relationship 
decreases as a function of temporal distance from the current behaviour. This "interconnectedness" or "channelling" of behaviour has long been recognised in theory (Auld \& White, 1959; Watzlawick, Beavin, \& Jackson, 1968, p. 131) and demonstrated in research (Taylor \& Donald, 2003; Thomas, 1985). Thus, rather than considering the immediate relations among behaviours (i.e., conditional relationships), the proximity approach considers the relationships among all behaviours within a sequence of codes as degrees of proximity. In so doing, the coefficient reduces the possibility of overlooking important delayed associations between cues and responses over time (Taylor, 2006).

The proximity coefficient varies between 0.00 and 1.00 . If the coefficient equals .00 , the behaviours occur only once at the first and last positions of the entire sequence. If the coefficient equals 1.00 , one behaviour precedes the second behaviour immediately without exception. A coefficient between these two limits reflects differing amounts of proximity between two behaviours on average, with a greater value indicating less intermittent behaviours (i.e., more proximity; for a detailed description, see Taylor, 2006; Taylor \& Donald, 2007). The absolute value of the proximity coefficient is typically less important than the relative value of the coefficient across cue-response contingencies. Indeed, in fluid interactions such as police interviews, the absolute value of the proximity coefficient is often high since interactants often use and re-use different constellations of behaviours. The high absolute value of the coefficients, however, does not stop researchers from identifying important relative differences across their independent variables of interest (see, for example, Taylor \& Donald, 2007; Giebels \& Taylor, 2009).

To test the significance of the proximity coefficients, we used a series of randomisation tests (Edgington, 1995; Good, 1994). A randomisation test (sometimes known as an exact test or permutation test) provides a more robust test of our hypotheses because its approach is free from assumptions about the distribution of proximities among cues and responses (e.g., assumptions about equal variance; Dunlap, Burke, \& Smith-Crowe, 2003; Switzer, Paese, \& Fritz, 1992). The test begins by making a conventional statistical comparison of the dependent variable across two or more conditions (in our case, a one-way ANOVA test). The result of this test (i.e., the test statistic) is then evaluated for its probability of occurring (i.e., its $p$-value), but in a different way from that traditionally reported. Specifically, the test statistic is compared not to a table of critical values, but to a sampling distribution that is derived from the available data. This sampling distribution is derived by permuting the original sequence many times (in our case, 10,000 times). On each occasion, an equivalent test statistic is calculated from the new sequence and stored. These stored statistics form a sampling distribution that represents the range of test statistics that might have been observed were the sequence to have occurred at random. This distribution is thus used to assess the probability of obtaining the original test statistic (i.e., to obtain its $p$-value). This is achieved by computing the number of test statistics in the derived distribution that are 
equal to, or greater than, the original test statistic. The number of equivalent or higher scores divided by the total number of permutations gives the probability of observing the difference being examined given that the null hypothesis is true (i.e., a $p$-value). Thus, the nearer the observed test statistic to the tails of the derived empirical distribution, the fewer times the observed score appears in the derived distribution, and the lower the resulting probability value. As with conventional approaches, we use $\alpha=.05$ as a measure of test significance.

\section{Results}

\section{Frequency of Behaviour}

In total, the 27 police interviews contained 17,066 speaking turns (Police officer $=8,536$; Suspect $=8,530)$. Of these speaking turns, $1,852(21.7 \%)$ could be typified in terms of the four influencing behaviours being kind (9.5\%), rational arguments (7.6\%), intimidating the individual (4.3\%), and intimidating the context (0.3\%). For the suspect, 4902 (57.5\%) speaking turns could be typified as case-related personal information, and 1595 (18.7\%) speaking turns could be typified as case-related contextual information. In total, 322 (3.8\%) speaking turns were coded as refusing to give information. Table 7 shows the (relative) distributions of code frequencies across the low-context and high-context cases. In six of the seven behavioural categories, there was no difference in frequency of occurrence across the low-/high-context conditions, Mann-Whitney U, all Z's between .81 and -.91, ns. The exception was for case-related personal information, where analysis suggested that low-context suspects appeared to provide more case-related personal information than high-context suspects, Mann-Whitney $\mathrm{U}, \mathrm{Z}=-\mathbf{2 . 0 5}$, $p<.05$.

\section{Table 7}

Frequencies of the police officers' cues (Rational arguments, Being kind and Intimidation) and the suspects' responses for Low-context suspects (left panel) and High-context suspects (right panel)

\begin{tabular}{lcc} 
& \multicolumn{2}{c}{ Absolute frequencies (and relative \%) } \\
\hline Police officer's cue & $L C$ & $H C$ \\
Rational arguments & $304(7.3 \%)$ & $342(7.8 \%)$ \\
Being kind & $395(9.5)$ & $417(9.5 \%)$ \\
Intimidating the individual & $247(5.9 \%)$ & $119(2.7 \%)$ \\
Intimidating the context & $18(0.4 \%)$ & $10(0.2 \%)$ \\
Suspect's response & & \\
Case-related personal information & $2635(63.3 \%)$ & $2267(51.9 \%)$ \\
Case-related contextual information & $765(18.4 \%)$ & $830(19.0 \%)$ \\
Refusing to give information & $129(3.1 \%)$ & $193(4.4 \%)$ \\
\hline
\end{tabular}




\section{Cross-Cultural Differences in Cue-Response Patterns}

Table 8 shows the mean proximity coefficients for the police officers' cues and the suspects' responses for low-context suspects (top panel) and high-context suspects (bottom panel). As can be seen from Table 8 , the overall value of the proximity coefficients is relatively high, which is due to the fact that most behaviours occur regularly across the interaction instead of in discrete periods of interaction (cf. Giebels \& Taylor, 2009). Consistent with previous research, this suggests that strategic adjustments by both parties are being made continuously (Olekalns \& Weingart, 2008). Table 8 also reveals that all influencing behaviours are relatively closely related to case-related personal information. Nevertheless, analyses of our data revealed that the relationships between the police officer's cues and the suspect's responses varied considerably across police interviews with low-context and highcontext suspects. For example, as indicated by the coefficient of .759 , low-context suspects responded less immediately to being kind with refusing to provide information. In contrast, they often responded almost immediately to rational arguments with case-related personal information $(P=.994)$.

Since the effectiveness of influencing behaviour may be dependent on timing (e.g., Hartwig et al., 2005, 2006; Sinaceur \& Neale, 2005), we explored the time factor by dividing all interviews into two time periods (cf. Giebels \& Taylor, 2009) before testing our hypotheses. We only found two main effects of time. Specifically, intimidating the individual was more closely followed by case-related personal information in the first part of the interview, compared to the second part of the interview, $F=8.75, p<.01, d=1.17$, while suspects seemed to respond more immediately to intimidating the context with refusing to give information in the second part of the interview compared to the first part of the interview, $F=6.67, p<.01$, $d=1.04$. No interaction effects were found, all $F<4.90$, ns. 
Table 8

Mean proximity coefficients for the police officers' cues (Rational arguments, Being kind and Intimidation) and the suspects' responses for Low-context suspects (top panel) and Highcontext suspects (bottom panel)

\begin{tabular}{|c|c|c|c|}
\hline & \multicolumn{3}{|c|}{ Suspect's response (LC) } \\
\hline Police officer's cue & $\begin{array}{l}\text { Case-related personal } \\
\text { information }\end{array}$ & $\begin{array}{l}\text { Case-related contextual } \mathrm{R} \\
\text { information }\end{array}$ & Refusing to give information \\
\hline Rational arguments & 0.994 & 0.908 & 0.878 \\
\hline Being kind & 0.986 & 0.943 & 0.759 \\
\hline Intimidating the individual & 0.988 & 0.910 & 0.837 \\
\hline \multirow[t]{2}{*}{ Intimidating the context } & 0.989 & 0.903 & 0.912 \\
\hline & \multicolumn{3}{|c|}{ Suspect's response (HC) } \\
\hline \multicolumn{4}{|l|}{ Police officer's cue } \\
\hline Rational arguments & 0.985 & 0.931 & 0.860 \\
\hline Being kind & 0.975 & 0.936 & 0.839 \\
\hline Intimidating the individual & 0.974 & 0.907 & 0.881 \\
\hline Intimidating the context & 0.984 & 0.956 & 0.815 \\
\hline
\end{tabular}

\section{Hypothesis Tests}

As predicted by Hypothesis 1, and in line with previous research (Beune et al., in press), we found a main effect of culture on the relationship between the rational arguments and the suspect's response of case-related personal information. Specifically, this response was significantly more immediate following rational arguments in police interviews with lowcontext compared to high-context suspects, $F=7.96, p<.01, d=1.14$. This finding is consistent with the hypothesis that strategies referring to logic and rationality impact more directly on people from low-context as compared to high-context cultures (cf. Adair \& Brett, 2004). No effects were found for the suspect's responses of case-related contextual information, $F=$ 1.55, ns., and refusing to give information, $F=0.88$, ns., respectively.

Our second hypothesis predicted that compared to low-context suspects, highcontext suspects would respond more positively (i.e., provide information) to being kind (Hypothesis 2). This hypothesis was not supported. Providing information did not vary across the two cultural conditions; neither did providing Case-related personal information, $F=2.36$, $\mathrm{ns}$, nor providing Case-related contextual information, $\mathrm{F}=0.09$, ns. Moreover, and contrary to our expectations, for high-context suspects in particular, being kind tended to be somewhat related to Refusing to give information, $F=3.67, p<.07, d=.77$. That is, being kind seemed to be more immediately followed by Refusing to give information for high-context suspects compared to low-context suspects.

Finally, we predicted that for high-context suspects in particular, intimidation on the part of the police officer would be negatively related to the information suspects provided. Our analyses revealed significant main effects of both intimidating the individual and intimidating 
the context (marginally significant) on providing information. However, inspection of our data showed that the two types of intimidation indeed had different effects on suspects from low-l high-context cultures and in terms of the type of information suspects provided. Specifically, and in line with our expectations, intimidating the individual was less effective at eliciting case-related personal information from suspects from high-context compared to low-context cultures, $F=10.58, p<.01, d=1.31$. Interestingly, and contrary to our prediction, intimidating the context appeared to be effective in eliciting case-related contextual information from high-context suspects in particular. That is, high-context suspects seemed to respond more immediately to intimidating the context than low-context suspects, $F=3.07, p<.10, d=.71$. In a similar vein, we found that high-context suspects responded less immediately to intimidating the context with refusing to give information compared to low-context suspects, $F=2.53, p<$ $.07, d=.64$. Taken together, our findings partially support hypothesis 3 .

\section{Discussion}

A challenge faced by researchers and practitioners of investigative interviewing concerns identifying "good" or "effective" influencing strategies (Baldwin, 1993; Soukara et al., 2009) and understanding how such strategies contribute to the primary purpose of information gathering (Bull \& Soukara, in press; Dando, Wilcock, \& Milne, 2009; Dando, Wilcock, Milne, $\&$ Henry, in press). In response to these issues, we examined in the current research how police officers' use of different influencing behaviours is related to suspects' responses in terms of information provision. In line with previous work on influencing behaviour (Beune et al., in press; Giebels \& Taylor, 2009), we expected this effectiveness to be dependent on the cultural background of the suspect. In line with our expectation, we demonstrated that lowcontext suspects were quicker to respond to rational arguments with case-related personal information provision than were high-context suspects. This is consistent with the general assumption that people from low-context cultures highly value logic and deductive thinking (Gelfand \& Dyer, 2000). Consequently, low-context suspects may be particularly likely to respond to behaviour that appeals to these values. This notion is supported by a recent study in the field of crisis negotiations, in which Giebels and Taylor (2009) found that when negotiators used persuasive arguments, low-context perpetrators compared to high-context perpetrators responded more immediately with compromising behaviour. Moreover, our findings compliment previous work on influence in police interviews (Beune et al., submitted, in press) by showing that rational arguments directly impact the information provision of low-context suspects. The recognition that people from low-context cultures typically rely on logic and rationality (cf. Adair \& Brett, 2004) may be of particular importance for the investigative process, as police interviews are primarily based on reasoned argumentation (Walton, 2003). Indeed, from a legal point of view, police officers have to address certain 
points of proof, such as evidence, to sustain prosecution (Baldwin, 1993). However, from a cross-cultural point of view, the use of rational arguments may be less appropriate in eliciting desirable suspect behaviours when interviewing high-context suspects compared to lowcontext suspects. This poses the challenge of identifying behaviours that positively impact the information provision of high-context suspects.

A strategy that we predicted to be positively related to the information sharing of high-context suspects compared to low-context suspects is being kind. Interestingly, and contrary to what was expected, the data revealed that high-context suspects, compared to low-context suspects, did not differ in the immediacy of their responses to being kind. One explanation for this finding may be that we examined being kind in terms of the frequently promoted active listening behaviour (e.g., Bull \& Cherryman, 1996; Milne \& Bull, 1999). It might be the case that active listening is not perceived as kind behaviour by suspects, but as inherent to the situation. It is "the job" of the police officer to pose questions and listen to the suspect. Put differently, it might be the case that active listening is not perceived as kind behaviour. However, this does not explain why high-context suspects were found to respond more immediately to being kind with refusing to provide information than low-context suspects. One possible explanation may follow from the opportunistic betrayal model, which states that whether someone decides to betray another party's trust is dependent on the perceived likelihood of being punished (Olekalns \& Smith, 2007; see also Elangovan \& Shapiro, 1998). That is, being kind is likely to be perceived as positive and trustworthy, and consequently, one (e.g., a suspect) might perceive the chance of being punished by the other party (e.g., police officer) as being rather small. This could be a cue to deception (Olekalns \& Smith, 2007). As deception is more acceptable in high-context cultures (Triandis, Carnevale, Gelfand, Robert, \& Wasti, 2001), it could be argued that high-context suspects are more prone to opportunistic betrayal. However, when the evidence against a suspect is strong, the risk of deception being detected is high (Elangovan \& Shapiro, 1998). Therefore, a suspect might choose to refuse to provide information instead of providing false information and still believe (s)he will not be punished for this. Understanding of possible cues to deception and their possible relatedness with suspects' cultural backgrounds could be explored in greater depth in future research. Furthermore, it might be interesting to examine to what extent other behaviours that may reflect being kind (such as rewarding desirable behaviours, or cooperative statements) may influence low- and high-context suspects' information provision.

As research - reasonably - places a strong emphasis on appropriate questioning strategies (Walkley, 1987), until now, the effects of more intimidating behaviours on the information-gathering process in investigative interviews had remained relatively understudied. This is surprising since research suggests that intimidation is both relatively frequently observed (Leo, 1996; Moston \& Engelberg, 1993) and reported (Kassin et al., 2007). We therefore examined the effects of two types of intimidation: Intimidating the individual 
and intimidating the context. In line with our reasoning, we demonstrated that intimidation differently impacts suspects from low-context and high-context cultures. As expected, we found that high-context suspects were less likely to immediately respond to intimidating the individual with case-related personal information than were low-context suspects. This finding suggests that intimidating behaviour is indeed less appropriate in high-context cultures compared to low-context cultures (see also Fu \& Yukl, 2000). It is also consistent with our theorising and previous research suggesting that the communication of threats is more central to and effective in low-context cultures compared to high-context cultures (Giebels \& Taylor, 2009). For instance, Giebels and Taylor found that high-context rather than low-context perpetrators of hostage crises responded more immediately with counter threats and less information provision when confronted with intimidating police behaviour. However, in response to intimidating the context, high-context suspects compared to lowcontext suspects seemed to respond more positively with information provision; i.e., highcontext rather than low context suspects responded more immediately with case-related contextual information in response to intimidating the context.

A possible explanation for this differential and seemingly opposite finding may lie in the target of the intimidating act. That is, intimidating the context refers to behaviour that accuses, threatens or warns of particular consequences for the suspect's family and/ or friends. As family and friends are highly valued in high-context cultures (Hall, 1976), a suspect may be triggered by a strategy that appeals to this value and therefore feel inclined to respond to it. This line of reasoning seems to be supported by the overall pattern of relationships between influencing behaviours and the two types of case-related information we included. For low-context suspects, influencing behaviours were particularly related to personal information but not contextual information, while the opposite was true for highcontext suspects. This may be explained by the general assumption that the social context is of particular importance in high-context cultures, while individualistic values are more closely related to low-context cultures (Adair, 2003; Adair \& Brett, 2005; Gudykunst \& Ting-Toomey, 1988; Hofstede, 2001; Triandis \& Suh, 2002). More precisely, individuals from individualistic cultures prefer dispositional explanations for behaviour (e.g., Krull et al., 1999; Lee, Hallahan, \& Herzog, 1996; Miller, 1984; Morris \& Peng, 1994), while people from collectivistic cultures tend to explain their behaviour in terms of person-situation interactions (Choi \& Nisbett, 1998; Miller, 1984; Morris \& Peng, 1994; Norenzayan, Choi, \& Nisbett, 2002). From these points of view, it could be argued that suspects not only react positively to information that is consistent with their cultural background, but also respond with information that is particularly valued by their own culture.

Although we have contributed to previous research, some important questions remain unanswered. One important set of questions relates to the psychological processes underlying the impact of influencing behaviour. For instance, research on the communication 
of threats suggests that the effectiveness of threats may be determined by the perceived credibility of the communicator (Sinaceur \& Neale, 2005). More specifically, threats are only found to be effective when the person who communicated the threat is perceived as being credible. In a similar vein, a recent study on the reciprocity of liking shows that behavioural attraction is only reciprocated when the partner is perceived as benevolent; when benevolence could not be taken at face value, the attraction was significantly reduced (Montoya \& Insko, 2008). Together, these findings suggest that research on investigative interviewing might benefit from a closer examination of the psychological mechanisms underlying influencing behaviour in police interviews.

A second question could be how well our cultural categorisation into low- and high-context describes our groups of Dutch and Moroccan suspects. By assigning suspects to either the low-context or high-context category based on their country of origin, we essentially inferred rather than measured cultural differences. Although this approach has often been used in previous research (e.g., Adair, 2003; Adair \& Brett, 2005; Adair et al., 2004; Hall, 1976; Hall \& Hall, 1990), other factors besides low-/high-context may underlie our results. For instance, Dutch and Moroccan suspects might differ on other cultural dimensions, such as power distance (Hofstede, 2001). Research shows that high-context suspects rather than low-context suspects are concerned with status differences and establishing dominance (Adair \& Brett, 2004). Therefore, it would be interesting to disentangle possible overlap in cultural dimensions to gain more insight into the unique contributions of different cultural dimensions. Another factor that warrants attention is that the groups of Dutch and Moroccan suspects seemed to differ in their average ages. More specifically, the Moroccan suspects were twenty-five years old on average, while the Dutch suspects were thirty-eight years old on average. This may have influenced our results. For instance, research suggests that adolescents, compared to adults, experience less responsibility for their actions and are less likely to adopt the viewpoints of others (e.g., a victim; Modecki, 2008). Hence, this may result in less inclination and/or willingness to provide information. Our data seem to provide some indirect support for this explanation, as Moroccan suspects were significantly less willing to share case-related personal information than were Dutch suspects. However, if this explanation were underlying our results, one would also expect a difference in case-related contextual information, which was not found.

A final area of unaccounted variation lies in the fact that we cannot account for the quality of the information provided by the suspects. Although ultimately any information could be considered helpful in (dis)confirming and/or legitimating police narratives (McConville et al., 1991), the purpose of investigative interviewing is to obtain complete and reliable information (Milne \& Bull, 1999) and, ultimately, to find the truth (Baldwin, 1993). Therefore, research has attempted to identify ways to increase the gathering of complete and reliable information. For example, research on investigative interviewing of witnesses 
has greatly improved with the development of the Cognitive Interview approach (Fisher, Brennan, \& McCauley, 2002; Fisher \& Geiselman, 1992), which has been found to increase both the quantity and the quality of the information provided (see also Milne \& Bull, 1999). In addition, there exists a growing body of literature on how to improve the veracity assessment of (trained) police interviewers (e.g., Akehurst, Bull, Vrij, \& Köhnken, 2004; Hartwig, 2006, 2007; Hartwig et al., 2005, 2006). However, no research is yet able to assess how specific behaviours of police officers are directly related to the provision of complete and truthful information by suspects; in other words how to address and assess "effective" informationgathering (cf. Baldwin, 1993; Bull \& Soukara, in press). It is, in our opinion, one great challenge for future research to answer this question, from which, arguably, both science and practice will benefit.

\section{Practical Implications and Conclusions}

In conclusion, we have demonstrated that different types of influencing behaviours differently impact the (type of) information suspects provide. Moreover, this process was influenced by the cultural backgrounds of suspects. An important finding is that rational arguments, which are an important feature of police interviewing (Walton, 2003), seem to be particularly effective in influencing low-context suspects. On the other hand, high-context suspects seemed to be particularly influenced by intimidating behaviour when providing information. Specifically, high-context suspects, compared to low-context suspects, responded positively to intimidating the context, but negatively to intimidating the individual. In addition, different types of influencing behaviours seem to elicit specific types of information from low-context and high-context suspects. When appealed by specific behaviour, low-context suspects particularly responded with personal information, while high-context suspects responded primarily with contextual information. Taken together, our findings suggest that police officers would benefit from (being able and sensitive to) incorporating several influencing behaviours into one interview (cf. Vrij, Mann, \& Fisher, 2006), particularly since police interviews increasingly involve cross-cultural encounters. 


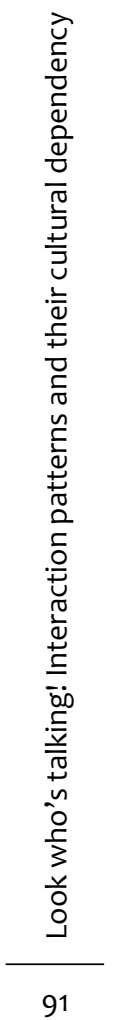



General Discussion 
n
$\frac{1}{ \pm}$
$\frac{a}{0}$
$\frac{0}{U}$
94 
Globalisation has intensified contacts between cultures more than ever in the history of humankind (Karstedt, 2001, p. 285). Police interviews are no exception to this observation: police officers now face an increasing percentage of suspects from a different cultural background than their own. For instance, up to thirty-two percent of the suspects in the Netherlands originate from a non-Western culture (Jennissen \& Blom, 2007). With research evidence suggesting that the effectiveness of communication is culturally specific (Fu \& Yukl, 2000; Giebels \& Taylor, 2009), one would expect this topic to be on centre stage in the literature on investigative interviewing. Surprisingly, however, this topic has received scant attention. The present thesis aims to fill this void by proposing that approaches to the interviewing of suspects would benefit from a cultural perspective. In three empirical chapters, we found cumulative evidence for our central proposition that the effectiveness of police officers' influencing behaviour is dependent on suspects' cultural background.

Influencing behaviour is omnipresent; people influence and are influenced in almost all social interactions (Cialdini, 1993, 2001). Particularly in high-stakes situations where parties may have conflicting interests, interpersonal influence offers important opportunities to change a person's attitudes or behaviours (Perloff, 1993). Until now, no theoretical foundation for the examination of police interviews was available (cf. Bull \& Soukara, in press). Recently, however, a theoretical framework has been developed for the examination of influencing behaviours in police-civilian interactions (i.e., the Table of Ten; Giebels, 2002; Giebels \& Taylor, in press). This comprehensive framework has proven valuable in police contexts such as crisis negotiations (Giebels \& Noelanders, 2004; Giebels \& Taylor, 2009). For instance, it may be useful to refer to agreements with society or others in order to legitimise one's actions (e.g., "I cannot do that for you, that would be against the law"), or one could try to persuade the other by playing upon his or her emotions (e.g., "How would your family think about your behaviour?"; Giebels \& Taylor, in press). The present dissertation demonstrates that the Table of Ten is, indeed, well applicable to investigative interviews. That is, police officers' behaviour was found to be well described by the ten categories of interpersonal influencing behaviours. Police officers were found to use frequently behaviours such as being kind, direct pressure, rational persuasion, and being credible. Behaviours that were used to a lesser extent were imposing a restriction, emotional appeals, or being equal. Interestingly, these patterns are consistent with observations of police negotiators' behaviour in a large field study conducted in the Netherlands and Belgium (Giebels \& Noelanders, 2004). One behaviour could be less clearly distinguished in police interviews as opposed to crisis negotiations; i.e., exchanging. However, this is not very surprising. Where negotiations typically involve back and forth exchanges of offers and counteroffers between negotiators (Olekalns \& Weingart, 2008, p. 136 ), police interviews are characterised by more unidirectional information gathering (Milne \& Bull, 1999; Moston \& Stephenson, 1993; Vrij, Mann, \& Fisher, 2006). 
For the purpose of the present dissertation, we focussed our examination on two behaviours in particular -i.e., being kind and rational arguments- because these behaviours are both frequently expressed in police interviews and particularly relevant in an investigative context (cf. Bull \& Soukara, in press). While being kind is more person-oriented and focuses on the relationship with a suspect (cf. Holmberg \& Christianson, 2002), rational arguments are more content-oriented, referring to logic and facts aiming to address the evidence and/or apparent contradictions with the evidence (cf. Hartwig, 2006; Hartwig, Granhag, Strömwall, \& Kronkvist, 2006; Hartwig, Granhag, Strömwall, \& Vrij, 2005).

Together, the results of the three empirical chapters support our prediction that police officers use interpersonal influencing to a large extent. In addition, we were able to demonstrate that the impact of their behaviour is dependent on the cultural background of the suspect.

\section{Rational Arguments}

In line with previous research suggesting that influencing behaviours based on logic and rationality are particularly valued and effective in low-context cultures (Adair \& Brett, 2004; Giebels \& Taylor, 2009), we argued and demonstrated that low-context suspects are strongly influenced by behaviour referring to these principles. Consistent across a variety of settings, the use of rational arguments was found to facilitate cooperation from low-context suspects. In Chapter 2, we showed that mock theft suspects' ultimate admissions were positively related to the expression of rational arguments by the police officer during the preceding interaction. As predicted, this relationship was only found for low-context and not high-context suspects. However, using the relative frequency of behaviour as a unit of analysis may have caused important information loss -i.e., other behaviours or aspects besides rational arguments may have influenced this relationship. Therefore, we examined the unique effects of rational arguments as part of strategic sequences in a follow-up study. Building on previous notions of strategic contrasts (e.g., Brodt \& Tuchinsky, 2000; Hilty \& Carnevale, 1993), we showed in Chapter 3 that a strategic contrast that highlighted rational arguments influenced low-context suspects more positively than high-context suspects. More specifically, these sequences appeared to increase both low-context suspects' admissions of the alleged theft and their willingness to provide information. Moreover, when analysing the complete makeup of authentic police-suspect interactions in Chapter 4, rational arguments were found to be more closely related to suspects' information provision for suspects originating from low-context rather than high-context cultures. Taken together, our findings support the notion that the effectiveness of rational arguments is particularly bound to people from low-context cultures (Giebels \& Taylor, 2009). 


\section{Being Kind}

Although relational harmony is valued by people of all kinds and natures, it is particularly appreciated in high-context cultures (e.g., Adair \& Brett, 2004; Brinker Dozier, Husted, \& McMahon, 1998; Kim, Pan, \& Park, 1998). Therefore, we predicted behaviour appealing to this value (i.e., being kind) to have a positive impact on suspects originating from high-context cultures. This proposition was largely supported by our results. In Chapter 2, we showed that the more a police officer uses being kind (in terms of active listening) during an interview, the higher the chance of an ultimate admission by a mock theft suspect. As predicted, this was particularly the case for high-context, but not low-context, suspects. In Chapter 3, we showed that interview success for high-context suspects benefitted by the use of such kind behaviour when this behaviour was highlighted in a strategic sequence. More specifically, high-context suspects were both more willing to provide information and more inclined to admit that they had committed the alleged theft when the strategic sequence highlighted being kind (instead of rational arguments). The second study reported in Chapter 3 focussed on ordering effects of being kind and rational arguments and showed that admissions were particularly high when the strategic sequence began with being kind for high-context but not low-context suspects. Again, this finding is in line with the assumption that relationshipbuilding is particularly important for people from high-context cultures (Ohbuchi, Fukushima, \& Tedeschi, 1999; Triandis \& Suh, 2002). It is also consistent with findings that were obtained for two other manifestations of being kind, i.e., rewarding and offering (Nierop, 2005), reported in the second chapter. Although these behaviours were used to a relatively low extent (see also Kassin et al., 2007; Leo, 1996), they influenced relationship perceptions of high-context rather than low-context suspects. That is, the perceived working relationship between police officers and high-context suspects particularly benefitted from the use of rewarding and offering behaviour. Together, these findings demonstrate that being kind is conducive to the cooperation of high-context suspects, both in terms of increasing the propensity of an ultimate admission as well as the suspects' estimation of the quality of the relationship with the police officer. The latter may be particularly important if continued interaction with a suspect is expected (cf. Viki, Culmer, Eller, \& Abrams, 2006).

Interestingly, a somewhat fuzzier pattern emerged when examining effects on the information provision of suspects. First, the studies reported in both Chapters 2 and 3 found that being kind in terms of active listening behaviour (either used separately or combined with rational arguments) stimulated the suspects' information provision (or willingness to do so) regardless of the suspects' cultural background. Thus, and in line with the principles of investigative interviewing (Bull \& Cherryman, 1996; Dando, Wilcock, \& Milne, 2009; Dando, Wilcock, Milne, \& Henry, in press; Lamb et al., 1996; Milne \& Bull, 1999), active listening behaviour appears to be an effective strategy in eliciting information from both low- and highcontext suspects. Yet, and perhaps more puzzling, our analyses of authentic police interviews 
in Chapter 4 showed that active listening behaviour negatively impacted the informationgathering process among high-context suspects; i.e., high-context suspects were quicker to respond with refusing to give information than were low-context suspects.

A first explanation for this unanticipated finding may be sought in differences in personality make-up between our suspect populations. Research suggests that juvenile offenders score relatively highly on a range of personality traits (Heaven, 1996) that are related to antisocial behaviour (Lynam \& Miller, 2004) compared to non-delinquent youth. These include, for instance, anger/hostility (e.g., Heaven, 1993), sensation-seeking, lack of empathy (e.g., Eysenck \& Gudjonsson, 1989), and psychopathic personality traits (e.g., Vaughn \& Howard, 2008; Walsh \& Kosson, 2007). Youth with such personality traits are likely to be difficult to handle (cf. Vidal \& Skeem, 2007). Consequently, it could be the case that they perceive being kind differently than non-delinquent youth due to inadequate understandings of others' social behaviours. A second explanation could be that the stakes are clearly much higher in the real world compared to research settings (e.g., Vrij et al., 2009). As a consequence, the 'real' offenders might have been more motivated to resist kind behaviour than were the mock theft suspects (Shepherd, 1993). Particularly, as research indicates that intrinsic motivation will gain strength when decisions (e.g., to commit a crime) are made voluntarily (Isen \& Reeve, 2005), real offenders might not take being kind at face value (see also Montoya \& Insko, 2008). Instead, they may decide to refuse information first in order to determine the best long-term outcome (cf. Isen \& Reeve, 2005). If this reasoning holds, one would, however, expect similar results for rational arguments (cf. Knowles \& Linn, 2004), and this is clearly not the case.

98 A third possible explanation taps into the different nature of the studies. That is, the evidence against the suspects in the field setting was quite strong compared to the experimental settings. As police officers are likely to confront suspects with the evidence they have (Kassin et al., 2007), it might well be the case that the 'real' suspects perceived the evidence against them as stronger than did the mock theft suspects. This might be important since research indicates that when the evidence is strong (rather than weak or medium), kind behaviour proves unsuccessful (Leo, 1996). This happens mostly because strong evidence could be a cue to refuse cooperation in order to avoid (further) incrimination (Shepherd, 1993). A final explanation might be that the effectiveness of (kind) behaviour is dependent on the context in which it is presented (cf. Taylor, 2006; Taylor \& Donald, 2004, 2007). Remember that the study reported in Chapter 3 showed that being kind preceding (but not following) rational arguments significantly increased the propensity of high-context suspects to ultimately confess. It therefore might well be that the specific constellation in which being kind was represented was ineffective, rather than kind behaviour per se. Moreover, and perhaps particularly important because we observed relatively low levels of being kind in the authentic setting, the predictive power of strategic sequences may rest in the repetition of 
these behavioural patterns rather than the arbitrary or single use of behavioural shifts (Van de Vliert, Nauta, Giebels, \& Janssen, 1999, p. 486). Future research should look into these different alternative explanations in order to shed more light on the relationship between being kind and information provision.

\section{A Firm Approach?}

Firm behaviour, or intimidation (see Chapter 4), is generally disapproved of in the context of investigative interviewing (Milne \& Bull, 1999; see also Walton, 2003). Nevertheless, it is regularly expressed in many social interactions, including police interviews (Kassin et al., 2007; King \& Snook, in press; Leo, 1996). Moreover, it may sometimes serve a legitimate and useful function (Walton, 2003). For instance, the literature on conflict resolution indicates that forcing behaviour could be appropriate when responding to emergencies or when unpopular decisions have to be made (Rahim, 1992; Thomas, 1992; Van de Vliert et al., 1999). It may also serve as a signal (Shomer, Davis, \& Kelley, 1966) in order to avoid exploitation (cf. Olekalns \& Weingart, 2008). These findings justify a closer examination of this type of behaviour within the domain of investigative interviewing. We responded to this opportunity by exploring the impact of intimidation in two ways. First, we elaborated on previous work on psychological contrast sequences (Brodt \& Tuchinsky, 2000; Hilty \& Carnevale, 1993; Rafaeli \& Sutton, 1991) that indicates that intimidating behaviour may serve as a reference point against which other behaviours can be evaluated (Bazerman, 1990; see also Pietroni, Van Kleef, De Dreu, \& Pagliaro, 2008). In Chapter 3, it was demonstrated that strategic contrast sequences strongly impact suspects' behaviour in a way dependent on their fit with the suspect's cultural background. That is, intimidation followed by rational arguments was particularly successful when interviewing low-context suspects, while interview success for high-context suspects benefitted most from an intimidation followed by kind approach. An important question, however, remained unanswered; i.e., what impact does the use of intimidating behaviour have on suspects in general, and how may this depend on cultural fit? To address this question, the effects of two types of intimidation were explored in Chapter 4. These types were expected to be specific manifestations of cultural values of either lowcontext (intimidating the individual) or high-context (intimidating the context) suspects. The results supported our context dependency proposition. That is, when the intimidating behaviour was directed at the individual, low-context suspects were found to respond more quickly with case-related personal information than did high-context suspects. On the other hand, when the intimidating behaviour was directed at the context (e.g., friends or family of the suspect), it was more closely related to contextual information provision of high-context rather than low-context suspects. 
Taken together, a first important conclusion is that the joint impact of intimidation and rational arguments/being kind may increase the possibility that guilty suspects will admit to theft and/or increase their willingness to provide information. However, it is crucial for possible success that the contrasting behaviour matches the suspect's cultural framework (Chapter 3). Another important conclusion is that the use of intimidation alone was closely related to suspects' information provision but, again, only when it appealed to culture-specific values (Chapter 4). Together, our findings seem to provide some support for the notion that intimidation is not necessarily destructive (Walton, 2003).

\section{A Multi-Method Pursuit}

Studying how to successfully interview suspects is rather challenging (Bull \& Milne, 2004; Bull \& Soukara, in press; Gudjonsson, 2003; Milne \& Bull, 1999). On the one hand, controlled research settings are necessary in order to establish relevant causal relationships between police officers' behaviour and interview outcomes (Vrij et al., 2009). On the other hand, identifying psychological and/or behavioural processes may be of little use if police officers believe that these findings are not transferable into practice (Mann, Vrij, Fisher, \& Robinson, 2008). In response to these challenges, we conducted multi-method research in order to test our hypotheses. In doing so, we aimed to take advantage of the strengths of different research paradigms while overcoming - at least some of - their weaknesses. Research in naturalistic settings is often promoted because it will adequately reflect the complexity of authentic interactions, including (the measurement of) actual behaviour (Perloff, 1993). As such, it is conducive to the ecological validity of the research and the generalisability of results (e.g., Vrij et al., 2009). A major problem with authentic interviews, however, is that it is hard to assess some sort of 'ground truth' (Baldwin, 1993); i.e., one can never be completely sure about a suspect's guilt or innocence. Moreover, suspects may have reasons for disguising their true intentions or responses. Thus, while research in naturalistic settings provides valuable insights, research in a more controlled environment could overcome some of the inherent limitations. Moreover, an important advantage of laboratory research is that behaviours and/or variables can be controlled. This enables researchers to establish causal relationships between, for instance, a police officer's behaviour and interview outcomes. A frequently mentioned limitation, on the other hand, is that the ecological validity of results obtained through laboratory research and/or student participants can be questioned (Vrij et al., 2009). In response to these issues, three different research methods were used in this dissertation: simulated police interviews with mock theft suspects (i.e., real interaction in a simulated setting); a computer simulated chat session (i.e., key behaviours were isolated and manipulated); and the examination of authentic police interviews in terms of police-suspect cue-response patterns. 


\section{Theoretical Implications}

The present dissertation contributed to the existing literature by examining the (culturespecific) effects of interpersonal influencing in police settings. In doing so, we extended previous research in three interrelated domains. Most importantly, we added to the growing body of research on investigative interviewing. As noted by several scholars (e.g., Gudjonsson, 2003; Leo, 1996), too little is known about what happens in police interviews (Bull \& Soukara, in press). Clearly, research would benefit from more systematic research on the matter. The present dissertation attests to this need by providing a theoretical framework (i.e., the Table of Ten; Giebels, 2002; Giebels \& Taylor, in press) for the examination of police officers' behaviours. Rather than the mere observation of behaviour (e.g., Kassin et al., 2007; Leo, 1996; Moston \& Engelberg, 1993), we added to the literature by examining the specific relationships between these influencing behaviours and several interview outcomes (Bull \& Soukara, in press). Finally, and perhaps most importantly, we included an increasingly important situational factor in our analysis: i.e., the cultural background of suspects. By introducing a cultural perspective to police interviews, we started to fill a large knowledge gap in the investigative literature (cf. Gudjonsson, 2003).

Next, we built on previous work on interpersonal influencing behaviour, specifically the Table of Ten (Giebels, 2002; Giebels \& Taylor, in press). We extended the scope of this framework to the police interview context and subdivided being kind into three more concrete types of kind behaviour: active listening, rewarding and offering. These types were found to impact interview outcomes differently. Although these behaviours apply particularly well to police interviews, they may also be translated to other police-civilian interactions,

such as crisis negotiations. Furthermore, we replicated previous research by demonstrating that rational arguments are central to and effective in influencing offenders and that the impact of this behaviour is largely dependent on culture (Giebels \& Taylor, 2009). Finally, we extended previous work by examining the impact of intimidation in investigative interviews. Interestingly, it was found that intimidation may increase suspects' information provision, but only when it is directed at the cultural values of a suspect or when it is followed by behaviour that appeals to these values.

Finally, the present dissertation contributes to conflict and negotiation research in two ways. First, it builds on important work on combined conflict behaviours (e.g., Van de Vliert et al., 1999) by furthering knowledge on what specific behaviours form effective sequences. Second, our findings extend existing work on perceptual contrast effects (Brodt \& Tuchinsky, 2000; Hilty \& Carnevale, 1993; Rafaeli \& Sutton, 1991) by demonstrating that in addition to affect-based contrast (Pietroni et al., 2008), more substantive contrasts (i.e., contrasting rational arguments) can also be identified. 


\section{General Limitations and Directions for Future Research}

The present dissertation argues that it is important to interview suspects from a cultural perspective. However, a critical reader might ask what perspective. As the high-context participants in our studies originated from different nations, it could be argued that they might differ on other cultural dimensions than the ones we described. For instance, research indicates that high-context suspects are concerned with status differences and establishing dominance (Adair \& Brett, 2004) and that (acceptance of) power distance varies across nations (Hofstede, 2001). This may have caused considerable within-group variability, and as such, it may account for the relatively low reliabilities of the culture-scales that were used to check whether our low-/high-context categorisation was valid. Although low internal reliabilities of the instruments used to assess, for instance, collectivism are not uncommon (Bond, 2002; Brett, Tinsley, Janssens, Barsness, \& Lytle, 1997; Fiske, 2002; Oyserman, Coon, \& Kemmelmeier, 2002), we cannot rule out the possibility that variation within the highcontext group influenced our results. More practically, however, our samples of high-context suspects do reflect a representative sample of the suspects who police officers encounter in daily life. Thus, although one could argue about the core (cultural) dimensions underlying our results, we demonstrated that the effect of police officers' influencing behaviour varies considerably and rather consistently across the two groups.

Another methodological limitation can be found in the design underlying our research. By focusing our examination on the interaction between Dutch (low-context) police officers and low-/high-context suspects, we essentially compared intracultural (low-l low-context) with intercultural (low-/high-context) interviews (cf. Giebels \& Taylor, 2009). In doing so, we left two conditions out of consideration: high-context officers interviewing high-context suspects and high-context officers interviewing low-context suspects. Although police officers in the Netherlands can be non-Dutch in origin, they are taught the same standard method of interviewing as Dutch police officers (Nierop, 2005; Van Amelsfoort, Rispens, \& Grolman, 2005). In other words, they are likely to express similar interview strategies as Dutch officers, and the question is whether they will or can incorporate high-context cultural values into these strategies. Thus, particularly the absence of a high-/high-context condition may be a missed opportunity because there is research evidence suggesting that intracultural interactions are more successful than intercultural interactions (Adair, Okumura, \& Brett, 2001; Adair, Taylor, \& Tinsley, 2009; Brett \& Okumura, 1998). Translating this to police interviews, the questions is: are same- (high-context) culture interviews better suited to reach their full potential (e.g., in terms of information provision or admissions) than mixed-culture interviews? We cannot discard this option on the basis of the present dissertation. However, if this reasoning holds, one would expect low-context interviews to be more successful than high-context interviews because the two parties come from the same culture (i.e., both police officer and suspect originate from low-context cultures). Since we demonstrated positive 
effects for both low-context and high-context suspects, this reasoning is not supported by our results. Future research could explore the issue in greater depth.

Another caveat is that we directed our attention mainly at being kind, which is defined in terms of active listening behaviour. The reason for this is that active listening plays a pivotal role in the investigative process (Bull \& Soukara, in press), while rewarding and offering are relatively infrequently used (see also Kassin et al., 2007; Leo, 1996). However, there is one limitation to this approach: Although we showed in Chapter 3 that suspects perceive active listening as more kind and humane compared to more coercive behaviour (cf. Holmberg \& Christianson, 2002), the question is to what extent they actually perceive this behaviour as being kind. Put differently, it might be the case that they perceive it as "the job" of the police officer to pose questions and listen to the suspect instead of a sincere attempt to establish a good quality relationship. This reasoning is supported by a study showing that police officers' attitudes toward minority youths were improved after cooperation in a competitive tournament, while the minority youths showed no improvement in attitude toward the police (Rabois \& Haaga, 2002). This seems to suggest that suspects perceive mere cooperation (e.g., through active listening behaviour) as instrumental rather than kind in nature (cf. Montoya \& Insko, 2008), implying that other factors - such as the perceived sincerity of kind behaviour - might reflect kind behaviour to a larger extent. It would be interesting to explore this proposition in future research.

It might also be the case that other behaviours described in the Table of Ten might prove more successful for the interviewing of high-context suspects. For instance, research on crisis negotiations demonstrated that the use of direct pressure stimulated exchange proposals from high-context perpetrators (Giebels \& Noelanders, 2004). In addition, other relationship-oriented behaviour, such as being credible, might offer an effective alternative. Being credible communicates that one has the position and the capacity to handle a situation and that one can be trusted (Giebels \& Taylor, in press). As such, it might appeal to two (rather than one) important values of high-context cultures: care for the interpersonal relationship (e.g., Victor, 1992) and relational positioning (e.g., Adair \& Brett, 2004). Future work might take these behaviours and their relationship with suspects' cultural background into consideration.

A final limitation of the present dissertation is that we did not include measures to tap into the psychological processes underlying influencing behaviour. Based on the influential work of Robert Cialdini (for an overview, see Cialdini, 2001) and the Table of Ten (Giebels, 2002; Giebels \& Taylor, in press), we inferred rather than measured the underlying mechanisms. For instance, we argued that the impact of being kind is driven by perceptions of kindness and liking (see also Holmberg \& Christianson, 2002). As such, it could be expected that the effects of being kind are determined by the principle of liking (Cialdini, 2001; Giebels \& Taylor, in press). Indeed, initial research evidence indicates that cooperation with the police is 
determined by the quality of (previous) contact (Viki et al., 2006). Likewise, previous studies have found that the impact of influencing behaviour was determined by perceived credibility of the agent (Heilman, 1974; Horai \& Tedeschi, 1969; Sinaceur \& Neale, 2005). Future work could examine whether current findings are mediated by processes such as liking, credibility, or motivation, geared toward a better understanding of strategic influencing in police interviews.

\section{Implications for Practice}

Inappropriate interviewing of suspects has led to many miscarriages of justice in the past (Milne \& Bull, 1999). Even though the importance of appropriate interview techniques has been noted by numerous authors (e.g., Bull \& Cherryman, 1996; Bull \& Milne, 2004; Lamb et al., 1996; Moston \& Stephenson, 1993; Shepherd, 1996), research on how to conduct police interviews successfully is scant (Bull \& Soukara, in press). The present dissertation aims to fill this void by offering theoretical and research-based insights into interviewing practices, resulting in four main recommendations for the further refinement of suspect interviewing.

A first recommendation concerns the use of rational arguments when interviewing suspects. Rational arguments can be considered a central element of police interviews (Walton, 2003) because police officers need to address the evidence to build their case (Baldwin, 1993). Thus, the use of logic and rationality is important to confirm and/or legitimate police narratives both from a legal perspective (cf. McConville et al., 1991) and in order to find the truth (Bull \& Soukara, in press). However, our results strongly suggest that rational arguments differ in terms of successfulness when interviewing suspects from low-context and highcontext cultures. While rational arguments are consistently found to increase low-context suspects' cooperation in terms of information provision and admissions, no beneficial effects are found for high-context suspects. Moreover, one of our studies clearly demonstrated that when police officers use rational arguments to a large extent, the propensity of high-context suspects to admit their offense declines. Put differently, it is important for police officers to realise that despite the fact that rational arguments are usually necessary to address the evidence, they may not prove successful in changing the behaviour of high-context suspects in a desired direction.

Secondly, and congruent with the principles of investigative interviewing, it is advisable to devote much attention to the use of active listening behaviour in every suspect interview (e.g., Bull \& Cherryman, 1996; Bull \& Milne, 2004; Bull \& Soukara, in press; Milne \& Bull, 1999). Active listening behaviour has been found to stimulate both the actual information suspects provide and their inclination to do so. This information-gathering aspect is particularly important because it serves two purposes: a relational (i.e., inviting a suspect to give an account in his or her own words; Shepherd, 1991) and a substantive purpose (i.e., the possibility to identify (in)consistencies in suspects' statements; Granhag, 
Strömwall, \& Hartwig, 2007). An important practical implication is, thus, that the frequent use of active listening may comfort suspects (cf. Holmberg \& Christianson, 2002), which is in line with ethical interviewing (Shepherd, 1991), while it is also conducive to the ultimate goal of finding the truth (Milne \& Bull, 1999). Finally, when using both active listening and rational arguments, it seems important to let acts of active listening precede rational arguments.

A third recommendation is that it pays to use acts of rewarding and offering behaviour, even in small doses. This is particularly the case when interviewing high-context suspects, as rewarding and offering were found to positively influence perceptions of the quality of the relationship with police officers. This is important because suspects become more and more 'regular customers' of the police (e.g., WODC, 2006), and the quality of police contact has been found to be an important predictor of future cooperation (Viki et al., 2006).

A final recommendation concerns the use of firm behaviour. Although our results suggest that intimidation might sometimes be successful, I would advise police officers to be careful using such behaviour. There are three reasons for this. First, we have shown that the effect of intimidation is highly dependent upon the context in which it is presented; i.e., its effectiveness depends on whether it matches suspects' cultural framework or what specific type of intimidation is used. Second, there is a large body of literature showing that intimidation could easily be perceived as a personal attack or evoke hostile counteracts, setting in motion an escalatory, destructive conflict spiral (Rubin, Pruitt, \& Kim, 1994; see also Van de Vliert et al., 1999). Finally, perceptions of inappropriate use of intimidation might undermine one's perceived credibility (Heilman, 1974), something particularly problematic when cooperation is needed (cf. Sinaceur \& Neale, 2005). Thus, although police officers may sometimes encounter situations in which a firm approach seems to be part of the solution (e.g., when a suspect is obviously not telling the truth) or seems legitimate (Walton, 2003), it is advisable to restrict the use of such behaviour to a minimum.

Overall, the present thesis suggests that police officers could benefit from awareness of the impact of their behaviour when interacting with suspects from different cultural backgrounds (cf. Hofstede, 2001, p. 427). Research has identified several personality traits that are conducive to successful intercultural communication (i.e., cultural empathy, open-mindedness, emotional stability, social initiative, and flexibility; Leone, Van der Zee, Van Oudenhoven, Perugini, \& Ercolani, 2005; Van der Zee \& Van Oudenhoven, 2000, 2001; Van Oudenhoven \& Van der Zee, 2002). Future selection of police officers for intercultural police interviews could include an assessment of multicultural effectiveness. In addition, cultural sensitivity training could be designed to heighten awareness of cultural differences. It is important to note, however, that sensitivity training is only one part of a multi-faceted intervention (Adair et al., 2009, p. 157). Adair and colleagues argued and showed that when interacting with someone of another culture, people try to adjust to their counterpart's assumptions. In doing so, it is likely that they overcompensate culturally specific behaviours 
(Adair et al., 2009). For successful implementation, it is thus necessary but not sufficient to be culturally sensitive. In addition, police officers need to be flexible and open-minded (Bull \& Soukara, in press) in order to recognise the caveats of cultural miscommunication (see also Hofstede, 2001).

Finally, the success of many police interviews is still dependent on the admissions of guilty suspects (cf. Baldwin, 1993; Blair, 2007). However, focusing on obtaining admissions may result in too much pressure being exerted and even false confessions (cf. Vrij, 2004). The present dissertation contributes to the police practice by examining alternative interview outcomes, such as the (actual and self-reported) information provision of suspects or their perceived quality of the relationship with the police officer. Moreover, the direct relationships between those outcomes and the tactics police officers use were assessed. In doing so, we demonstrated that interpersonal influencing offers possibilities to enhance suspects' cooperation in several ways. Together, this is conducive to the ultimate purpose of investigative interviewing: finding the truth (Baldwin, 1993; Bull \& Milne, 2004; Bull \& Soukara, in press; Milne \& Bull, 1999). 



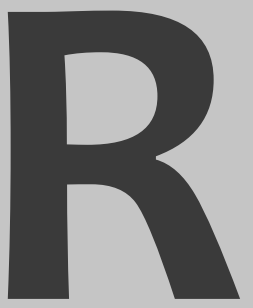

References 
Adair, W. L. (2003). Integrative sequences and negotiation outcome in same- and mixedculture negotiations. International Journal of Conflict Management, 14, 273-296.

Adair, W. L., Brett, J., Lempereur, A., Okumura, T., Shikhirev, P., Tinsley, C. H., et al. (2004). Culture and negotiation strategy. Negotiation Journal, 20, 87-111.

Adair, W. L., \& Brett, J. M. (2004). Culture and negotiation processes. In J. M. Gelfand \& J. M. Brett (Eds.), The handbook of negotiation and culture (pp. 158-176). Palo Alto, CA: Stanford University Press.

Adair, W. L., \& Brett, J. M. (2005). The negotiation dance: time, culture, and behavioural sequences in negotiation. Organization Science, 16, 33-51.

Adair, W. L., Buchan, N., \& Chen, X. P. (2008). Communication and Social Interaction Style (CSIS). Paper presented at the 2008 Association for International Business conference, Milan.

Adair, W. L., Okumura, T., \& Brett, J. M. (2001). Negotiation behaviour when cultures collide: the United States and Japan. Journal of Applied Psychology, 86, 371-385.

Adair, W. L., Weingart, L. R., \& Brett, J. (2007). The Timing and Function of Offers in U.S. and Japanese Negotiations. Journal of Applied Psychology, 92, 1056-1068.

Aiken, L. S., \& West, S. G. (1991). Multiple regression: Testing and interpreting interactions. Thousand Oaks, CA: Sage.

Akehurst, L., Bull, R., Vrij, A., \& Köhnken, G. (2004). The effects of training professional groups and lay persons to use criteria-based content analysis to detect deception. Applied Cognitive Psychology, 18, 877-891.

Aronson, E. (1992). The return of the repressed: Dissonance theory makes a comeback. Psychological Inquiry, 3, 303-311.

Auld, F., Jr., \& White, A. M. (1959). Sequential dependencies in psychotherapy. Journal of Abnormal and Social Psychology, 58, 100-104.

Bakeman, R., \& Gottman, J. M. (1997). Observing interaction: An introduction to sequential analysis (2nd ed.). New York: Cambridge University Press.

Baldwin, J. (1993). Police interview techniques: Establishing truth or proof? The British Journal of Criminology, 33, 325-352.

Bazerman, M. H. (1990). Judgment in managerial decision making. New York: Wiley.

Beune, K., Giebels, E., \& Sanders, K. (in press). Are you talking to me? Influencing behaviour and culture in police interviews. Psychology, Crime \& Law.

Beune, K., Giebels, E., Adair, W.L., Fennis, B.M., Van der Zee, K.I. (submitted). Chatting with suspects: Strategic sequences and the importance of order and cultural fit.

Blair, J.P. (2007). The roles of interrogation, perception, and individual differences in producing compliant false confessions. Psychology, Crime \& Law, 13, 173-186.

Bond, M. H. (2002). Reclaiming the individual from Hofstede's ecological analysis - A 20-year odyssey: Comment on Oyserman et al. Psychological Bulletin, 128, 73-77. 
Brett, J. M. (2001). Negotiating across cultures. San Francisco, CA: Jossey-Bass.

Brett, J. F., Northcraft, G. B., \& Pinkley, R. L. (1999). Stairways to heaven: An interlocking selfregulation model of negotiation. Academy of Management Review, 24, 452-471.

Brett, J. M., \& Okumura, T. (1998). Inter- and intracultural negotiation: U.S. and Japanese negotiators. Academy of Management Journal, 41, 495-510.

Brett, J. M., Tinsley, C. H., Janssens, M., Barsness, Z. I., \& Lytle, A. L. (1997). New approaches to the study of culture in industrial organizational psychology. In P. C. Earley \& M. Erez (Eds.), New perspectives on international industrial/organizational psychology (pp. 75-129). San Francisco: The New Lexington Press.

Brewer, M. B., \& Chen, Y. (2007). Where (who) are collectives in collectivism? Toward conceptual clarification of individualism and collectivism. Psychological Review, 114, 133-151.

Brinker Dozier, J., Husted, B. W., \& McMahon, J. T. (1998). Need for approval in low-context and high-context cultures: a communications approach to cross-cultural ethics. Teaching Business Ethics, 2, 111-125.

Brodt, S. E., \& Tuchinsky, M. (2000). Working together but in opposition: An examination of the "Good-Cop/Bad-Cop" negotiating team tactic. Organizational Behaviour and Human Decision Processes, 81, 155-177.

Buckwalter, A. (1983). Interviews and interrogations. Boston: Butterworth Publishers.

Bull, R., \& Cherryman, J. (1996). Helping to identify skill gaps in specialist investigative interviewing: Enhancement of professional skills. Final report to the home office police research group. London: HSMO.

Bull, R., \& Milne, R. (2004). Attempts to improve the police interviewing of suspects. In D. Lassiter (Ed.), Interrogations, confessions, and entrapment (pp. 182-195). New York: Kluwer Academic.

Bull, R., \& Soukara, S. (in press). Studies of what really happens in police interviews. In G. D. Lassiter \& C. Meissner (Eds.), Interrogations and confessions: Current research, practice and policy. Washington, DC: American Psychological Association.

Carnevale, P. J., \& Pruitt, D. G. (1992). Negotiation and mediation. Annual Review of Psychology, 43, 531-552.

Cheney, J., Harford, T., \& Solomon, L. (1972). The effects of communicating threats and promises upon the bargaining process. The Journal of Conflict Resolution, 16, 99-107.

Choi, I., \& Nisbett, R. E. (1998). Situational salience and cultural differences in the correspondence bias and in the actor-observer bias. Personality \& Social Psychology Bulletin, 24, 949-960.

Choi, I., \& Nisbett, R. E. (2000). Cultural psychology of surprise: holistic theories and recognition of contradiction. Journal of Personality and Social Psychology, 79, 890905. 
Cialdini, R. B. (1993). Influence. The psychology of persuasion. New York: Quill William Morrow.

Cialdini, R. B. (2001). Influence: science and practice (4 ed.). Boston: Allyn \& Bacon.

Cialdini, R. B., Cacioppo, J. T., Bassett, R., \& Miller, J. A. (1978). Low-ball procedure for producing compliance: Commitment then cost. Journal of Personality and Social Psychology, 36, 463-476.

Cialdini, R. B., \& Goldstein, N. J. (2004). Social influence: Compliance and conformity. Annual Review of Psychology, 55, 591-621.

Cialdini, R. B., \& Trost, M. R. (1998). Social influence: Social norms, conformity, and compliance. In D. T. Gilbert, S. T. Fiske \& G. Lindzey (Eds.), The handbook of social psychology (4th ed., Vol. 2, pp. 151-192). Boston: McGraw-Hill.

Cialdini, R. B., Wosinska, W., Barrett, D. W., Butner, J., \& Gornik-Durose, M. (1999). Compliance with a request in two cultures: the differential influence of social proof and commitment/consistency on collectivists and individualists. Personality \& Social Psychology Bulletin, 25, 1242-1253.

Corrigan, J. D., \& Schmidt, L. D. (1983). Development and validation of revisions in the Counsellor Rating Form. Journal of Counselling Psychology, 30, 64-75.

Cross, S. E., \& Madson, L. (1997). Models of the self: Self-construals and gender. Psychological Bulletin, 122, 5-37.

Dando, C., Wilcock, R., \& Milne, R. (2009). The Cognitive Interview: The efficacy of a modified mental reinstatement of context procedure for frontline police investigators. Applied Cognitive Psychology, 23, 138-147.

Dando, C., Wilcock, R., Milne, R., \& Henry, L. (in press). An adapted Cognitive Interview procedure for frontline police investigators. Applied Cognitive Psychology.

Dillon, J. T. (1990). The practice of questioning. London: Routledge.

Donohue, W. A. (1981). Development of a model of rule use in negotiation. Communication Monographs, 48, 106-120.

Dunlap, W. P., Burke, M. J., \& Smith-Crowe, K. (2003). Accurate tests of statistical significance for $r$-sub(WG) and average deviation interrater agreement indexes. Journal of Applied Psychology, 88, 356-362.

Edgington, E. S. (1995). Randomization tests. New York: Marcel Deckker, Inc.

Eiser, J. R. (1990). Social judgment. Buckingham, England: Open University Press.

Elangovan, A., \& Shapiro, D. L. (1998). Betrayal of trust in organizations. Academy of Management Review, 23, 547-566.

Emans, B., Laskewitz, P., \& Van de Vliert, E. (1994). The Netherlands. In A. A. Blum \& M. A. Rahim (Eds.), Global perspectives on organizational conflict (pp. 53-66).

Eysenck, H., \& Gudjonsson, G. H. (1989). The causes and cures of criminality. New York: Plenum.

Falbe, C. M., \& Yukl, G. (1992). Consequences for managers of using single influence tactics and combination of tactics. Academy of Management Journal, 35, 638-652. 
Festinger, L. (1957). A theory of cognitive dissonance. Stanford: Stanford University Press.

Fisher, R. P., Brennan, K. H., \& McCauley, M. R. (2002). The cognitive interview method to enhance eyewitness recall. In M. L. Eisen, J. A. Quas \& G. S. Goodman (Eds.), Memory and suggestibility in the forensic interview (pp. 265-286). Mayway, NJ: Lawrence Erlbaum.

Fisher, R. P., \& Geiselman, R. E. (1992). Memory enhancing techniques for investigative interviewing: the cognitive interview. Springfield, IL: Thomas.

Fiske, A. P. (2002). Using individualism and collectivism to compare cultures- A critique of the validity and measurement of the constructs: Comment on Oyserman et al. Psychological Bulletin, 128, 78-88.

Fu, P. P., \& Yukl, G. (2000). Perceived effectiveness of influence tactics in the United States and China. The Leadership Quarterly, 11, 251-267.

Gass, R. H., \& Seiter, J. S. (1999). Persuasion, social influence and compliance gaining. Needham Heights, MA: Allyn \& Bacon.

Gelfand, M. J., \& Dyer, N. (2000). A cultural perspective on negotiation: progress, pitfalls, and prospects. Applied Psychology: An International Review, 49, 62-99.

Gelfand, M. J., Nishii, L. H., Holcombe, K. M., Dyer, N., Ohbuchi, K. I., \& Fukuno, M. (2001). Cultural influences on cognitive representations of conflict: Interpretations of conflict episodes in the United States and Japan. Journal of Applied Psychology, 86, 1059-1074.

Giebels, E. (2002). Beinvloeding in gijzelingsonderhandelingen: de tafel van tien. Nederlands Tijdschrift voor de Psychologie, 57, 145-154.

Giebels, E., \& Noelanders, S. (2004). Crisis negotiations: A multipartty perspective. Veenendaal, The Netherlands: Universal Press.

Giebels, E., \& Taylor, P. J. (2009). Interaction patterns in crisis negotiations: Persuasive arguments and cultural differences. Journal of Applied Psychology, 94, 5-19.

Giebels, E., \& Taylor, P. J. (in press). Communication Predictors and Social Influence in Crisis Negotiations. In R. G. Rogan \& F. Lancely (Eds.), Contemporary Theory, Research, and Practice of Crisis/Hostage Negotiations. Westport, CT: Praeger.

Giles, H., \& Smith, P. M. (1979). Accommodation theory: Optimal levels of convergence. In H. Giles \& R. N. St. Clair (Eds.), Language and social psychology (pp. 45-65). Baltimore, MD: University Park Press.

Giles, H., \& Street, R. L., Jr. (1985). Communicator characteristics and behavior. In M. L. Knapp \& G. R. Miller (Eds.), Handbook of interpersonal communication (pp. 205-261). Beverly Hills, CA: Sage.

Good, P. (1994). Permutation tests: A practical guide to resampling methods for testing hypotheses. New York: Springer. 
Granhag, P. A., \& Strömwall, L. A. (1999). Repeated interrogations: Stretching the deception detection paradigm. Expert Evidence, 7, 163-174.

Granhag, P. A., \& Strömwall, L. A., \& Hartwig, M. (2007). The SUE technique: The way to interview to detect deception. Forensic Update, 88, 25-29.

Greeno, J. G., \& Simon, H. A. (1988). Problem solving and reasoning. In R. C. Atkinson, R. J. Herrnstein, G. Lindzey \& R. D. Luce (Eds.), Stevens' handbook of experimental psychology (2nd ed., Vol. 2, pp. 589-672). New York: Wiley.

Grice, H. (1975). Logic and conversation. In E. Cole \& J. Morgan (Eds.), Syntax and semantics (Speech acts ed., Vol. 3, pp. 107-142). New York: Academic Press.

Gudjonsson, G. H. (2003). The psychology of interrogations and confessions: $a$ handbook (2nd ed.). Chichester: Wiley.

Gudykunst, W. B., \& Matsumoto, Y. (1996). The influence of cultural individualism-collectivism, self construals, and individual values on communication styles across cultures. Human Communication Research, 22, 510-537.

Gudykunst, W. B., \& Ting-Toomey, S. (1988). Culture and interpersonal communication. Newbury Park, CA: Sage.

Hall, E. T. (1976). Beyond culture. Garden City, NY: Anchor Press/Doubleday.

Hall, E. T., \& Hall, M. R. (1990). Understanding cultural differences. Yarmouth, Maine: Intercultural Press.

Hartwig, M. (2006). Interrogation to detect truth and deception: Effects of strategic use of evidence. Unpublished PhD thesis, Göteborg University, Sweden.

Hartwig, M. (2007). Guilty and innocent suspects' strategies during police interrogations. Psychology, Crime \& Law, 13, 213-227.

Hartwig, M., Granhag, P. A., Strömwall, L. A., \& Kronkvist, O. (2006). Strategic use of evidence during police interviews: When training to detect deception works. Law and Human Behavior, 30, 603-619.

Hartwig, M., Granhag, P. A., Strömwall, L. A., \& Vrij, A. (2005). Detecting deception via strategic disclosure of evidence. Law and Human Behavior, 29, 469-484.

Heaven, P. C. L. (1993). Personality predictors of self-reported delinquency. Personality \& Individual Differences, 14, 67-76.

Heaven, P. C. L. (1996). Personality and self-reported delinquency: Analysis of the "Big Five" personality dimensions. Personality \& Individual Differences, 20, 47-54.

Heilman, M. E. (1974). Threats and promises: Reputational consequences and transfer of credibility. Journal of Experimental Social Psychology, 10, 310-324.

Higgings, C. A., Judge, T. A., \& Ferris, G. R. (2003). Influence tactics and work outcomes: a meta-analysis. Journal of Organizational Behaviour, 24, 89-106.

Hilty, J. A., \& Carnevale, P. J. (1993). Black-hat/White-hat strategy in bilateral negotiation. Organizational Behaviour and Human Decision Processes, 55, 444-469. 
Hofstede, G. (2001). Culture's consequence: comparing values, behaviours, institutions, and organizations across nations. Thousand Oaks, CA: Sage.

Holmberg, U., \& Christianson, S. A. (2002). Murderers' and sexual offenders' experiences of police interviews and their inclination to admit or deny crimes. Behavioural Sciences and the Law, 20, 31-45.

Holtgraves, T. (1997). Styles of language use: Individual and cultural variability in conversational indirectness. Journal of Personality and Social Psychology, 73, 624-637.

Horai, J., \& Tedeschi, J. T. (1969). Effects of credibility and magnitude of punishment on compliance to threats. Journal of Personality and Social Psychology, 12, 164-169.

Inbau, F. E., Reid, J. E., \& Buckley, J. P. (1986). Criminal interrogation and confessions (3rd ed.). Baltimore, MD: Williams and Wilkins.

Inbau, F. E., Reid, J. E., Buckley, J. P., \& Jayne, B. C. (2001). Criminal interrogation and confessions (4th ed.). Gaithersberg, MD: Aspen.

Irving, B. (1980). Police interrogation: A case study of current practice. Royal Commission on Criminal Procedure Research Study No. 2. London: HMSO).

Isen, A. M., \& Reeve, J. (2005). The influence of positive affect on intrinsic motivation and extrinsic motivation: Facilitating enjoyment of play, responsible work behaviour, and self-control. Motivation and Emotion, 29, 297-325.

lyengar, S. S., \& Brockner, J. (2001). Cultural differences in self and the impact on personal and social influences. In W. Wosinska, R. B. Cialdini, D. W. Barrett \& J. Reykowski (Eds.), The practice of social influence in multiple cultures (pp. 13-32). Mahwah, NJ: Lawrence Erlbaum Associates.

Jacobs, M. (2004). Bekennen en ontkennen van verdachten. WODC. Cahier 2004 - 2, from http://www.wodc.nl/images/ca2004-2_Volledige\%20tekst_tmc44-58070.pdf.

Jennissen, R. P. W., \& Blom, M. (2007). Allochtone en autochtone verdachten van verschillende delicttypen nader bekeken (No. Cahier 2007-4): WODC).

Kagitcibasi, C. (1997). Individualism and collectivism. In J. W. Berry, M. H. Segall \& C. Kagitcibasi (Eds.), Handbook of cross-cultural psychology (2nd ed., pp. 1-50). Boston: Allyn \& Bacon.

Kamisar, Y. (1980). Police interrogation and confession: Essays in law and policy. Ann Arbor: University of Michigan.

Karstedt, S. (2001). Comparing cultures, comparing crime: Challenges, prospects and problems for a global criminology. Crime, Law and Social Change, 36, 285-308.

Kashima, Y., Yamaguchi, S., Kim, U., Choi, S. C., Gelfand, J. G., \& Yuki, M. (1995). Culture, Gender, and Self: A perspective from Individualism-Collectivism research. Journal of Personality and Social Psychology, 69, 925-937. 
Kassin, S.M. (1997). The psychology of confession evidence. American Psychologist, 52, 221233.

Kassin, S.M., Goldstein, C.C., \& Savitsky, K. (2003). Behavioral confirmation in the interrogation room: On the dangers of presuming guilt. Law and Human Behavior, 27, 187-203.

Kassin, S. M., Leo, R. A., Meissner, C. A., Richman, K. D., Collwell, L. H., Leach, A. M., et al. (2007). Police interviewing and interrogation: A self-report survey of police practices and beliefs. Law and Human Behavior, 31, 381-400.

Kellerman, K., \& Cole, T. (1994). Classifying compliance gaining messages: Taxonomic disorder and strategic confusion. Communication Theory, 4, 3-60.

Kelley, H. H. (1997). Expanding the analysis of social orientations by reference to the sequential-temporal structure of situations. European Journal of Social Psychology, 27, 373-404.

Kim, D., Pan, Y., \& Park, H. S. (1998). High- versus low-context culture: A comparison of Chinese, Korean, and American cultures. Psychology and Marketing, 15, 507-521.

Kim, U. (1994). Individualism and collectivism: Conceptual clarification and elaboration. In U. Kim, H. C. Triandis, C. Kagitcibasi, S.-C. Choi \& G. Yoon (Eds.), Individualism and collectivism: Theory, method, and applications (pp. 189-194). Thousand Oaks, CA: Sage.

King, L., \& Snook, B. (in press). Peering inside the Canadian interrogation room: An examination of the Reid model of interrogation, influence tactics, and coercive strategies. Criminal Justice and Behaviour.

Knowles, E. S., \& Linn, J. A. (2004). Resistance and Persuasion. Mahwah, N.J.: Erlbaum.

Krull, D. S., Hui-Min Loy, M., Lin, J., Wang, C.-F., Chen, S., \& Zhao, X. (1999). The fundamental attribution error: Correspondence bias in individualistic and collectivistic cultures. Personality \& Social Psychology Bulletin, 25, 1208-1219.

Lalwani, A. K., Shavitt, S., \& Johnson, T. (2006). What is the relation between cultural orientation and socially desirable responding? Journal of Personality and Social Psychology, 90, 165-178.

Lamb, M. E., Hershkowitz, L., Sternberg, K. T., Esplin, W. P., Hovav, M., Manor, T., et al. (1996). Effects of investigative utterance types on Isreali children's responses. International Journal of Behavioural Development, 19, 627-638.

Langer, E. J. (1978). Rethinking the role of thought in social interaction. In J. H. Harvey, W. J. Ickes \& R. F. Kidd (Eds.), New directions in attribution research (Vol. 2nd, pp. 35-58). Hillsdale, NJ: Lawrence Erlbaum Associates.

Langer, E. J. (1989). Mindfulness. Reading, MA: Addison-Wesley.

Leary, T. F. (1957). Interpersonal diagnosis of personality: a functional theory and methodology for personality evaluation. New York: The Ronald Press Co. 
Lee, F., Hallahan, M., \& Herzog, T. (1996). Explaining real-life events: How culture and domain shape attributions. Personality \& Social Psychology Bulletin, 22, 732-741.

Leo, R. A. (1996). Inside the interrogation room. Journal of Criminal Law \& Criminology, 86, 266-302.

Leo, R. A., \& Ofshe, R. J. (1998). The consequences of false confessions: deprivation of liberty and miscarriages of justice in the age of psychological interrogation. The Journal of Criminal Law and Criminology, 88, 429-496.

Leone, L., Van der Zee, K. I., Van Oudenhoven, J. P., Perugini, M., \& Ercolani, A. P. (2005). The cross-cultural generalizability and validity of the Multicultural Personality Questionnaire. Personality \& Individual Differences, 38, 1449-1462.

Leung, K. (1997). Negotiation and reward allocations across cultures. In P. C. Earley \& M. Erez (Eds.), New perspectives on international industrial and organizational psychology (pp. 640-675). San Francisco: Lexington.

Lindskold, S., \& Bennett, R. (1973). Attributing trust and conciliatory intent from coercive power capability. Journal of Personality and Social Psychology, 28, 180-186.

Lynam, D. R., \& Miller, J. D. (2004). Personality pathways to impulsive behaviour and their relations to deviance: Results from three samples. Journal of Quantitative Criminology, 20, 319-341.

Lytle, A., Brett, J. M., Barsness, Z. I., Tinsley, C. H., \& Janssens, M. (1995). A paradigm for confirmatory cross-cultural research in organizational behaviour. In L. L. Cummings \& B. M. Staw (Eds.), Research in organizational behaviour (Vol. 17, pp. 167-214). Greenwich, CT: JAI Press.

Mann, S., Vrij, A., Fisher, R. P., \& Robinson, M. (2008). See no lies, hear no lies: Differences in discrimination accuracy and response bias when watching or listening to police suspect interviews [Electronic Version]. Applied Cognitive Psychology.

Markus, H. R., \& Kitayama, S. (1991). Culture and the self: Implications for cognition, emotion, and motivation. Psychological Review, 98, 224-253.

McConville, M., \& Baldwin, J. (1982). The role of interrogation in crime discovery and conviction. British Journal of Criminology, 22, 165-175.

McConville, M., Sanders, A., \& Leng, R. (1991). The case for the prosecution. London: Routledge.

McIntire Peters, K. (2005). Dark Art - Interrogation should be a powerful tool in the war on terror, but too often it is thwarted by abuse and interagency conflict. Government Executive, 37, 46-53.

Miller, J. G. (1984). Culture and the development of everyday social explanation. Journal of Personality and Social Psychology, 46, 961-978.

Milne, R., \& Bull, R. (1999). Investigative interviewing: Psychology and practice. Chichester: Wiley. 
Modecki, K. L. (2008). Addressing gaps in the maturity of judgment literature: Age differences and delinquency. Law and Human Behavior, 32, 78-91.

Montoya, R. M., \& Insko, C. A. (2008). Toward a more complete understanding of the reciprocity of liking effect. European Journal of Social Psychology, 38, 477-498.

Morris, M. W., \& Peng, K. (1994). Culture and cause: American and Chinese attributions for social and physical events. Journal of Personality and Social Psychology, 67, 949-971.

Moston, S., \& Engelberg, T. (1993). Police questioning techniques in tape recorded interviews with criminal suspects. Policing and Society, 6, 61-75.

Moston, S., \& Fisher, M. (2007). Perceptions of coercion in the questioning of criminal suspects. Journal of Investigative Psychology and Offender Profiling, 4, 85-95.

Moston, S., \& Stephenson, G. M. (1993). The changing face of police interrogation. Journal of Community \& Applied Social Psychology, 3, 101-115.

Nail, P. R., MacDonald, G., \& Levy, D. A. (2000). Proposal of a four-dimensional model of social response. Psychological Bulletin, 126, 454-470.

Newell, A., \& Simon, H. A. (1972). Human problem solving. Englewood Cliffs, NJ: Prentice-Hall.

Nierop, N. M. (2005). Het verdachtenverhoor in Nederland: wat wordt verhoorders geleerd? Nederlands Juristenblad, 17, 887-890.

Norenzayan, A., Choi, I., \& Nisbett, R. E. (2002). Cultural similarities and differences in social inference: Evidence from behavioural predictions and lay theories of behaviour. Personality \& Social Psychology Bulletin, 28, 109-120.

Ohanian, R. (1990). Construction and validation of a scale to measure celebrity endorsers' perceived expertise, trustworthiness, and attractiveness. Journal of Advertising, 19, 39-52.

Ohbuchi, K.-I., Fukushima, O., \& Tedeschi, J. T. (1999). Cultural values in conflict management: goal orientation, goal attainment, and tactical decision. Journal of Cross Cultural Psychology, 30, 51-71.

Olekalns, M., \& Smith, P. L. (2000). Understanding optimal outcomes. The role of strategy sequences in competitive negotiations. Human Communication Research, 26, 527557.

Olekalns, M., \& Smith, P. L. (2003). Testing the relationship among negotiators' motivational orientations, strategy choices, and outcomes. Journal of Experimental Social Psychology, 39, 101-117.

Olekalns, M., \& Smith, P. L. (2007). Loose with the truth: Predicting deception in negotiation. Journal of Business Ethics, 76, 225-238.

Olekalns, M., Smith, P. L., \& Walsh, T. (1996). The process of negotiation: Strategy and timing as predictors of outcomes. Organizational Behaviour and Human Decision Processes, $68,68-77$. 
Olekalns, M., \& Weingart, L. R. (2008). Emergent Negotiations: Stability and shifts in negotiation dynamics. Negotiation and Conflict Management Research, 1, 135-160.

Onkvisit, S., \& Shaw, J. J. (1993). International marketing: Analysis and strategy (2nd ed.). New York: Macmillan.

Oyserman, D., Coon, H. M., \& Kemmelmeier, M. (2002). Rethinking individualism and collectivism: Evaluation of theoretical assumptions and meta-analyses. Psychological Bulletin, 128, 3-72.

Park, H. S., Levine, T. R., McCornack, S. A., Morrison, K., \& Ferrara, M. (2002). How people really detect lies. Communication Monographs, 69, 144-157.

Pearse, J., \& Gudjonsson, G. H. (1996). Police interviewing techniques at two South London police stations. Psychology, Crime \& Law, 3, 63-74.

Perloff, R. M. (1993). The dynamics of persuasion. Hillsdale, NJ: Lawrence Erlbaum.

Petty, R. E., \& Cacioppo, J. T. (1986). Communication and persuasion: Central and peripheral routes to attitude change. New-York: Springer-Verlag.

Pietroni, D., Van Kleef, G. A., De Dreu, C. K. W., \& Pagliaro, S. (2008). Emotions as strategic information: Effects of other's emotional expressions on fixed-pie perception, demands, and integrative behaviour in negotiation. Journal of Experimental Social Psychology, 44, 1444-1454.

Pinkley, R. L. (1990). Dimensions of conflict frame: Disputant interpretations of conflict. Journal of Applied Psychology, 75, 117-126.

Pruitt, D. G. (1981). Negotiation behaviour. New York: Academic Press.

Rabois, D., \& Haaga, D. A. (2002). Facilitating police-minority youth attitude change: The effects of cooperation within a competitive context and exposure to typical exemplars. Journal of Community Psychology, 30, 189-195.

Rafaeli, A., \& Sutton, R. I. (1991). Emotional contrast strategies as means of social influence: Lessons from criminal interrogators and bill collectors. Academy of Management Journal, 34, 749-775.

Rahim, M. A. (1992). Managing conflict in organizations (2nd ed.). Westport, CT: Praeger.

Roger, D. B., \& Schumacher, A. (1983). Effects of individual differences in dyadic conversational strategies. Journal of Personality and Social Psychology, 45, 247-255.

Roloff, M. E. (1980). Self-awareness and the persuasion process: Do we really know what we're doing? In M. E. Roloff \& G. R. Miller (Eds.), Persuasion: New directions in theory and research (pp. 29-66). Beverly Hills, CA: Sage.

Rubin, J. Z., \& Brown, B. (1975). The social psychology of bargaining and negotiation. New York: Academic Press.

Rubin, J.Z., Pruitt, D.G., and Kim, S.H. (1994). Social Conflict: Escalation, Stalemate, and Settlement $\left(2^{\text {nd }}\right.$ ed). New York: McGraw-Hill. 
Shepherd, E. (1991). Ethical interviewing. Policing, 7, 42-60.

Shepherd, E. (1993). Resistance in interviews: The contribution of police perceptions and behaviour. In E. Shepherd (Ed.), Aspects of police interviewing. Issues in Criminological and Legal Psychology, No. 18. Leicester: British Psychological Society.

Shepherd, E. (1996). Becoming skilled. London: Law Society.

Shepherd, E., \& Kite, F. (1988). Training to interview. Policing, 4, 264-280.

Shomer, R. W., Davis, A. H., \& Kelley, H. H. (1966). Threats and the development of coordination: further studies of the Deutsch and Krauss trucking game. Journal of Personality and Social Psychology, 4, 119-126.

Shweder, R. A., \& Bourne, E. J. (1984). Does the concept of the person vary cross-culturally? In R. A. Shweder \& R. A. LeVine (Eds.), Culture theory: Essays on mind, self, and emotion (pp. 158-199). Cambridge, England: Cambridge University Press.

Sinaceur, M., \& Neale, M. A. (2005). Not all threats are created equal: How implicitness and timing affect the effectiveness of threats in negotiations. Group Decision and Negotiation, 14, 63-85.

Smith, P. B., \& Bond, M. H. (1994). Social psychology across cultures: Analysis and perspectives. Needham Heights, MA: Allyn \& Bacon.

Soukara, S., Bull, R., Vrij, A., Turner, M., \& Cherryman, J. (2009). What really happens in police interviews of suspects? Tactics and confessions. Psychology, Crime, \& Law, 15, 493506.

Switzer, F. S., Paese, P. W., \& Fritz, D. (1992). Bootstrap estimates of standard errors in validity generalization. Journal of Applied Psychology, 77, 123-129.

Taylor, P. J. (2002). A cylindrical model of communication behaviour in crisis negotiations. Human Communication Research, 28, 7-48.

Taylor, P. J. (2006). Proximity coefficients as a measure of interrelationships in sequences of behaviour. Behaviour Research Methods, 38, 32-50.

Taylor, P. J., \& Donald, I. J. (2003). Foundations and evidence for an interaction based approach to conflict. International Journal of Conflict Management, 14, 213-232.

Taylor, P. J., \& Donald, I. J. (2004). The structure of communication behaviour in simulated and actual crisis negotiations. Human Communication Research, 30, 443-478.

Taylor, P. J., \& Donald, I. J. (2007). Testing the relationship between local cue-response patterns and the global structure of communication behaviour. British Journal of Social Psychology, 46, 273-298.

Taylor, P. J., Jacques, K., Giebels, E., Levine, M., Best, R., Winter, J., et al. (2008). Analysing forensic processes: Taking time into account. Issues in Forensic Psychology, 8, 45-57.

Thomas, A. P. (1985). Conversational routines: A Markov chain analysis. Language and Communication, 5, 287-296. 
Thomas, K. W. (1992). Conflict and negotiation processes in organizations. In M. D. Dunnette \& L. M. Hough (Eds.), Handbook of industrial and organizational psychology (2nd ed., pp. 651-717). Palo Alto, CA: Consulting Psychologists Press.

Ting-Toomey, S. (1988). Intercultural conflict styles: A face negotiation theory. In Y. Y. Kim \& W. B. Gudykunst (Eds.), Theories in intercultural communication (pp. 213-235). Newbury Park, CA: Sage.

Ting-Toomey, S., \& Kurogi, A. (1998). Facework competence in intercultural conflict: An updated face-negotiation theory. International Journal of Intercultural Relations, 22, $187-225$.

Ting-Toomey, S., \& Oetzel, J. G. (2001). Managing intercultural conflict effectively. Thousand Oaks, CA: Sage.

Triandis, H. C. (1989). The self and social behaviour in differing cultural contexts. Psychological Review, 96, 506-520.

Triandis, H. C. (1994). Culture and social behaviour. New York: McGraw-Hill.

Triandis, H. C. (1995). Individualism and collectivism. Boulder, CO: Westview.

Triandis, H. C., Carnevale, P. J., Gelfand, M. J., Robert, C., \& Wasti, A. (2001). Culture, personality and deception. International Journal of Cross-Cultural management, 1, 73-90.

Triandis, H. C., \& Suh, E. M. (2002). Cultural Influences on Personality. Annual Review of Psychology, 53, 133-160.

Tse, D. K., Lee, K., Vertinsky, I., \& Wehrung, D. A. (1988). Does culture matter? A cross-cultural study of executives' choice, decisiveness, and risk adjustment in international marketing. Journal of Marketing, 52, 81-95.

Van Amelsfoort, A., Rispens, I., \& Grolman, H. (2005). Handleiding verhoor. 's-Gravenhage: Elsevier Overheid.

Van de Vliert, E. (1997). Complex interpersonal conflict behaviour: theoretical frontiers. Sussex: Psychology Press.

Van de Vliert, E., Euwema, M. C., \& Huismans, S. E. (1995). Managing conflict with a subordinate or a superior: Effectiveness of conglomerated behaviour. Journal of Applied Psychology, 80, 271-281.

Van de Vliert, E., Nauta, A., Giebels, E., \& Janssen, O. (1999). Constructive conflict at work. Journal of Organizational Behaviour, 20, 475-491.

Van der Zee, K. I., \& Van Oudenhoven, J. P. (2000). The Multicultural Personality Questionnaire: A multidimensional instrument of multicultural effectiveness. European Journal of Personality, 14, 291-309.

Van der Zee, K. I., \& Van Oudenhoven, J. P. (2001). The Multicultural Personality Questionnaire: Reliability and Validity of Self- and Other Ratings of Multicultural Effectiveness 
Van Oudenhoven, J. P., \& Van der Zee, K. I. (2002). Predicting multicultural effectiveness of international students: The Multicultural Personality Questionnaire. International Journal of Intercultural Relations, 26, 679-694.

Vaughn, M. G., \& Howard, M. O. D., M. (2008). Psychopathic personality traits and delinquent careers: An empirical examination. International Journal of Law and Psychiatry, 31, 407-416.

Victor, D. A. (1992). International Business Communication. New York: HarperCollins Publishers Inc.

Vidal, S., \& Skeem, J. L. (2007). Effects of psychopathy, abuse, and ethnicity on juvenile probation officers' decision-making and supervision strategies. Law and human behavior, 31, 479-498.

Viki, G. T., Culmer, M. J., Eller, A., \& Abrams, D. (2006). Race and willingness to cooperate with the police: The roles of quality of contact, attitudes towards the behaviour and subjective norms. The British Journal of Social Psychology, 45, 285-302.

Vrij, A. (1992). Het maken van een verdachte indruk op rechercheurs: de invloed van stereotiepen, sociale vaardigheden, verbaal- en non-verbaal gedrag op de oordeelsvorming. Tijdschrift voor Criminologie, 34, 129-141.

Vrij, A. (1994). The impact of information and setting on detection of deception by police officers. Journal of Nonverbal Behaviour, 18, 117-136.

Vrij, A. (2001). Credibility judgments of officers: The impact of nonverbal behaviour, social skills, and physical characteristics on impression formation. Journal of Applied Social Psychology, 133, 601-610.

Vrij, A. (2004). Cooperation of liars and truth tellers. Applied Cognitive Psychology, 19, 39-50.

Vrij, A., Leal, S., Granhag, P. A., Mann, S., Fisher, R. P., Hillman, J., et al. (2009). Outsmarting the liars: The benefit of asking unanticipated questions. Law and Human Behavior, 33, 159-166.

Vrij, A., Mann, S., \& Fisher, R. P. (2006). Information-gathering vs. accusatory interview style: Individual differences in respondents' experiences. Personality \& Individual Differences, 41, 589-599.

Vrij, A., Mann, S. A., Fisher, R. P., Leal, S., Milne, R., \& Bull, R. (2008). Increasing cognitive load to facilitate lie detection: The benefit of recalling an event in reverse order. Law and Human Behavior, 32, 253-265.

Walkley, J. (1987). Police interrogation. London: Police Review Publishing.

Walsh, Z., \& Kosson, D. S. (2007). Psychopathy and violent crime: A prospective study of the influence of socioeconomic status and ethnicity. Law and Human Behavior, 31, 209229.

Walton, D. (2003). The interrogation as a type of dialogue. Journal of Pragmatics, 35, 1771-1802. 
Watzlawick, P., Beavin, J. H., \& Jackson, D. D. (1968). Pragmatics of human communication: A study of interactional patterns, pathologies, and paradoxes. London: Faber.

Weick, K. E. (1979). The social psychology of organizing (2nd ed.). Reading, MA: AddisonWesley.

Williamson, T. M. (1993). From interrogation to investigative interviewing: Strategy trends in police questioning. Journal of Community \& Applied Social Psychology, 3, 89-99.

Williamson, T. M. (1994). Reflections on current police practice. In D. Morgan \& G. Stephenson (Eds.), Suspicion and silence. The rights of silence in criminal investigations. (pp. 107116). London: Blackstone.

WODC. (2006). Rapport criminaliteit en rechtshandhaving 2006. Retrieved 18-12-2007, from http://www.wodc.nl/images/ob255_volledige_tekst_tcm44-88814.pdf.

Yukl, G., Falbe, C. M., \& Youn, J. Y. (1993). Patterns of influence behaviour for managers. Group and Organization Management, 18, 5-24.

Yukl, G., \& Tracey, J. B. (1992). Consequences of influence tactics used with subordinates, peers, and the boss. Journal of Applied Psychology, 77, 525-535. 

Summary in Dutch (Samenvatting) 


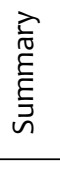

128 
In deze dissertatie wordt voortgebouwd op eerder onderzoek naar verdachtenverhoren (zie bijv., Bull \& Milne, 2004; Bull \& Soukara, in druk; Dando, Wilcock, \& Milne, 2009; Dando, Wilcock, Milne, \& Henry, in druk; Milne \& Bull, 1999). Daarbij is specifiek gekeken naar het gebruik en effect van inter-persoonlijk beïnvloedingsgedrag van rechercheurs op verdachten met een verschillende culturele afkomst. Beïnvloedingsgedrag is geanalyseerd op basis van een theoretisch raamwerk - de Tafel van Tien (Giebels, 2002; Giebels \& Taylor, in druk) - dat specifiek is ontwikkeld voor de analyse van interacties tussen politie en burgers. Een belangrijk uitgangspunt in dit onderzoek is dat het effect van beïnvloedingsgedrag afhankelijk is van de culturele achtergrond van verdachten. In een serie van drie empirische onderzoeken hebben we onderzocht in hoeverre rechercheurs gebruik maken van beïnvloedingsgedrag zoals beschreven in de Tafel van Tien, en in hoeverre dit gedrag cultureel specifiek is. Gezien het feit dat we met ons onderzoek zowel een theoretische als praktische bijdrage beogen te leveren, is het onderzoek uitgevoerd in verschillende onderzoekssettings, variërend van een gecontroleerd experiment tot echte verdachtenverhoren in de praktijk. In de eerste studie hebben we scholieren gevraagd om geld te stelen (in een gecontroleerde setting) waarna zij verhoordwerden doorervaren rechercheurs(Hoofdstuk2).Zowel het gedrag van rechercheurs en verdachten is geanalyseerd (door middel van transcripten en video-opnamen), als hun respons op de vragenlijsten die zijn ingevuld na afloop van het onderzoek. In een tweede studie hebben we twee veelvoorkomende beïnvloedingsgedragingen geïsoleerd (gebaseerd op de resultaten van Hoofdstuk 2) en gemanipuleerd in een experimentele setting (Hoofdstuk 3). Hierdoor konden we vaststellen wat het directe effect van deze gedragingen was op het gedrag van verdachten. Tot slot hebben we video-opnamen van verdachtenverhoren geanalyseerd, ter beschikking gesteld door een Nederlands politiedistrict (Hoofdstuk 4). De bevindingen van deze drie hoofdstukken zullen hieronder kort worden gerapporteerd.

In Hoofdstuk 2 is onderzocht in hoeverre rechercheurs inter-persoonlijk beïnvloedingsgedrag (in termen van de Tafel van Tien; Giebels, 2002) gebruiken. Daarbij is specifiek gekeken naar de relatie tussen twee gedragingen die belangrijk zijn voor het verhoren van verdachten (aardig zijn en rationeel overtuigen) en verschillende typen uitkomstmaten: de verklaringsbereidheid van verdachten, hun (geschatte) kwaliteit van de relatie met de rechercheur en het feit of ze de diefstal uiteindelijk wel of niet bekennen. Een centrale verwachting is dat het effect van aardig zijn en rationeel overtuigen afhankelijk is van culturele achtergrond van de verdachten $(n=52)$. Concreet verwachten we dat aardig zijn, wat beschouwd kan worden als meer relationeel gedrag, met name effectief is voor het verhoren van allochtone verdachten (in deze dissertatie 'hoge-context' verdachten genoemd), terwijl rationeel overtuigen, gedrag dat meer op de inhoud en logica van een boodschap is gericht, vooral effectief is in verhoren met autochtone verdachten ('lage-context' verdachten). In lijn met onze verwachtingen vinden we dat, voor allochtone verdachten aardig zijn in termen van belonen en iets aanbieden positief gerelateerd is aan hun inschatting van de kwaliteit van de 
relatie met de rechercheur, terwijl aardig gedrag, door middel van actief luisteren, samengaat met een hoger aantal bekentenissen. Daarnaast wordt bevestigd dat voor autochtone verdachten rationeel overtuigen een effectieve strategie is; rationeel overtuigen van de rechercheur blijkt positief gerelateerd aan de uiteindelijke bekentenissen van autochtone verdachten.

Hoofdstuk 3 bouwt voort op deze resultaten door in twee studies te onderzoeken wat het effect van aardig zijn en rationeel overtuigen is wanneer zij gecombineerd worden met ander beïnvloedingsgedrag (zogenoemde strategische sequenties). In een eerste studie $(n=52)$ wordt onderzocht of het effect van een strategisch contrast sequentie (d.w.z. dat de beoogde beïnvloedingspoging wordt afgezet tegen intimiderend gedrag) afhankelijk is van 'fit' met de culturele achtergrond van verdachten. In lijn met onze verwachtingen, vinden we dat intimiderend gedrag gevolgd door rationeel overtuigen leidt tot meer bekentenissen en bereidheid om informatie te verschaffen bij autochtone verdachten (vergeleken met allochtone verdachten). Daarnaast blijkt dat intimideren gevolgd door aardig zijn de kans op bekentenissen en bereidheid tot het verschaffen van informatie van met name allochtone verdachten vergroot. Echter omdat aardig zijn en rationeel overtuigen in verhoren vaak naast elkaar voorkomen, hebben we een tweede studie $(n=53)$ uitgevoerd. Hierin is onderzocht wat het effect is van een combinatie van deze twee gedragingen, afhankelijk van volgorde en culturele fit. Voor alle verdachten blijkt aardig zijn gevolgd door rationeel overtuigen positiever uit te werken dan rationeel overtuigen gevolgd door aardig zijn. Dit is in lijn met de gedachte dat het belangrijk is om eerst aan de relatie met een verdachte te werken, alvorens over te gaan tot het bespreken van de zaak (vgl. Standaard Verhoorstrategie; Nierop, 2005; Van Amelsfoort, e.a., 2005). Echter twee van de hoofdeffecten (op bekentenissen en verklaringsbereidheid) worden verklaard door een interactie met de culturele achtergrond van verdachten; voor allochtone verdachten blijkt dat aardig zijn gevolgd door rationeel overtuigen de kans op een bekentenis vergroot, terwijl deze sequentie voor autochtone verdachten met name de verklaringsbereidheid stimuleert.

Tot slot kijken we in Hoofdstuk 4 naar de directe samenhang tussen beïnvloedingsgedragingen van rechercheurs en de informatieverstrekking van autochtone en allochtone verdachten in authentieke verdachtenverhoren $(n=27)$. In lijn met de vorige hoofdstukken, vinden we dat rationeel overtuigen positief uitwerkt voor autochtone verdachten; autochtone verdachten reageren sneller met met het geven van persoonlijke informatie dan allochtone verdachten wanneer de rechercheur gebruik maakt van rationeel overtuigen. Tegengesteld aan de bevindingen in de eerste twee hoofdstukken, blijkt dat allochtone verdachten minder goed reageren op aardig zijn. Zo is gebleken dat allochtone verdachten sneller dan autochtone verdachten reageren met het weigeren van informatie wanneer de rechercheur aardig doet. Naast het aardig zijn en rationeel overtuigen kijken we tevens naar meer intimiderend gedrag van rechercheurs. Analyse wijst uit dat 
persoonsgericht intimiderend gedrag van de rechercheur sneller resulteert in het verstrekken van persoonsgerichte informatie door autochtone verdachten dan allochtone verdachten. Allochtone verdachten, aan de andere kant, reageren sneller dan autochtone verdachten met het geven van contextuele informatie wanneer de rechercheur gebruik maakt van intimiderend gedrag dat is gericht op de context (d.w.z., het misdrijf en/of familie en vrienden van de verdachte).

De resultaten van de drie empirische hoofdstukken verschaffen meer inzicht in de dynamiek van het verdachtenverhoor. Samenvattend kan worden gesteld dat rechercheurs in grote mate gebruik maken van inter-persoonlijk beïnvloedingsgedrag, waarbij aardig zijn en rationeel overtuigen kunnen worden beschouwd als de centrale pijlers van het verdachtenverhoor. Deze beïnvloedingsgedragingen hebben een verschillend effect op autochtone en allochtone verdachten en de diverse uitkomstmaten. Een belangrijke conclusie is verder dat meer direct, inhoudelijk gedrag met name effectief is in verhoren met autochtone verdachten, terwijl meer indirect, relationeel gedrag vooral goed aansluit bij allochtone verdachten. 



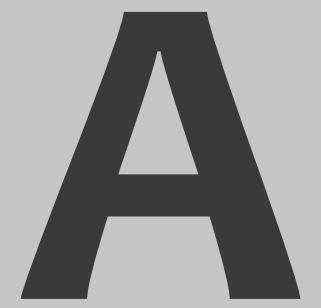

Acknowledgments 


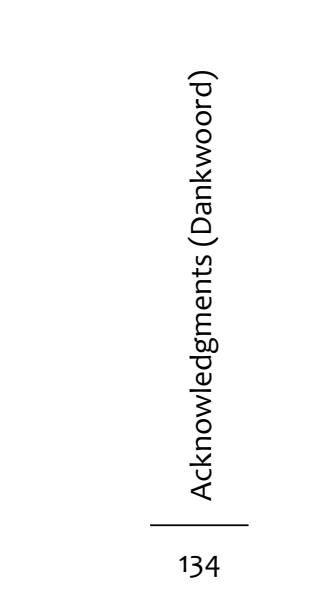


Clearly, I could not have written this dissertation without the help of others. First and foremost, l'd like to thank Ellen for being my mentor all along. You've introduced me to the craft of science, which I never dared to believe would fit me so well. During the past years you have set an inspiring example of how to conduct research and convinced me that, despite my initial scepticism, research can actually be fun! That is, if the right circumstances are presented. You were indispensable for creating these circumstances by providing me many opportunities to (im)prove myself, always pushing me to the edge (which is exactly what I need), in combination with relaxing activities (definitely peaking at the 'Weseper Zomerfeesten'). I've learned an incredible amount from your critical notes and constructive feedback, and I am very thankful for your support during the more turbulent period of this project. Overall, l'd very much like to thank you for being there at the right moment in the right place!

I am also indebted to Karen van Oudenhoven and Hubert Coonen, who were willing to guide this project to a successful conclusion and were very helpful in doing so! Clearly, I'd like to thank the members of my committee, with special thanks to the international guests who travelled all the way to Twente: Professor Bull, Wendi Adair and Paul Taylor. Paul (Taylor), Wendi, Bob (Fennis), and Karen, thank you for writing together with me; it was inspiring and very instructive. Also many thanks to Bob (Jansen) for developing the fabulous cover of this dissertation! It fits me extremely well. Sonja, I really enjoyed our constructive coffee breaks, but l'd like to thank you in particular for your brilliant contribution with respect to "title make-up". Leandra and Karin (Truijen), the joint impact of your company and tapas provided exactly the kind of support I needed to persevere in both good and bad times. Renske, Karin (Dijkstra) and colleagues of PCGR, thanks for taking me under your wings and offering companionship. Of all of the people who participated in the project, I would especially like to mention Peter, without whom it would not have been possible to chat with suspects at all. I'd also like to thank Johan Jonker, Joost, Jasper, Leandra, Moritz, and Elmira for their help with developing the research material and police district 'Binnensticht' in Zeist for lending us videotapes from police interviews. Furthermore, I'd like to thank ROC Oost-Nederland and Start.Deltion, and in particular Henk Ritzen, for their help with the data collection, and Arend de Vries and Marnix Willems for the discussions about the practical relevance of this work. I'd also like to thank the Institute of Behavioural Research, the Faculty of Behavioural Sciences, and the UT incentive fund (all of the University of Twente) for the funding of this project.

Finally, I'd like to thank my family and friends for just being there when I needed them most. However, most of all, I'd like to thank Paul; because no matter what happens, it appears that Love is all you need/Alles is Liefde! 
